Important Note: This pre-print has been peer-reviewed and published at Clinical Psychology Review. We advise readers to consult and cite the latest version of this work available at https://doi.org/10.1016/j.cpr.2022.102145.

The version available at PsyArXiv (https://psyarxiv.com/ar9wc/) is the accepted manuscript before any additional publisher value-added contributions (e.g., copy-editing, formatting, technical enhancements, pagination) and proof-reading.

\title{
Refining the link between psychopathy, antisocial behavior, and empathy: A meta- analytical approach across different conceptual frameworks
}

Carlos Campos a,b,c,1,*, Rita Pasion ${ }^{\mathrm{a}, \mathrm{d}, \mathrm{l}}$, Andreia Azeredo ${ }^{\mathrm{a}}$, Eduarda Ramião ${ }^{\mathrm{a}}$, Prune Mazer ${ }^{\mathrm{a}, \mathrm{b}, \mathrm{e}}$, Inês Macedo a, Fernando Barbosa ${ }^{\text {a }}$

${ }^{\text {a }}$ Laboratory of Neuropsychophysiology, Faculty of Psychology and Educational Sciences, University of Porto, Rua Alfredo Allen, 4200-135 Porto, Portugal

${ }^{\mathrm{b}}$ Faculty of Medicine, University of Porto, Alameda Prof. Hernâni Monteiro, 4200-319 Porto, Portugal ${ }^{c}$ Neurocognition Group | LabRP, Center for Rehabilitation Research, School of Health, Polytechnic Institute of Porto, Rua Dr. António Bernardino de Almeida 400, 4200-072 Porto, Portugal

${ }^{\mathrm{d}}$ HEI-LAB, Lusófona University, Portugal

${ }^{\mathrm{e}}$ School of Health, Polytechnic Institute of Porto, Rua Dr. António Bernardino de Almeida 400, 4200072 Porto, Portugal

* Corresponding author at: Laboratory of Neuropsychophysiology, Faculty of Psychology and Educational Sciences, University of Porto, Rua Alfredo Allen, 4200-135 Porto, Portugal. E-mail address: carlosm.martins.campos@gmail.com (C.Campos)

${ }^{1}$ Carlos Campos and Rita Pasion contributed equally to this manuscript (co-first authorship) 


\section{Author Notes}

Carlos Campos and Rita Pasion contributed equally to this manuscript (co-first authorship). This project was supported by $\mathrm{Ph}$. D. grants funded by the Portuguese Foundation for Science and Technology (FCT) under the POCH/FSE Program (SFRH/BD/136296/2018; SFRH/BD/117130/2016; SFRH/BD/136565/2018; SFRH/BD/137494/2018; 2021.07199.BD; 2021.06791.BD). We have no conflicts of interest to disclose.

Correspondence concerning this article should be addressed to Carlos Campos, Laboratory of Neuropsychophysiology, Faculty of Psychology and Educational Sciences, University of Porto, Rua Alfredo Allen, 4200-135 Porto, Portugal. Phone number: +351 22607 9700. Email: carlosm.martins.campos@gmail.com

We also provide the contact information for each author of the manuscript: Rita Pasion (ritapasion@gmail.com); Andreia Azeredo (andreia_azeredo_13@hotmail.com); Eduarda Ramião (eduarda_ramiao@hotmail.com); Prune Mazer (prunemazer@gmail.com); Inês Macedo (inesmassbd@gmail.com); Fernando Barbosa (fbarbosa@fpce.up.pt). 


\section{Role of Funding Sources}

This project was supported by $\mathrm{Ph}$. D. grants funded by the Portuguese Foundation for Science and Technology (FCT) under the POCH/FSE Program (SFRH/BD/136296/2018; SFRH/BD/117130/2016; SFRH/BD/136565/2018; SFRH/BD/137494/2018; 2021.07199.BD; 2021.06791.BD). The funding agency had no role in study design, data collection and analysis, writing the manuscript, or in the decision to submit the paper for publication.

\section{Contributors}

Carlos Campos and Rita Pasion: Co-First Authorship (contributed equally to this manuscript),

Conceptualization, Project Administration, Methodology, Investigation, Validation, Formal Analysis,

Data Curation, Visualization, Writing - Original Draft, Review \& Editing.

Andreia Azeredo and Eduarda Ramião: Investigation, Validation, Data Curation, Writing - Review \& Editing

Prune Mazer and Inês Macedo: Investigation, Validation, Formal Analysis, Data Curation, Writing Review \& Editing

Fernando Barbosa: Methodology, Supervision, Resources, Writing - Review \& Editing,

\section{Conflict of Interest}

All authors declare that they have no conflicts of interest.

\section{Acknowledgements}

We thank Dr. Tiago Figurinhas for proofreading the manuscript and aiding with figure design. 


\section{Highlights}

- High psychopathy samples and antisocial groups present distinct empathy profiles.

- Antisocial-related psychopathy traits are only mildly related to empathy deficits.

- Callous-affective traits are strongly associated with reduced affective empathy.

- Non-adaptive interpersonal traits are negatively related to both empathy domains.

- Adaptive boldness traits are not associated with cognitive empathy impairment. 


\begin{abstract}
The current meta-analysis includes 477 records $(N=142,692)$ and comprehensively explores the complex interplay between psychopathy, antisocial behavior, and empathy. First, empathy domains (cognitive and affective) were used to dissociate antisocial behavior from psychopathy. Cognitive empathy was more impaired in antisocial groups $\left(g_{\text {cognitive }}=-0.43 ; g_{\text {affective }}=-0.11\right)$, while samples scoring higher in psychopathy displayed larger deficits in affective empathy $\left(g_{\text {affective }}=-0.40 ; g_{\text {cognitive }}=-0.22\right)$. Secondly, the specific associations between empathy domains and psychopathy dimensions were evaluated. Most effect sizes pertaining to psychopathy traits closely related to antisocial behavior were mild for both empathy domains ( $r=-0.03$ to -0.21 ) Callous-affective traits were largely correlated with affective empathy ( $r=-0.34$ to -0.46$)$ and moderately correlated to cognitive empathy ( $r=-0.26$ to -0.27$)$. Diverging results were found for the interpersonal dimension, as boldness-adaptive manifestations were unrelated to cognitive empathy $(r=0.03)$, while non-adaptive interpersonal traits were negatively associated with both empathy domains $\left(r_{\text {cognitive }}=-0.16 ; r_{\text {affective }}=-0.25\right)$. Overall, these findings suggest that: $(1)$ psychopathy and antisocial behavior display distinct empathic profiles; (2) psychopathy dimensions are differentially associated with cognitive and affective empathy; (3) the interaction between interpersonal traits and empathy domains is different across the conceptual models of psychopathy.
\end{abstract}

Keywords: psychopathy; personality; antisocial; empathy; theory of mind; social cognition 


\section{Introduction}

Psychopathy can be broadly defined as a multidimensional, heterogeneous personality structure that clusters together a constellation of traits that are likely to interact and reflect on different phenotypic manifestations (Lilienfeld, 2018; Seelbom \& Drislane, 2021).

Cleckley (1941/1988) was one of the first authors to provide a complex, fine-grained conceptualization of psychopathy based on his work in psychiatric settings. According to Cleckley, psychopathy encompasses not only the more evident disruptive features (e.g., lack of remorse/shame, untruthfulness, pathological egocentricity, and antisocial behavior), but also adaptive traits for everyday functioning (e.g., superficial charm, absence of nervousness, and good intelligence). Nevertheless, other pioneering researchers in the field provided descriptions of psychopathy that mostly addressed its maladaptive features, proposing that psychopathy is closely linked to antisocial and criminal behavior (Karpman, 1941; McCord \& McCord, 1964).

Antisocial behavior refers to a wide set of actions that defeats the interests of the social order (e.g., aggression and rules violation) and its link with psychopathy has been a controversial topic of discussion for decades (Burt, 2012; Burt et al., 2012; Skeem and Cooke, 2010). Some scholars argue that antisocial behavior is a core component of psychopathy. The prevalence of psychopathy in forensic samples has been reported to oscillate between 15-25\% (Woodworth \& Porter, 2002) and estimates indicate that individuals with high psychopathy traits are responsible for about $50 \%$ of the most serious crimes (Hare, 1999) - and despite constituting only $1 \%$ of the general population (Neumann \& Hare, 2008). However, other authors argue that antisocial behavior is just a possible outcome of psychopathy that should be interpreted within the context of several other risk factors (Skeem \& Cooke, 2010; Steinert et al., 2017). Actually, recent studies describe that about 50\% of inmates display low levels of psychopathy, with only $7 \%$ exhibiting the full spectrum of psychopathic traits - a finding that is proximal to what is reported in student samples (Boduszek et al., 2019; Boduszek et al., 2017). 
This raises the possibility that the personalistic features of psychopathy can be generally distributed among the population, while the behavioral maladaptive features may be inflated in forensic settings simply due to criminal recording (Pasion et al., 2018a).

There are still no definitive answers for this longstanding debate, especially considering that the main conceptual frameworks in the field weigh differentially on maladaptive and adaptive features of psychopathy. These frameworks will be discussed in the following sections.

\subsection{The classical criminocentric view of psychopathy}

The most influential framework of psychopathy was driven by the extensive theoretical and empirical work produced by Hare, who advocated for a 2-factorial model encompassing both interpersonal-affective (Factor 1) and impulsive-antisocial features (Factor 2; Hare et al., 1990; Hare \& Neumann, 2008). The interpersonal-affective factor includes the more prototypical/primary psychopathic traits of manipulation, superficial charm, shallow affect, lack of remorse, and callousness, and can be distinguished from the impulsive-antisocial factor, which taps into secondary psychopathic traits associated with impulsivity, poor behavior control, recidivism, and criminal versatility (Blackburn \& Coid, 1998; Hare \& Neumann, 2008; Hemphill et al., 1998; Levenson et al., 1995; Skilling et al., 2002). Thus, psychopathic manifestations were historically conceived as a coherent part of the antisocial spectrum, and forensic samples were naturally expected to include these individuals (Hare \& Neumann, 2008). Even nowadays, both psychopathy and antisocial behavior can be clustered within the antagonistic externalizing spectrum since they can be mainly characterized by low consciousness and agreeableness (Vachon, 2019; Kotov et al., 2017). Furthermore, descriptions around Factor 2 comprise impulsive traits that are inherently connected to the disinhibited externalizing spectrum, a dimension that also interplays with the antagonism spectrum to explain antisocial behavior (Kotov et al., 2017). 
These two broad factors in Hare's model can be further decomposed into four more specific facets (facet 1: interpersonal traits, facet 2: affective traits, facet 3: impulsive lifestyle, facet 4: antisocial behavior) without losing model fit (Hare \& Neumann, 2008). The 2-factors and 4-facets models (see Figure 1) were initially operationalized by the Psychopathy ChecklistRevised (PCL-R; Hare, 2003), which is the most widely used instrument to evaluate psychopathy. Across the years, several alternative measures based on PCL were developed for adults (e.g., Self-Report Psychopathy Scale (SRP), Paulhus et al., 2016; Levenson Self-Report Psychopathy Scale (LSRPS), Levenson et al., 1995) and younger samples (e.g., Psychopathy Checklist: Youth Version; Forth et al., 1994, Antisocial Process Screening Device (ASPD); Frick \& Hare, 2001).

Considering the central role of criminal behavior in PCL-based factorial approaches (i.e., 2-factors and 4-facets models), other psychopathic personality traits are assumed to be intimately tied - not only psychometrically, but also genetically and longitudinally - to antisocial conducts (for a review see Hare \& Neumann, 2008). Notably, the first steps on the assessment of psychopathy based on these models revived the research on the construct and antisocial phenomena, namely by emphasizing the personality features that may help to explain patterns of persistent deviant behavior and resistance to treatment. The interpersonal-affective features of psychopathy proposed here reflect much of the notion of a complex personality type that strongly relates with Cleckley's (1941/1988) influential descriptions and that goes beyond the behavioral criteria used for diagnosing Antisocial Personality Disorder.

As such, this operationalization boosted the first inputs on basic research aiming to understand the etiological roots of psychopathy and set the foundations for translational studies addressing the implications of psychopathy in psychiatry and criminal justice systems, namely in what pertains to recidivism, violence, and treatment outcomes (Hare et al., 1990; Hare \& Neumann, 2008; Woodworth \& Porter, 2002). Of note, most of this research took advantage of 
using total and cut-off clinical scores to study psychopaths as a homogenous group. Neumann, Hare, and Newman (2007) asserted that PCL factors and facets can be accommodated within a single super-ordinate factor capturing something essential that spans across the lower-order factors - the variance in social deviance. Considering that all the dimensions of psychopathy are inherently tied to a cohesive antisocial super-ordinate factor, psychopaths were seen as a homogeneous taxonomic group fundamentally distinct from non-psychopaths regarding the expression of antisocial tendencies (Hare \& Neumann, 2008; Neumann et al., 2007).

\subsection{Contemporary models: encompassing adaptive and maladaptive expressions of psychopathy}

More recently, a few criticisms on the interplay between psychopathy and antisocial conducts have been set forward with some authors arguing against the centrality of criminal behaviour to psychopathy (e.g., Skeem and Cooke, 2010). First, impulsive and antisocial tendencies (Factor 2, facet 3 and 4) seem to co-occur with other externalizing disorders to predict criminal behavior and are not unique to psychopathy (Cleckley, 1941/1988; Gao \& Raine, 2010; Kennealy et al., 2010; Krueger et al., 2002; Krueger et al., 2007; Nelson \& Foell, 2018; Patrick et al., 2005). Secondly, behavioral outcomes comprised in Factor 2 have more weight than the personalistic characteristics included in Factor 1 (Hare \& Neumann, 2008). This means that individuals are more likely to be classified as psychopaths merely by scoring high in PCL Factor 2, even when the core interpersonal-affective personality traits of PCL Factor 1 are scored fairly low (Cooke \& Michie, 2001; Patrick, 2006; Venables et al., 2014). This can lead to an overdiagnosis of some non-psychopathic people (e.g., recidivists with a long history of substance abuse). Lastly, one should bear in mind that constructs have explanatory power but measures don't as they are only a way to operationalize a given construct in a given population (Skeem \& Cooke, 2010). The formulation of PCL items was undertaken in criminal samples, which produced a selection bias toward maladaptive 
characteristics (Cooke \& Michie, 2001; Patrick, 2006; Patrick et al., 2009; Skeem et al., 2011). Several positive adjustment indicators were discarded in PCL as they only explained 7\% of the variance and did not correlate with global psychopathy scores (Hare, 1980). This biased the ability of PCL to include adaptive content and possibly lead to the underinclusion of some psychopathic people (Skeem \& Cooke, 2010) namely among those who are still able to maintain relatively successful lives and occupying high-risk and/or high-power positions (Babiak et al., 2010; Bronchain et al., 2019; Costello et al., 2018; Gao et al., 2020; Lilienfeld et al., 2012; Mathieu et al., 2020; Patton et al., 2018; Smith et al., 2013).

From this standpoint, 3-dimensional models of psychopathy (see Figure 1) excluded more recently direct operationalizations of antisocial behavior and claimed for a hierarchical organization of the psychopathic personality structure, in which deficits in personality (i.e., interpersonal-affective features) can be (or not) a risk factor for behavioral outcomes (i.e., impulsive-antisocial; Cooke \& Michie, 2001; Cooke et al., 2006; Patrick, 2006; Skeem et al., 2011). Behavioral conducts (e.g., an act resulting in a criminal conviction) and personality traits (e.g., a callous disposition to commit crime) should not be confused according to Skeem and Cooke (2010). Antisocial tendencies are expected to co-vary with psychopathy, but this association is merely probabilistic and not linearly determined, as other individual and contextual risk factors (e.g., deficits in cognitive functioning and the lack of care experiences in infancy) are expected to moderate this association (Cooke \& Michie, 2001; Pasion et al., 2018a; Patrick, 2006; Patrick et al., 2009). In this view, antisocial behavior does not constitute a core feature of psychopathy per se and is best conceived as a possible second-order outcome (among others) of primary deficits in interpersonal and affective dimensions.

Therefore, 3-dimensional models do not attempt to replace the criminal conceptualizations of psychopathy; alternately, these models aim to extend the existing knowledge in the field by simultaneously accommodating risk factors for antisocial behavior 
and protective factors related to adaptive expressions of psychopathy (e.g., Triarchic Model of Psychopathy; Patrick et al., 2009). The 3-dimensional models include in their conceptualization (Cooke \& Michie, 2001; Patrick, 2006; Patrick et al., 2009; Skeem et al., 2011): (1) boldness-fearlessness traits, a dimension which maps several of Cleckley's (1941/1988) positive adjustment indicators that were initially excluded from psychopathy measures (e.g., low reactivity to stress, resilience, persuasion); (2) meanness/cold-heartedness traits, encompassing attributes related to cruelty, insensitivity, deficient empathy, and disdain for close attachments with others; (3) disinhibition, referring to behavioral deficits in impulse control and impulsivity. Hence, these models exclude direct referents of antisocial behavior, but left two dimensions that are seen as proximal attributes of antisocial expressions, i.e., meanness/cold-heartedness and disinhibition.

The operationalization conveyed by 3-dimensional models may be found across several inventories such as Triarchic Psychopathy Measure (TRiPM, Patrick, 2010), Psychopathic Personality Inventory (PPI, Lilienfeld \& Andrews, 1996) and Youth Psychopathic Traits Inventory (YPI, Andershed et al., 2002).

\subsection{Integrating theoretical framework of psychopathic personality}

The evolution of the frameworks of psychopathic personality described above has been an intricate process for over 30 years. The current meta-analysis aims to examine how empathic deficits in psychopathy can be characterized in light of the main models in the field, mainly addressing points of contact between the classical PCL-based 2-Factors /4-Facets models and the recent triarchic/3-dimensional approaches.

At this point, one should acknowledge that the first 3-dimensional conceptualization of psychopathy was developed by Cooke $\&$ Michie (2001). The authors' proposal can be interpreted as a direct reorganization of the 4-facets model since it only excluded the antisocial component (i.e., facet 4) from the psychopathic personality construct. Nevertheless, this 
represented a reorganization of the nuclear features of psychopathy and rescued an old idea by Cleckley (1941/1988) - that psychopathy is not essentially linked to antisocial behavior. Thus, Cooke \& Michie's (2001) proposal represented a major change in PCL-based assumptions and was just the first step for rethinking 3-dimensional models as currently known. Cooke \& Michie (2001) opened the door for researchers to recover the positive adjustment indicators that were excluded from PCL operationalizations and, since then, several authors gradually produced new evidence towards the idea that psychopathic traits are continuously distributed in the population and, more importantly, that adaptive manifestations needed to be included in newly developed questionnaires (Benning et al., 2005; Blagov et al., 2016; Brislin et al., 2017; Copestake et al., 2011; Drislane et al., 2015; Drislane et al., 2014; Evans \& Tully, 2016; Patrick, 2010; Patrick \& Drislane, 2015; Patrick et al., 2009; Poythress et al., 1998; Venables et al., 2014; Wall et al., 2015). As such, although the 3-dimensional and 4-facets models show a similar coverage of psychopathy dimensions (see Figure 1), they show nowadays fundamental differences in their operationalization of psychopathic traits, mainly regarding the interpersonal dimension.

2-factors and 4-facets models remained closely linked to PCL-like formulations (both in self-reports and interviews) and tend to focus on maladaptive features of psychopathy, even in the interpersonal facet 1 . Conversely, 3-dimensional models as currently known (e.g., Triarchic Model of Psychopathy) encompass adaptive manifestations of psychopathy by including lowanxiety, stress resilience, social dominance, boldness and fearlessness-related indicators. As a result, interpersonal traits (facet 1) and boldness represent core distinctive features of both models, which is not divorced from the debate around to what extent psychopathy is essentially about antisocial behavior, or if alternatively, it comprises adaptive features that allow these individuals to successfully navigate in the social world. The extent to which operationalizations of psychopathy leverage and converge with boldness and related positive indicators is indeed a 
determinant aspect for differentiating the main approaches in the field: PCL-criminogenic or boldness-adaptive approaches.

Empirical data can help us to clarify how the available psychopathy measures can be framed into both approaches. Overall, questionnaires inspired by the PCL-R structure do not represent adequately boldness-related features.

The SRP-III is a direct operationalization of the PCL 4-facets model (Williams et al., 2003). Its Interpersonal Manipulation subscale (facet 1) does not yield specific associations with boldness or fearless dominance as operationalized by TriPM (Patrick, 2010) and PPI (Lilienfed \& Andrews, 1996). This reveals that interpersonal conceptualizations of psychopathy differ across 3-dimensional and 4-facets models. Nevertheless, boldness might not be purely adaptive and can partially capture some interpersonal features indexed by facet 1 . Research shows only inconsistent links between both dimensions. A correlation between boldness and PCL facet 1 was observed in male prisoners, but not in female offenders (Brislin et al., 2017). Facet 1 exhibited moderate correlations with boldness, although it displayed larger associations with antisocial personality disorder symptoms (Wall et al., 2014).

The LSRP reproduces two PCL factors: primary and secondary psychopathy (Levenson et al., 1995). LSRP subscales are unrelated to boldness - despite correlations between meanness/primary psychopathy and disinhibition/secondary psychopathy (Drislane et al., 2014). Even when using 3-factorial solutions including interpersonal egocentricity, boldness relates to neither LSRP subscale (Brinkley et al., 2008; Sellbom, 2011; Somma et al., 2014). Egocentricity is indeed mostly associated with meanness (Sellbom and Phillips, 2012).

The APSD was developed to be a childhood extension of the PCL-R, even if items pertaining to antisocial behavior were removed or modified (Frick et al., 1994; Frick et al., 2000). The APSD is mainly employed with a 2-factorial solution (callous-unemotional and impulsivity-conduct problems). A new dimension of narcissism was added later by Frick et al. 
(2000), but even this presumably interpersonal dimension did not correlate with boldness (Drislane et al., 2014; Sellbom \& Philips, 2012). In fact, narcissism and callous-unemotional traits are equally related to both PCL factors (Vitacco et al., 2013).

Summing it up, psychopathy measures stemming from the PCL operationalization seem to do not adequately leverage adaptive interpersonal traits included in the boldness-like dimensions. Boldness traits of the 3-dimensional conceptualizations mirror in some aspects PCL's facet 1 but reduce the focus on its disruptive features by further covering positive adjustment indicators. Therefore, boldness features tend to not correlate systematically with 2factors and 4-facets models (Factor 1 and facet 1, respectively), while meanness (Factor 1 and facet 2) and disinhibition (Factor 2 and facet 3) converge more closely with PCL-based approaches. For instance, these dimensions were left in 3-dimensional models to better apprehend maladaptive expressions of psychopathy.

In contrast to PCL-driven measures, other psychopathy inventories cover into a greater extent adaptive boldness traits. The PPI was developed to assess a broad array of psychopathy manifestations, stemming from a comprehensive literature review which included Cleckley's (1941/1988) and Lykken's (1995) formulations (Lilienfeld \& Andrews, 1996). This allowed for recovering adaptive adjustment features of psychopathy that were initially retrieved from PCL such as superficial charm, lack of anxiety, and fearlessness. PPI displays two broader factors routed in the etiological paths of psychopathy - fearless dominance and self-centered impulsivity. The cold-heartedness domain did not load on either subfactor and can thus be used as a stand-alone subscale (e.g., Benning et al., 2003). Evidence suggests that PPI adequately represents the 3-dimensional phenotypes, including the adaptive boldness traits (Drislane et al., 2014; Stanley et al., 2013; Sellbom \& Philips, 2012). PPI fearless dominance and TriPM boldness converge themselves in community and criminal samples, while the PPI cold-heartedness subscale is uniquely related to TriPM meanness. PPI 
self-centered impulsivity has been mostly associated with disinhibition, although meanness can further predict this dimension (e.g., Blagov et al. 2016; Drislane et al., 2014; Stanley et al., 2013; Fanti et al., 2016). It is likely to be due to covariance between meanness and disinhibition through machiavellian egocentricity (Drislane et al., 2014). The content evaluation conducted by Hall et al. (2014) demonstrated that TriPM meanness blend PPI coldheartedness and machiavellian egocentricity. Regardless, empirical data strongly indicate that the most commonly reported factorial solution of PPI (fearless dominance, coldheartedness, and self-centered impulsivity) is an adequate operationalization of boldness, meanness, and disinhibition as intended by 3-dimensional models.

Finally, it is also important to address the YPI, which was developed to overcome problems when measuring psychopathy in youth community samples. Andershed et al. (2002) refer that YPI was conceived to evaluate the core personality traits of psychopathy rather than its behavioral expressions, as suggested by Cooke \& Michie (2001). Actually, the authors consulted both Hare's Psychopathy Checklist and Cleckley's descriptions and reached a 3factorial solution (grandiose-manipulate, affective, impulsive-irresponsible) which presumably encompasses views from both authors. As such, it might be not clear the concrete referent of YPI, especially when considering that its interpersonal dimension targets charm and grandiosity but also lying and manipulation (Andershed et al., 2002). Nonetheless, Drislane et al. (2014) reported that most of the interpersonal YPI subscales were positively associated with boldness - and although grandiose-manipulate traits were also associated with either meanness or inhibition. In the same vein, Andershed et al. (2007) observed that even though the 3-factors of YPI and PCL-Youth Version were moderately correlated, most grandiosemanipulate subscales of the YPI were not significantly correlated with the conceptually corresponding PCL-Youth items. Thus, YPI grandiose-manipulate traits seem to be inconsistently associated with both boldness-related traits and the non-adaptive interpersonal 
facet 1. For the purposes of this study, it is argued that YPI is a closer conceptualization of a 3dimensional model because of two main conceptual reasons: (1) YPI items were developed to be considered positive or admirable by individuals scoring high in psychopathy (e.g., "I usually feel calm when other people are scared", "I can get almost anyone to believe anything"), thus enhancing the likelihood of the grandiose-manipulate to index, at least partially, more adaptive interpersonal traits; (2) a revised triarchic structure of the YPI was developed through content evaluation, indicating that several grandiose-manipulate items effectively represent boldness (Drislane et al., 2015). This newly proposed structure of the YPI was more effective in discriminating triarchic dimensions than PCL-based facets. Even so, as most available studies using the YPI do not compute these triarchic YPI scores, additional control analysis will be conducted in the current work encompassing YPI in the 4-facets model as well.

\subsection{Dissociating psychopathy dimensions and antisocial behavior: what can empathy}

\section{teach us?}

Empathy is a fundamental process underpinning human interactions and is considered a hallmark of psychopathy. Although numerous definitions of empathy exist (for a comprehensive review see Hall \& Schwartz, 2019), empathy is widely regarded nowadays as a multidimensional construct (Eklund \& Meranius, 2020). It is less consensual, however, what are its specific subdomains (Blair, 2005; De Waal \& Preston, 2017; Dvash \& Shamay-Tsoory, 2014; Jolliffe \& Farrington, 2006; Reniers et al., 2011; Zaki \& Ochsner, 2012). Among distinct conceptualizations, it is possible to unveil a key point of convergence. There is a fairly growing consensus in the field that empathy encompasses at least two major domains - cognitive and affective empathy - and recent meta-analytical evidence from brain imaging studies unveiled distinct neuronal networks underlying these two dimensions (Kogler et al., 2020).

For the scope of this review, cognitive empathy will be broadly defined as the ability to infer the mental states of others or cognitively take their perspective. These inferences may be 
related to cognitive content (e.g., understanding thoughts, intentions, or beliefs) as well as emotional content (e.g., inferring what another person is feeling; Corradi-Dell'Acqua et al., 2020; Tesar et al., 2020). Conversely, affective empathy will be defined as the ability to be sensitive to and vicariously experience the emotional states felt by other people, as reflected by both empathic concern (e.g., other-oriented feelings of sympathy) and personal distress (e.g., self-oriented feelings of discomfort; Grynberg \& Konrath, 2020; Israelashvili et al., 2020).

Empathic dysfunctions have been associated with several disruptive behaviors (Blair, 2005; Jolliffe \& Farrington, 2004; Miller \& Eisenberg, 1988; Reniers et al., 2011; van Dongen, 2020; van Langen et al., 2014). Previous meta-analyses reported small to moderate empathic deficits in violent, juvenile, and sexual offenders (Jolliffe \& Farrington, 2004; Morrow, 2020; van Langen et al., 2014) as well as an association between antisocial outcomes and empathy in individuals with externalizing tendencies and a history of physical abuse in childhood (Miller \& Eisenberg, 1988). Interestingly, effect sizes are stronger for cognitive empathy than affective empathy, suggesting that impairment in the cognitive domain emerges as a specific risk factor for offending (Jolliffe \& Farrington, 2004; Miller \& Eisenberg, 1988; but see also Vachon et al., 2014; van Langen et al., 2014). Nevertheless, these meta-analyses did not evaluate the potential confounding role of psychopathy, which is of critical importance for two main reasons: (1) psychopathy is represented over criminal samples; and (2) affective empathy impairment in antisocial samples is thought to be dependent on the co-occurrence of psychopathy (Bons et al., 2013; Fairchild et al., 2019; Frick \& Kemp, 2020; Marsden et al., 2019; Sedgwick et al., 2017).

Thus, although empathy (broadly defined) can be viewed as a risk factor increasing the likelihood of antisocial outcomes, the most recent developments in the field call for a more fine-grained conceptual formulation on how cognitive and affective empathy may be differentially linked to psychopathy and antisocial behavior. This approach opens a promising 
venue to: (1) explore whether antisocial and psychopathy can be clearly dissociated in their empathic profiles and then (2) examine how the heterogeneous dimensions that compose the psychopathic personality relate to deficits in cognitive and affective empathy.

Importantly, the analysis on the second topic can provide critical insights on the everlasting emotion paradox of psychopathy (Lorenz \& Newman, 2002) - How may psychopathic individuals who lack the ability to fully grasp affective experiences, be so competent in the manipulation of others? This paradox, firstly inspired by Cleckley's (1941/1988) concept of the Mask of Sanity, is inherently connected to the delicate balance between cognition and affect in psychopathy - psychopathic individuals are apparently capable of superficially mimicking "normal human emotions", regardless of profound internal interpersonal-affective deficits displayed behind their mask. Their socioemotional deficits can be thus (and surprisingly) connected to exceptional social abilities (Glenn et al., 2022).

Recently, there has been additional evidence supporting this paradox. The metaanalytical work of Hoppenbrouwers et al. (2016) described that the experience of others' distress is impaired in psychopathy when it comes to affective responsivity at the automaticvisceral level (i.e., reduced heart rate, skin conductance, and startle responses), even though no significant deficits exist in the evaluation of such emotions at a more cognitive-elaborated level. Another recent systematic review reported that children with high callous-unemotional traits display reduced emotional responsiveness as assessed by physiological measures, especially when using other-oriented stimuli, but results were far more inconsistent when considering other measurement methods such as self-reported subjective experience or observed behavior (Northam and Dadds, 2020). Studies indicate indeed that individuals scoring high in psychopathy can accurately identify emotions; however, this is accompanied by a pervasive slowing of response times; that is, less efficiency in the automatic processing of affective stimuli as a consequence of cognitive top-down processing (Brennan \& Baskin- 
Sommers, 2020b; Hartmann \& Schwenck, 2020; Vitale et al., 2018). Whereas social cognition is assumed to be an automatic and implicit mechanism in the human brain (Frith \& Frith, 2007), deliberative and higher-level processing of social and emotional signals does exist in human species (Evans, 2008; Lieberman, 2007; Spunt \& Lieberman, 2013). The dual-route model for processing social information leaves an open door for a putative compensatory pathway in psychopathy: while automatic affective states are proposed to be directly dependent on visceral inputs that are lacking in psychopathy, cognitive computations may compensate for understanding these affective states (Hoppenbrouwers et al., 2016).

Building on these findings, the dissociation between cognitive and affective empathy provides a clear rationale to further examine the emotion paradox - and especially if the multidimensional nature of the psychopathic personality structure is taken into account. For instance, in some psychopathic traits, cognitive processing at the empathic level may compensate for deficits in affective empathy, while other psychopathy expressions may be characterized by broader empathy deficits.

Based on this assumption, Gao and Raine (2010) formulated a model to systematize factors preventing highly psychopathic individuals from engaging in criminal behavior and empathy played a central in this discussion. The most recent version of Gao and Raine's model (Gao et al., 2020) emphasizes that impulsive-antisocial traits are an attribute of impaired empathy at both cognitive and affective levels, although previous meta-analysis observed larger effects in cognitive empathy (Jolliffe \& Farrington, 2004; Morrow, 2020; van Langen et al., 2014). In the same vein, a meta-analysis reports that callous-unemotional traits are those expected to be strongly associated with both cognitive and affective empathy deficits in younger samples (Waller et al., 2020). By contrast, interpersonal (and presumably boldness) traits are assumed to be associated with preserved - or even increased - cognitive empathy. 
For instance, previous studies report better cognitive functioning (e.g., executive functioning) in boldness-fearlessness traits (e.g., Baskin-Sommers et al., 2019, Sellbom \& Verona, 2007; Pasion et al., 2018a). A superior cognitive performance - namely as reflected in cognitive empathic computations - might explain adaptive manifestations in psychopathy, particularly by considering that affective empathic deficits are placed as a transversal risk factor for disruptive outcomes (Gao et al., 2020). As such, individuals scoring higher in interpersonal-boldness traits can be more able of using cognitive empathy as an alternative strategy for processing social-affective information. These individuals may learn social norms regarding affective states by using effortful reasoning, such that cognitive processes can compensate for impaired affective-empathic responses. For example, research demonstrates that although total psychopathy scores relate to reduced discrimination between real and fake emotional expressions, boldness scores predict high accuracy in rating genuine smiles (Glenn et al., 2022). Moreover, fearless traits relate to emotional and social intelligence to predict improved accuracy in discriminating facial emotional cues (Sacco et al., 2016). Ultimately, the probabilistic combination of increased cognitive empathy with deficits in affective empathy may allow individuals scoring higher in boldness to understand the feelings of others without the accompanying affective sharing experience. This cognitive-affective dissociation may favor the process of taking advantage of others, particularly in situations involving self-benefit.

However, until this date, there is still not a systematic approach testing the assumptions of Gao and Raine's model regarding empathy while simultaneously integrating the main conceptual frameworks of psychopathy.

\subsection{The current study}

The current meta-analysis aims to provide the first comprehensive picture of the complex interaction between psychopathy, antisocial behavior, and empathy by integrating the main 
theoretical frameworks of psychopathy and considering the differential relations of psychopathy dimensions and antisocial behavior with distinct empathy domains.

The first step of the strategy consists of examining the differential role of cognitive and affective empathy in psychopathy and antisocial behavior, using both group-based and correlational analysis. Subsequently, a dimensional analysis decomposing the 2-factors, 4facets, and 3-dimensional models of psychopathy will be conducted to explore the differential associations of each psychopathic dimension with cognitive and affective empathy.

According to previously described evidence, it is expected that affective empathy will be more clearly impaired in psychopathy in comparison to cognitive empathy (H1), especially for those traits related to shallow affect, cruelty, and lack of remorse (facet 2, and meanness; Gao \& Raine, 2010; Gao et al., 2020; Waller et al., 2020). In turn, cognitive empathy is expected to be impaired to a greater extent in antisocial groups (Jolliffe \& Farrington, 2004; Miller \& Eisenberg, 1988; van Langen et al., 2014) and, therefore, (H2) in antisocial-impulsive expressions of psychopathy (Factor 2, facet 3 and 4, and disinhibition traits). For the adaptive dimensions of psychopathy, it is postulated that interpersonal (facet 1) and boldness traits will be associated with increased cognitive empathy (H3), despite deficits in affective empathy (Gao \& Raine, 2010; Gao et al., 2020).

[insert Figure 1 about here]

\section{Method}

\subsection{Search Strategy}

Records were identified by systematically searching several electronic databases, namely PubMed (Medline), Web of Science Core Collection, and EBSCO (Psychology and Behavioral Sciences Collection, APA PsycArticles, and Open Dissertations). The following search terms were used to design a search query for each database: psychopathy, sociopathy, antisocial behavior/personality disorder, callous-unemotional, conduct disorders/problems, 
disruptive behavior, oppositional defiant/behavior, problem behavior, violent, criminals, offenders, prisoners, inmates, delinquency, empathy, perspective-taking, theory of mind, mentalizing, mindreading and mental states. Variants and MeSH for these terms were included whenever possible. The full search query for each database can be found in Appendix A. The original search was conducted on 27 April 2019, but it was subsequently updated on 15 October 2020 and 11 November 2021. Additional records were also retrieved by scanning the reference lists of major reviews addressing psychopathy and antisocial behavior as well as empathy and social cognition. Finally, authors from the included records were invited to send any additional studies that met the eligibility criteria.

\subsection{Eligibility Criteria}

Only records written in the English language were considered for analysis. Records were included if they met the following criteria: (1) empirical studies with quantitative data, (2) antisocial and/or psychopathy assessment or group comparison, and (3) empathy assessment.

Regarding the first criterion, cross-sectional, longitudinal, and experimental studies reporting baseline assessments of psychopathy and empathy were included. Reviews, theoretical research papers, commentaries, case reports, editorial, and qualitative studies were excluded.

For the second criterion, this review included studies reporting between-group differences and correlational designs. Between-group analyses for antisocial samples covered studies comparing any given antisocial group (offenders, antisocial personality disorder, conduct disorders, latent antisocial profiles in community samples, etc.) with non-antisocial control groups. Between-group analyses for psychopathy samples comprised studies comparing any given group displaying higher psychopathic traits (e.g., clinical cut-off scores, quartile criteria) with control groups exhibiting low psychopathy levels. Overall, it is important to notice that samples with participants displaying comorbid internalizing (e.g., 
depression, anxiety) or externalizing (e.g., substance abuse, attention deficit and hyperactivity disorder) disorders were not excluded. Modern conceptualizations show that personalistic and psychopathological phenomena are continuously distributed in the general population and, therefore, are expected to naturally co-occur in the included samples (Kotov et al., 2017). Even the high-order dimensions of the internalizing and externalizing spectra are expected to rely on a broad latent factor that explains common variance $(r=.41$ to .72$)$ between the two dimensions (Cosgrove et al., 2011; Kendler \& Myers, 2014; Krueger, 1999; Krueger et al., 1998; Krueger et al., 2007); thus, psychopathic and antisocial samples mainly characterized by high externalizing traits are also expected to be prone to internalizing manifestations. Samples with comorbid cluster B personality disorders (e.g., narcissism) were included since empirically-based personality models show that antagonistic externalizing is a common feature among them (Kotov et al., 2017). Still, we excluded samples in group-based analysis where all participants were exclusively diagnosed with one of the above disorders, For example, a group where all participants had comorbid ADHD and conduct disorders would result in a confounding factor for isolating the variable of interest, i.e., antisocial behavior. Finally, studies including participants with other comorbid psychiatric disorders (e.g., schizophrenia and autism), neurological disorders, or intellectual disabilities were excluded because they are expected to interfere significantly with empathic abilities and/or overall cognitive functioning. For correlational analyses, studies reporting psychopathy and/or antisocial behavior scores and their zero-order correlation coefficients with empathy measures were included. This enabled to assess the continuous covariation between the two main variables of interest.

For the third criterion, studies had to include at least one self-report or performancebased measure assessing empathy. For cognitive empathy, measures related to the ability to infer the mental states of others or cognitively take their perspective were considered. This encompassed cognitive empathy scores on questionnaires, but also a wide range of measures 
related to mentalizing, perspective-taking, emotional understanding, and theory of mind. For affective empathy, measures representing the ability to be sensitive to and vicariously experience the feelings of others were considered into analysis (e.g., scores of affective empathy, affective sharing, personal distress, and empathic concern). Total empathy scores were further extracted to better test whether they are sufficiently informative for exploring the role of empathy in antisocial behavior and psychopathy.

\subsection{Study Selection and Data Coding}

The non-duplicate records were initially screened by title and abstract to remove studies that were clearly out of topic. The remaining records were then full text screened by two blinded researchers to determine their eligibility for the review. Conflicts between researchers were solved by consensus in a meeting with the research team. Those records that were manually retrieved or sent by authors were further assessed for eligibility in these meetings.

Data extraction was completed by several members of the research team and was always verified by a second independent researcher. A spreadsheet was developed to extract the required information from the included studies, namely: (1) Study information - title, authors, and publication year; (2) Conditions for analysis - groups under comparison (e.g., offenders vs. controls, high psychopathy vs. low psychopathy, etc.) or correlated measures (e.g., total psychopathy and affective empathy); (3) Sample characteristics - sample size ( $n$ for each sample/group), sample type (community, criminal and/or clinical), age (mean or other metrics if mean was not available); and percentage of females; (4) Antisocial and psychopathy criteria/measure - for group-based analyses, antisocial and/or psychopathy criteria to define groups (e.g., offenders with criminal records, DSM-V APSD diagnosis, PCL-R cut-off score for high and low psychopathy), while for correlational analyses the main psychopathy dimensions under analysis were coded (see Figure 1 and the Analytic Strategy heading); and 
(5) Empathy measure - each measure was classified according to its domain (total, cognitive, or affective empathy) and measure type (self-report and performance-based).

For effect size calculation in between-group analyses, means and standards deviation for each group were coded whenever possible. Alternatively, Cohen's d, $t$-, $F$-, and $p$-values were considered if these statistics granted an accurate estimation of the effect size of interest (e.g., an effect size was not estimated if the only information available was $p>.05$ or $p<.05$ ). For correlational analyses, only zero-order correlations were retrieved (i.e., we did not retrieve partial coefficients and we excluded studies that did not report zero-order correlations). Effect size direction was labeled for each available condition. Negative effects represent reduced empathy in antisocial/psychopathy groups (group-based analyses) and lower empathy in higher levels of psychopathic or antisocial behavior (correlational analyses).

Missing information for effect size calculation and other queries regarding included studies (e.g., unclear information, duplicate samples, etc.) were requested by email to the authors. Studies were excluded since no information was available for effect size calculation and the authors did not reply to the request. Any inconsistencies after verification were clarified with the original authors or addressed in a meeting by the research team.

\subsection{Analytical Strategy}

As previously described, this work encompassed a wideset of analyses that required distinct analytical strategies.

Group-based analysis required the dissociation of antisocial and psychopathy groups whenever possible, given that this confounding factor exists in previous meta-analyses. For this purpose, antisocial groups were classified according to psychopathy traits (e.g., offenders with high vs. low psychopathy). Only groups with low psychopathy were included in the antisocial group comparison whenever this information was available (e.g., low psychopathy offenders vs. community controls). Conversely, antisocial groups with low psychopathy scores were 
included as the control group in the psychopathy group comparison, allowing us to compare high vs. low psychopathy groups. For studies including high, moderate, and low psychopathy groups, we combined high and moderate psychopathy groups to compare them with the low psychopathy group.

Then, antisocial and psychopathy group-based analyses were complemented with additional correlational analyses intersecting total psychopathy and antisocial scores with empathy. This is particularly relevant for psychopathy as this concept is nowadays more widely conceptualized as being continuously distributed in the general population (Guay et al., 2007; Skeem et al., 2011). Total psychopathy included not only multidimensional psychopathy measures that provide a total score (e.g., PCL, Triarchic Psychopathy Measure) as well as other questionnaires that assess psychopathy as a unidimensional construct (e.g., Dirty Dozen, Short Dark Triad). Broad antisocial measures included delinquency and criminal activities questionnaires (e.g., Self-Reported Delinquency, Antisocial Behavior Questionnaire), conduct and oppositional-behavior problems scales (e.g., Child Behavior Checklist - Rule-Breaking subscale, Strength and Difficulties Questionnaire - Conduct Problems subscale), and Conduct Disorders or Antisocial Personality Disorder symptoms (indexed by DSM-based measures).

Finally, a major goal of this meta-analysis was to examine different psychopathy models (2-factors, 4-facets, and 3-dimensions). Thus, effect sizes extracted for correlational analyses were labeled according to the psychopathy framework in which each scale can be framed. This categorization is described in Table 1 and relies on the rationale presented in the introduction section. As callous-unemotional questionnaires models (e.g., Inventory of Callous-Unemotional Traits (ICU); Kimonis et al., 2008) are represented in both 3-dimensional and 4-facets models, additional control analyses were conducted excluding these measures to examine whether the same pattern of results was retained using only model-specific effect sizes. Due to the previously mentioned theoretical reasons, control analyses were further 
conducted using YPI Grandiose-Manipulate traits alone. This YPI subscale was firstly excluded from boldness analyses and then added to interpersonal facet 1 effects.

[insert Table 1 about here]

\subsection{Meta-Analytic Methods}

Data analysis was conducted using Comprehensive Meta-Analysis software (version 3.0; Biostat, U.S.A). Random effect models were used for each meta-analysis as variability in effect sizes for the included records is not only due to sampling error and can be explained by other moderating factors (e.g., age, sex, type of measure). As such, these models allow for the generalization of results beyond the scope of the observed studies (Borenstein et al., 2009; Hedges \& Vevea, 1998).

Each analysis encompassed multiple effect sizes stemming from the same sample and, therefore, a mean effect size was calculated to account for the lack of independence between effects. These mean effect sizes were computed so that each available measure had the same weight in the combined effect. The following scenarios were accounted for when combining effect sizes: (1) in longitudinal studies, only correlations between measures collected at the same timepoint were included for analysis; if no simultaneous timepoints were available, a mean correlation between all assessment moments was calculated; (2) in studies encompassing different raters (e.g., parents, teacher, self-report), correlations between measures completed by the same rater were prioritized; if both psychopathy/antisocial and empathy measures were not available for the same rater, a mean correlation between all available measures for that rater was computed; (3) when a study reported different versions of the same measure, only correlations regarding the latest and/or longest version available were considered; (4) effect sizes were separately included for each independent subgroup whenever this information was available (e.g., men and women, offenders, and controls). 
For group-based analyses (antisocial and psychopathy groups) effect sizes were estimated using Hedges' g (Hedges, 1981). Hedges' g includes a correction factor that allows reducing effect size overestimation in small sample sizes. In several studies, it was required to combine groups before proceeding with effect size calculation (e.g., sex and non-sex offenders vs. controls, psychopathic offenders vs. non-psychopathic offenders and community controls). Groups were combined using the formulas provided by the Cochrane Handbook for Systematic Reviews (Higgins et al., 2019). For correlations analyses, effect sizes were calculated as zeroorder correlations and transformed to Fisher's $z$ scale. Correlation coefficients are not usually used in meta-analytical calculations as its variance widely depends on the correlation itself (Borenstein et al., 2009). The transformed values were then converted back to $r$ for easier interpretation. It is important to notice that the same record could originate group-based and correlational effect sizes as they were independent analyses (e.g., a study could be included for group comparison of high vs. low psychopathy groups using extreme quartiles as well as continuous correlations between psychopathy and empathy scores).

Moderation analyses were conducted to explore additional factors accounting for overall effect sizes. For the categorical moderator "type of empathy measure", self-report and performance-based measures were separately analyzed. For continuous moderators (age and \% of females), meta-regression techniques were implemented to examine the association between these variables and the mean effect size ( $b$, and $95 \%$ confidence intervals). Of note, when interpreting meta-regression coefficients for negative effect sizes, a positive coefficient implies that the effect size is larger (more negative) for lower values of the predictor (age or percentage of females). For example, when an effect size is negative, a positive meta-regression coefficient for age equates to larger effect sizes for younger samples and smaller effect sizes for older samples. 
Heterogeneity of effect sizes and publication bias were also evaluated on overall effect sizes for each analysis. More specially, between-study variability was tested using the Q (Cochran, 1954) and $\mathrm{I}^{2}$ tests (Higgins et al., 2019). Publication bias was assessed using the Eggers's test of intercept bias (Egger et al., 1997). For those effect sizes displaying publication bias $(p<.05)$, the trim-and-fill method was used to correct them (Duval \& Tweedie, 2000).

For each analysis, the weighted mean effect size, $95 \%$ confidence intervals, and $p$ values were reported. Effect sizes for correlational analyses were labeled as small $(r \geq|.10|)$, medium $(r \geq|.20|)$, and large $(r \geq|.30|)$ according to recent meta-analytical normative guidelines for interpreting results in the individual differences research field (Funder \& Ozer, 2019; Gignac \& Szodorai, 2016). These cut-off values were converted to between-group effect sizes using the formulas provided by Rosenthal (1994) to allow for comparability across analyses. Thus, for group-based analyses, effect sizes were labeled as small $(g \geq|0.20|)$, medium $(g \geq|0.41|)$, and large $(g \geq|0.63|)$.

Finally, the statistical significance threshold for inference testing was set using the twostage false discovery rate procedure described by Benjamini and colleagues (2006). This method allows for improved power over the classical false-discovery rate method and performs well in analyses encompassing correlated $p$-values. The threshold was calculated for a false discovery rate of .010 and considering only $p$-values used for inferential testing (weighted mean effect size, categorical moderators, and meta-regression). These procedures were implemented using a spreadsheet from Pike (2011) and returned a statistical significance threshold of $p \leq .006$. FDR-threshold adjusted confidence intervals for each effect size are supplied in Appendix B.

\section{Results}

\subsection{Search results}


A detailed flow diagram of study selection was developed using the PRISMA guidelines (Figure 2). A total of 5,817 records were retrieved after the electronic search. After removing duplicates $(n=1,779)$ and out of topic records $(n=596)$, the remaining records were full text screened for eligibility $(n=3,442)$. From these records, 541 met the eligibility criteria, although only 424 records were further included for analysis as there was not enough information to compute effect sizes and the authors did not reply to the information request. An additional 53 records were also added by manual search, including additional records sent by contacted authors $(n=7)$ and unpublished data from our research group $(n=9)$. Thus, a total of 477 records were included (citations available in Appendix C). However, after contacting authors, several records were shown to be replicated data. Thus, the effective number of samples included for analysis were 417, encompassing a total of 142,692 subjects.

[insert Figure 2 about here]

\subsection{Antisocial behavior}

A total of 127 samples were analyzed to test for empathy differences between antisocial and non-antisocial groups. The antisocial groups included a total of 8,660 participants, while the control groups included 10,123 participants $\left(25.80 \%\right.$ females, $M_{\text {age }}=21.45$, pooled for both groups). In the antisocial samples, only $13.39 \%$ studies recruited participants from the community, while $68.50 \%$ and $25.98 \%$ included subjects from criminal and clinical settings, respectively. ${ }^{1}$ Self-report measures were more frequently used to assess empathy $(84.25 \%)$ and the most widely used measure was the Interpersonal Reactivity Index (45.67\%), followed by Hogan's Empathy Scale (10.24\%), the Basic Empathy Scale (7.87\%), the Index of Empathy for Children and Adolescent/Bryant's (7.09\%), and the Empathy Quotient (6.30\%). Performancebased measures were used in $34.65 \%$ of the samples.

\footnotetext{
${ }^{1}$ Cumulative percentage surpasses $100 \%$ as some studies included participants from more than one setting (e.g., community and clinical). The same happens with studies including participants that fulfilled more than one criterion (e.g., juvenile offenders with conduct disorders).
} 
For correlational analyses, a total of 124 samples were included $(n=62,216,46.24 \%$ females, $M_{\text {age }}=19.02$ ). Most of the samples encompassed subjects recruited from the community $(83.06 \%$ ), while $20.16 \%$ and $12.10 \%$ had participants recruited from criminal and clinical samples, respectively. To assess antisocial behavior, the most widely used measure was the Achenbach System of Empirically Based Assessment (Child Behavior Checklist - 12.10\% and Youth Self Report - 10.48\%) together with the Strengths and Difficulties Questionnaire $(13.71 \%)$. However, the array of measures included for these analyses were more heterogeneous (other antisocial measures $=67.74 \%$ ). Self-report assessment of empathy (86.29\%) was mostly accomplished using the Interpersonal Reactivity Index (32.26\%), the Basic Empathy Scale (10.48), the Index of Empathy for Children and Adolescent/Bryant's $(8.87 \%)$, and the Griffith Empathy Measure (8.06\%). Performance-based measures were applied in $24.19 \%$ of the samples.

Results from group-based and correlational analyses for antisocial behavior are reported in Tables 2 and 3, respectively.

\subsubsection{Group-based analyses.}

Overall, reduced empathy was observed in antisocial groups (Table 2), $g=-0.37,95 \%$ CI [-0.47, -0.27], $p<.001$, although there was evidence for publication bias $(p=.005)$. The adjusted effect size after correction was smaller, $g=-0.23,95 \%$ CI $[-0.34,-0.13]$. However, these deficits were larger for cognitive empathy, $g=-0.43,95 \%$ CI $[-0.51,-0.34], p<.001$, than for affective empathy, $g=-0.13,95 \%$ CI $[-0.21,-0.05], p=.001$. Publication bias was detected for affective empathy $(p=.010)$, but the adjusted effect size after the trim-and-fill method displayed a similar magnitude, $g=-0.11,95 \%$ CI $[-0.19,-0.03]$. The results for affective empathy were moderated by age and measurement type such that effects were more robust in younger samples and only significant when using self-report empathy measures. 
Performance-based measures yielded medium effects in the cognitive empathy domain, while the results were only small for self-report measures.

\subsubsection{Correlational analyses.}

Correlational results addressing the association between total empathy scores and antisocial behavior were less robust than group effects, $r=-.16,95 \% \mathrm{CI}[-.18,-.14], p<.001$, namely regarding the dissociation between cognitive, $r=-.11,95 \%$ CI [-.14, -.07], $p<.001$, and affective empathy, $r=-.12,95 \%$ CI $[-.14,-10], p<.001$. Both yielded small effects (Table 3). Moderation analyses further revealed that self-report measures (all empathy domains) and samples with lower percentage of females (total empathy) were associated with larger effects. There was no significant publication bias on neither of the analyses (all $p \geq .072$ ).

[insert Tables 2 and 3 about here]

\subsection{Psychopathy}

For group-based analyses, 43 samples were meta-analyzed, encompassing 2,065 participants with high levels of psychopathy and 2,438 subjects with low/no psychopathic traits (18.27\% females, $\left.M_{\text {age }}=23.38\right)$. Most samples recruited participants from criminal settings (58.14\%), while only $34.88 \%$ and $23.26 \%$ included subjects from clinical groups and the community, respectively. Psychopathy groups were mainly evaluated thought PCL-R (39.53\%), although other measures such as the ICU (20.93\%), ASPD (11.63\%), SRP (4.65\%), LSRP (4.65\%), and YPI were also used (4.65\%). Self-report measures of empathy were used most often $(72.09 \%)$, although $55.81 \%$ of the studies also used performance-based measures. Regarding self-report measures, the Interpersonal Reactivity Index stood out as the preferential measure (44.19\%), followed by the Basic Empathy Scale (11.63\%), Hogan's Empathy Scale (4.65\%), Griffith Empathy Measure (4.65\%), and the Index of Empathy for Children and Adolescent/Bryant's (4.65\%). 
For correlational analyses, 221 samples were included, representing a sample size of 76,420 (49.77\% females, $\left.M_{a g e}=22.84\right)$. Most samples included participants recruited from the community $(80.54 \%$ ), while $20.81 \%$ and $9.05 \%$ recruited subjects from criminal and clinical settings, respectively. The most frequently used measures to evaluate psychopathy were: ICU (21.27\%), LSRPS (19.91\%), SRP (15.84\%), PPI (10.86\%), ASPD (9.05\%), YPI (7.69\%), TriPM (7.24\%), and PCL (6.79\%). Self-report measures were more frequently used to assess empathy $(84.62 \%)$, while performance-based were only used in $31.22 \%$ of the samples. The most common self-report measures of empathy were: Interpersonal Reactivity Index (36.20\%), Basic Empathy Scale (16.29\%), Questionnaire of Cognitive and Affective Empathy (6.33\%), Griffith Empathy Measure (5.43\%), and Empathy Quotient (4.52\%).

Results from group-based and correlational analyses for total psychopathy scores can be found in Tables 4 and 5, respectively. correlational analyses for each conceptual framework are presented in Table 6 (2-factors), Table 7 (4-facets model), and Table 8 (3-dimensional models).

\subsubsection{Group-based analyses}

In contrast with antisocial groups, empathy deficits in high psychopathy groups were larger in the affective domain, $g=-0.40,95 \% \mathrm{CI}[-0.55,-0.25], p<.001$, compared to cognitive empathy, $g=-0.22,95 \%$ CI [-0.32, -0.12$], p<.001$ (Table 4). A medium effect was further observed for total empathy scores, $g=-0.54,95 \%$ CI $[-0.85,-0.24], p<.001$. There was no evidence for publication bias on all these analyses (all $p \geq .476$ ). Contrarily to what was reported in antisocial groups, moderation analysis in the cognitive empathy domain revealed significant effects only for self-report measures (not performance-based).

\subsubsection{Correlational analyses: total scores}

According to previous analyses, a medium and negative correlation was observed between psychopathy scores and affective empathy, $r=-.29$, 95\% CI [-.32, -.25], $p<.001$, as well as total empathy, $r=-.29,95 \%$ CI [-.33, -.25], $p<.001$, while the effects were small for 
cognitive empathy, $r=-.19,95 \%$ CI [-.22, -.16], $p<.001$ (Table 5). Effect sizes across all empathy domains were larger for self-report measures (medium to large) in comparison to performance-based tasks (residual to small). There was no publication bias for any of the analyses (all $p \geq .459)$.

[insert Tables 4 and 5 about here]

\subsubsection{Correlational analyses: 2-factors model}

Factor 1 (interpersonal-affective traits) was negatively associated with affective empathy, $r=-.33,95 \%$ CI [-.36, -.30], $p<.001$, and total empathy, $r=-.38,95 \%$ CI [-.42, $.34], p<.001$ (large effect sizes for both analysis; Table 6). The findings for affective empathy were moderated by age such that effects were increased in older samples. In cognitive empathy, the negative association was medium, $r=-.26$, 95\% CI [-.29, -.23], $p<.001$, with effects being more robust for samples with larger percentage of females. There was some evidence for publication bias $(p=.022)$ in the latter analysis, although the bias adjustment actually suggested a large effect size $r=-.31,95 \%$ CI [-.33, -.28]. Importantly, self-report measures were once again associated with higher effect sizes (medium to large) in comparison to performance-based task (small effect) in both cognitive and affective empathy. For Factor 1, effects did not change substantially when callous-unemotional traits measures were removed from the analysis $\left(r_{\text {affective }}=-0.33, k=87 ; r_{\text {cognitive }}=-0.22, k=75 ; r_{\text {total }}=-0.36, k=49\right)$.

The effect sizes regarding Factor 2 (impulsive-antisocial traits) were small for both total, $r=-.17,95 \%$ CI [-.23, -.12], $p<.001$, and cognitive empathy, $r=-.15,95 \%$ CI [-.18, $.11], p<.001$. For affective empathy, the negative correlation was residual, $r=-.09,95 \%$ CI [$.14,-.05], p<.001$. For these analyses, there were not any major differences in the effect size magnitude of self-report vs. performance-based measures, although the association between performance-based affective empathy and Factor 2 was not statistically significant. There was no publication bias (all $p \geq .153$ ). 
As it stands, the interpersonal-affective traits of psychopathy seem to emerge as the core dimension to explain deficits in affective empathy, while impulsive-antisocial traits are less informative for dissociating cognitive and affective empathy and yield a more proximal pattern for what was reported in antisocial behavior analysis (i.e., significant deficits in cognitive empathy). Nevertheless, after adjusting for publication bias $(p=.022)$, interpersonalaffective traits appear to relate to robust findings in cognitive deficits as well.

\subsubsection{Correlational analyses: 4-facets model}

By separately considering the facets included in Factor 1 (facet 1: interpersonal and facet 2: affective), it was possible to unveil that impaired affective empathy was mainly related to the affective features of psychopathy (facet 2). Effect sizes were large in facet 2 for affective, $r=-.34,95 \%$ CI [-.38, -.29], $p<.001$, and total empathy, $r=-.40,95 \%$ CI [-.45, $.35], p<.001$, while effects were medium for cognitive empathy, $r=-.27,95 \%$ CI [-.31, -.23 ], $p<.001$ (Table 7). There was evidence for publication bias in the total empathy estimate $(p=$ $.021)$ but the effect size was even larger after bias correction, $r=-.49,95 \%$ CI $[-.54,-.44]$. After removing callous-unemotional traits measures, effect sizes for cognitive empathy reduced even more $\left(r_{\text {cognitive }}=-0.19, k=26, p<.001\right)$ and the effects of total empathy became even higher $\left(r_{\text {total }}=-0.42, k=17, p<.001\right)$. Removing callous-unemotional traits measures produced only negligible changes in the large effect size previously reported in affective empathy $\left(r_{\text {affective }}=-0.33, k=31, p<.001\right)$.

This dissociation between affective and cognitive empathy was also observed in interpersonal traits (facet 1) but at more modest levels (Table 7). The effects were medium in facet 1 for affective, $r=-.25,95 \%$ CI [-.31, -.19], $p<.001$, and total empathy, $r=-.25,95 \% \mathrm{CI}$ $[-.30,-.20], p<.001$, and small for the cognitive domain, $r=-.16,95 \%$ CI $[-.21,-.10], p<$ .001 . The cognitive empathy model displayed publication bias $(p=.004)$ and the negative correlation of this domain with facet 1 was larger after correction, $r=-.24$, 95\% CI [-.29, -.19]. 
As previously described, there are some reasons to frame the YPI Grandiose-Manipulate traits within the non-adaptive facet 1 . Thus, control analyses were implemented to check unique associations of YPI Grandiose-Manipulate with empathy domains and also to examine whether including it within the interpersonal facet 1 interfered with the pattern of results. YPI Grandiose-Manipulate traits alone were only significantly associated with affective empathy, although the negative effect size was only residual, $k=15, r=-.08,95 \%$ CI [-.13, -.03], $p=$ .002. The association of this YPI domain with cognitive and total empathy was not significant and even smaller ( $r=.00$ and -.04 , respectively). Interestingly, merging the YPI with facet-1 operationalization significantly reduced effect sizes across all empathy domains. After including YPI Grandiose-Manipulative effect, the association between cognitive empathy and facet 1 was only residual, $r=-.09,95 \%$ CI [-.14, -.04], $p=.001$. Similarly, facet 1 effects sizes for affective and total empathy downgraded to small negative effects $(r=-.19$ and $r=-.17$, respectively). Thus, YPI Grandiose-Manipulate seems to be suppressing the expected association of psychopathy maladaptive traits with empathic deficits, possibly suggesting that it is a closer operationalization of the 3-dimensional models.

The impulsive lifestyle and antisocial traits (facets 3 and 4, respectively) yielded a pattern of findings that was consistent with the broad factor they encompass (i.e., Factor 2), with effect sizes being small in all analyses. For facet 3, effect sizes were small for total and affective empathy (both $r=-.12$ ), as well as for cognitive empathy, $r=-.10$, 95\% CI [-.15, $.05], p<.001$. The effect size regarding facet 3 and affective empathy was likely influenced by publication bias $(p=.029)$ and the trim-and-fill correction suggested a residual association between both constructs, $r=-.03,95 \%$ CI $[-.09, .02]$. For facet 4 , effect sizes also were quite similar and small for total, affective, and cognitive empathy ( $r=-.14$ to -.11$)$.

Regarding moderation analyses, effect sizes for facets 1 and 2 were consistently larger for self-report measures (small to large effects) in comparison to performance-based tasks 
(mostly residual effects) in both empathy domains. Effect sizes for performance-based cognitive and affective empathy were not statistically significant for facet 1 . The magnitude of effects for facets 3 and 4 were less discrepant between measures, although most effect sizes computed for performance-based tasks were not statistically significant (only the effect regarding facet 3 and cognitive empathy was significant). Moreover, effect sizes were larger in younger samples for the analysis addressing the association of total empathy with facets 3 and 4, as well as for the relationship between cognitive empathy and facet 3 .

In summary, the 4-facets model seems to be more informative than the 2-factors model. Affective traits (facet 2) appear to be the critical factor explaining reduced affective empathy in the broad Factor 1. Even though facet 2 is also negatively associated with cognitive empathy, effects are consistently larger in total and affective empathy. Although a similar pattern was found for interpersonal traits (facet 1), effect sizes remained at the medium range and more modest compared to affective traits (facet 2) even after adjusting for publication bias ( $p=$ .004). Finally, both impulsive lifestyle (facet 3) and antisocial traits (facet 4) displayed small or residual negative associations with both cognitive and affective empathy, similarly to findings for Factor 2 and general antisocial behavior measures. There were no significant changes in these facets after correcting for publication bias (facet 2 with total empathy, $p=.021$, and facet 3 with affective empathy, $p=.029)$.

\subsubsection{Correlational analyses: 3-dimensions model}

In this model (Table 8), meanness was the dimension more strongly associated with reduced affective empathy scores, $r=-.35,95 \% \mathrm{CI}[-.40,-.31], p<.001$, even though there was some evidence for publication bias in this analysis $(p=.018)$. The adjusted estimate for this effect originated an even stronger negative correlation $r=-.46,95 \% \mathrm{CI}[-.51,-.42]$. This large effect was also observed in total empathy, $r=-.41,95 \%$ CI [-.46, -.35], $p<.001$, with both findings being moderated by age (larger effects in older samples). In turn, the effect size 
for cognitive empathy was only medium, $r=-.26,95 \% \mathrm{CI}[-.30,-.22], p<.001$, suggesting that effects related to meanness were more robust in the affective domain of empathy. In this psychopathy phenotype, self-report measures exhibited stronger effects compared to performance-based tasks on affective empathy (large vs. moderate effects, respectively), but especially in the cognitive domain (larger vs. residual effects, respectively). Of note, the main effects remained almost unaltered when excluding callous-unemotional traits measures from meanness $\left(r_{\text {affective }}=-.38, k=49 ; r_{\text {cognitive }}=-.22, k=49 ; r_{\text {total }}=-.42, k=33\right)$.

Effect sizes for disinhibition were negligible to small (Table 8) across all empathy domains ( $r=-.14$ to -.08 ), providing similar results to Factor 2, facets 3 and 4, and general antisocial behavior measures. Yet these effects were moderated by age in affective empathy such that older samples depicted larger effects. In the association between disinhibition and affective empathy, it was found evidence for publication bias $(p=.028)$. The trim-and-fill adjusted estimate suggested that disinhibition and affective empathy are moderately and negatively associated $r=-.21,95 \%$ CI [-.27, -.16]. The effect sizes for disinhibition were all small and significant for self-report measures, but none of the empathy domains displayed a statistically significant association when using performance-based tasks.

Finally, there was a negative association between boldness and total empathy, $r=-.14$, 95\% CI [-.21, -.06], $p=.001$. The specific analysis for each empathy domain showed that affective empathy is the main factor accounting for this effect, $r=-.17,95 \%$ CI $[-.22,-.12], p<$ .001 , although the negative correlation was still small. Here it is important to notice that this effect was moderated by measurement type, as the effect size was small and significant for self-report measures, but not statistically significant when using performance-based tasks. Conversely, no significant effects at the false discovery rate threshold were detected for cognitive empathy, suggesting that boldness is not associated with deficits in this domain, $r=$ $.03,95 \%$ CI $[-.02, .08], p=.200$. No publication bias was observed (all $p \geq .700$ ). 
Additional control analyses were conducted to assess whether YPI GrandioseManipulate traits moderated the boldness-related associations with empathy. That is, it was explored whether the associations between boldness and empathy remained the same after excluding YPI Grandiose-Manipulate from these analyses. Non-YPI boldness measures were still negatively associated with affective and total empathy, only with a slight increase in magnitude ( $r=-.21$ and $r=-.20$, respectively). Even after removing effects pertaining to the YPI, boldness was still not significantly associated with cognitive empathy, $r=.04,95 \%$ CI [$.02, .11], p=.181$. YPI Grandiose-Manipulative traits are similarly associated with empathy domains as other 3-dimensional measures, further justifying the option of considering it within the psychopathy personality operationalization.

Thus, in the 3-dimensional model, meanness results closely resemble those reported for the affective domain of the 4-facets model (facet 2) with larger effects being reported after correcting for publication bias $(p=.018)$. Disinhibition further presents a similar pattern to impulsive and antisocial traits (Factor 2, facets 3 and 4 and correlations with general antisocial behavior measures). Nevertheless, after correcting for publication bias $(p=.028)$ a medium effect was reported in its association with affective empathy. Boldness and interpersonal traits (facet 1) shared a negative association with affective empathy with a non-significant (positive) effect being reported for cognitive empathy. As a result, boldness seems to be associated with preserved cognitive empathy.

[insert Tables 6, 7, and 8 about here]

\section{Discussion}

Empathy deficits are widely regarded as a hallmark of psychopathy. However, it is still lacking a comprehensive endeavor examining the complex interplay between empathy domains (cognitive and affective) and psychopathy dimensions, particularly addressing the conceptual controversies between the main frameworks in the field. The available theoretical models 
provide different assumptions about the role of antisocial behavior in psychopathy and tend to progress on their separate lanes without any major integration attempts for evaluating how underlying processes - such as empathy - are differently related to heterogeneous expressions of psychopathy. To address this gap, this meta-analysis set out to systematically review the association between psychopathy traits, antisocial behavior, and empathy domains. The next sections will review the main results and discuss their implications for the theoretical conceptualization of psychopathy and antisocial behavior.

\subsection{Main Findings}

In this section, we aim to provide an overview of the main meta-analytical findings. We will focus on group-based analysis and how they can inform on fundamental differences in empathic profiles in psychopathy and antisocial behavior and then on correlational analysis and what they can tell us about the heterogeneity of the personality structure, especially regarding the dissociation of adaptive and maladaptive features and their links with empathy.

\subsubsection{Psychopathy vs. antisocial behavior: the differential role of cognitive and affective empathy}

A longstanding research question in the field leans on whether antisocial behavior is a coherent part of the psychopathic personality structure. Some theoretical models argue that antisocial behavior is inherently blended in the construct of psychopathy (Hare \& Neumann, 2008; Neumann et al., 2007), while others postulate that this association is not linear (Cooke \& Michie, 2001; Pasion et al., 2018a; Patrick, 2006; Patrick et al., 2009). As a result, critical processes that may underpin psychopathy and antisocial behavior - e.g., empathy - are critical to examine points of convergence/divergence between both constructs.

Results on group-based analyses indicated that antisocial groups display deficits in cognitive empathy. Smaller effects are reported in the affective domain. Overall, these findings are consistent with previous meta-analyses describing that cognitive empathy is the core 
component that is impaired in criminal and antisocial samples (Jolliffe \& Farrington, 2004; Miller \& Eisenberg, 1988; van Langen et al., 2014; Morrow, 2020). However, these metaanalyses did not account for the confounding role of psychopathy, which is thought to be a criminogenic trait with high prevalence in forensic settings. The implemented analytical strategy removed samples with high psychopathy traits from the antisocial groups whenever this information was available, allowing to better control for this confounding factor.

Psychopathy group-based analysis revealed an opposite pattern of results in comparison to antisocial groups. High psychopathy groups displayed affective empathy deficits (nearly reaching the medium cut-off) that were almost twice the size of cognitive empathy impairments (near the lower threshold of small effects). These findings are compatible with previous studies suggesting that affective empathy is impaired in antisocial samples only when callous-unemotional (Fairchild et al., 2019; Frick \& Kemp, 2020) and psychopathic traits covary (Bons et al., 2013; Fairchild et al., 2019; Frick \& Kemp, 2020; Marsden et al., 2019; Sedgwick et al., 2017) Importantly, these results strengthen the assumption that psychopathic and antisocial groups exhibit fundamentally differences in empathic profiles, which suggests that these two constructs are not linearly associated and should not be clustered together.

Even so, the distinct empathy profiles of antisocial behavior and psychopathy were not as clearly observed in correlational analyses. Although total psychopathy scores were more strongly correlated with affective empathy rather than cognitive empathy (as expected), general antisocial behavior displayed similar small effect sizes for both empathy domains. Hence, the small correlation between general antisocial behavior and cognitive empathy fell short of the greater deficits found in group-based analysis for this empathy domain. Interestingly, psychopathy dimensions closely related to antisocial expressions (Factor 2, facet 3, facet 4, and disinhibition) also yielded residual or small associations with both cognitive and affective empathy, similar to the correlational analysis for general antisocial behavior. The unique 
exception was for disinhibition after correcting for publication bias, since it yielded associations in the medium range with affective empathy.

These findings do not invalidate the latter conclusions from group-based analysis, but rather suggest that cognitive empathy deficits are only observed in the extreme end of the antisocial spectrum. A possible mechanism to explain these results may rely on differences in cognitive functioning, namely the dysfunction of executive brain networks in antisocial behavior. A previous meta-analysis systematically documented the interplay between executive functioning and cognitive empathy, such that the lack of inhibitory control was specifically associated with deficits in cognitive empathy (Yan et al., 2020). Findings from developmental and cognitive neuroscience further demonstrate that theory of mind and executive functioning share neurobiological commonalities (Wade et al., 2018). Thus, executive functioning may play a critical role in the ability to understand the mental states of oneself and others, allowing human beings to inhibit self-perspective and shift towards the perspective of others more effectively. As executive functioning is widely impaired across antisocial groups (Ogilvie et al., 2011), one can argue that deficits in these domain-general mechanisms may interfere with cognitive empathy. Whilst this may be the case for the antisocial group-based analysis, impairments on basic cognitive dimensions might not play a role in correlational analysis, particularly considering that over $80 \%$ of the included studies encompassed community samples, which likely explains the gap between group and correlational analyses.

Regardless of these results for antisocial behavior, correlational analysis still suggested that psychopathy is more strongly and negatively associated with affective rather than cognitive empathy, which emphasizes out the importance of identifying which psychopathy dimension better explains these deficits.

4.1.2. The core underlying factor of empathy deficits in psychopathy: affective, callous, and meanness traits 
The current results strongly suggest that the affective dimension of psychopathy (facet 2 , meanness, and callous-unemotional traits) is associated with a broad empathy impairment, although effect sizes were larger for affective empathy. Regardless of the conceptual framework, this dimension displayed large correlations with affective empathy and medium effect sizes for cognitive empathy, allowing for two important considerations. Firstly, results exhibit the pattern reported in the psychopathy group-based analysis, suggesting that callousunemotional and meanness-affective traits can be of a nuclear role in psychopathy-related empathic deficits. Secondly, the pattern of results in these dimensions were clearly distinct from traits more closely related to antisocial behavior (i.e., disinhibition and impulsiveantisocial traits). This strengthens the assumption that psychopathy is not a unitary construct insofar empathic profiles differ across psychopathic dimensions.

Despite these findings, it is imperative to evaluate whether empathic deficits in affective, callous, and meanness traits of psychopathy are not due to item-overlap between inventories assessing empathy and psychopathy. For instance, callous-unemotional questionnaires are often used as interchangeable measures of empathy since they include items that resemble those commonly included in empathy scales (e.g., ICU -"I do not care whom I hurt to get what I want", "I do not feel remorseful when I do something wrong"; TriPM - "How other people feel is important to me", "I am sensitive to the feelings of others", "It's easy for me to relate to other people's emotions"). This could cause a certain circularity in assessing the interrelations between both constructs (Waller et al., 2020). However, several aspects of the current analytical approach enabled to somewhat discard the idea that the covariance between psychopathy and empathy is only due to item overlap. Firstly, the correlation coefficients reported were far from being multicollinear and Waller et al. (2020) previously noted that measures of empathy and callous-affective psychopathy traits map onto different attributes (e.g., items related to exploitation, excitement seeking, defiance to authority, etc.). 
Secondly, there were also medium correlation effects with cognitive empathy, a domain much lesser represented in psychopathy inventories. Thirdly, performance-based affective empathy further yielded significant negative associations with these psychopathic traits. Effects were smaller but this is likely due to shared method variance (i.e., self-report measures will correlate higher between them than with other measurement modalities) and the reduced number of included studies (cf. also Further Results section).

In sum, callous-unemotional, meanness, and affective traits of psychopathy seem to be essentially linked to deficits in affective empathy and, to a lesser extent, with cognitive empathy impairments. However, these deficits in the affective dimension cannot solve the emotion paradox, which stresses the importance of exploring how interpersonal traits interact with cognitive and affective empathy.

\subsubsection{Adaptive vs. non-adaptive interpersonal traits: the differential role of cognitive empathy}

Effect size directions regarding the association between empathy and interpersonal features of psychopathy (facet 1 and boldness) were conflicting across the theoretical models under analysis. In the 4-facets model, the interpersonal dimension (facet 1) correlated with reduced empathy in both domains although at a more modest range compared to the affective dimension (facet 2). Conversely, preserved cognitive empathy was found in boldness traits, despite evidence for small deficits in affective empathy.

PCL-based measures used to operationalize the 4-facets models are extensively used in forensic settings and intend to capture the maladaptive characteristics of psychopathy (e.g., glibness/superficial charm, pathological lying, conning/manipulative; Hare \& Neumann, 2008). Inversely, boldness was conceived to map the positive adjustment features of psychopathy as distributed in the general community (e.g., TriPM, "I can get over things that would traumatize others", "I am well-equipped to deal with stress", "I function well in new 
situations, even when unprepared", "I'm a born leader" (Patrick, 2010). Similarly, to minimize social desirability bias, the items of the Youth Psychopathic Traits Inventory (3dimensional operationalization) were written in terms that may be considered positive or admirable by individuals scoring high in psychopathy (Drislane et al., 2015). Our control analysis confirmed that YPI suppressed the effects of facet 1 and results were more proximal of those reported in boldness. As such, one could argue that distinct conceptualizations and operationalizations exist in the field. PCL-based interpersonal domains (facet 1) will be inherently more closely related to antisocial expressions of behavior, while this association is much less linear for the positive adjustment indicators weighted into a greater extent in boldness-related traits from TriPM, PPI, or YPI.

The distinct architecture of psychopathy inventories is a direct consequence of the fundamental differences between the 3-dimensions and 4-facets models, which may ultimately lead to opposite associations with cognitive empathy. Although the association of empathy with the affective (facet 2 and meanness) and antisocial-behavioral components of psychopathy (facets 3 and 4, disinhibition) indicates some degree of overlap in the conceptual frameworks of psychopathy, the same cannot be said regarding the operationalization of the interpersonal dimension. As a result, the divergence between PCLbased and triarchic models is not only inherently related to the controversy on whether the antisocial dimension can be excluded from psychopathy inventories but also to what extent interpersonal traits should be operationalized in an adaptive manner.

Hence, adaptive interpersonal traits (boldness but not facet 1) may be critical to understanding the emotion paradox of psychopathy. These traits could explain why some psychopathic individuals may be able to use cognitive computations to infer the mental states of others (i.e., intact cognitive empathy), while simultaneously masking their inability to share the emotional states of others (i.e., impaired affective empathy). This can allow them to mimic 
normal human interactions and take advantage of these features to deceive and manipulate others for self-benefit.

\subsection{Further results, clinical practice, limitations, and future directions}

In this section, we aim to comprehensively explore additional moderators of effect sizes, reflect on limitations and future directions, and analyze how our results translate for psychological assessment and intervention practices.

\subsubsection{Sociodemographic moderators}

Moderation analyses were conducted to explore how age and sex played a role in the relationship between psychopathy and empathy.

Empathy and psychopathic traits are thought to be differentially expressed in males and females (Cale \& Lilienfeld, 2002; Christov-Moore et al., 2014; Verona \& Vitale, 2018). For instance, a meta-analysis indicated that overall empathy is less affected in female offenders in comparison to male offenders (van Langen et al., 2014). However, globally, the current metaanalysis does not show the moderation effects of sex. In general antisocial scores, only total empathy effects were moderated by studies including a higher proportion of males. Regarding psychopathy, only studies measuring Factor 1/cognitive empathy reported increased effect sizes for studies including a higher percentage of females. The lack of sex moderation effects is consistent with a previous meta-analysis (Waller et al., 2020).

Nineths, age was a significant moderator for several of the computed effect sizes, albeit regression coefficients were quite small. Waller et al. (2020) argued that larger effect sizes for empathy deficits in younger offender samples are likely due to the increased prevalence of delinquent behaviors during adolescence. Our data in antisocial groups and psychopathic traits closely related to antisocial behavior (facets 3 and 4) aligns with these suggestions. Interestingly, several analyses in the 3-dimensional model yielded opposite results; that is, effect sizes were larger in older samples for the correlation between meanness and 
total/affective empathy, as well disinhibition and affective empathy. These results are once again probably best explained by differences in the operationalization of psychopathy. Given that 3-dimensional questionnaires remove the antisocial dimension and weight to a greater extent adaptive features, they can be less able to detect delinquent acts in younger samples. It is also important to emphasize that cognitive and affective empathy display different development patterns across the lifespan (Main \& Kho, 2020; Sun et al., 2018). Hence, future longitudinal studies need to explore how psychopathy and empathy evolve across development while also shedding light on environmental factors that may moderate this link.

\subsubsection{Lessons learned for empathy assessment}

Despite the focus on the dissociation between cognitive and affective empathy, the analytical strategy of the current work also encompassed the computation of effect sizes for total empathy scores. Across both group-based and correlational analyses, total empathy was more strongly associated with psychopathy than antisocial behavior, making it reasonable to state that empathic deficits are much largely a core feature of psychopathy rather than antisociality. Despite this valuable insight, only the analyses for each empathy domain allowed to dissociate distinct profiles in psychopathy and antisocial behavior and the differential role of each empathy domain across psychopathy dimensions. Thus, stating that empathy is a major hallmark in psychopathy is not an incorrect saying, but it provides an unprecise picture of the complex interaction between these two variables.

Even more so, several empathy models and empirical data reveal that specific subcomponents of empathy exist within the broader cognitive and affective domains (e.g., Schurz et al., 2020; Dvash \& Shamay-Tsoory, 2014; Stevens \& Taber, 2021). Cognitive empathy can be further subdivided into cognitive and affective theory of mind; that is, the ability to mentalize about non-emotional mental states (cognitive perspective-taking) in contrast to mentalizing about others' feelings and emotions (affective perspective-taking). 
There is evidence suggesting that cognitive and affective theory of mind display somewhat different neuroanatomical correlates, despite both constructs being associated with activation of classic theory of mind brain networks (Kalbe et al., 2010; Sebastian et al., 2012; ShamayTsoory \& Peretz, 2007; Schlaffke et al., 2015). Similarly, affective empathy can be further decomposed into affective sharing, personal distress, and empathic concern. Affective sharing diverges from other affective empathy subcomponents due to its degree of isomorphism and it has been associated with distinct neurobiological correlates when compared, for example, to empathic concern (Decety et al., 2015; de Vignemont \& Singer, 2006; Klimecki et al., 2014). Personal distress and empathic concern further differ on the degree of self- vs. other-orientation responses when seeing someone in distress (Stevens \& Taber, 2021). These constructs were differentially associated with emotion recognition (Israelashvili et al., 2020) and pro-social behavior (Williams et al., 2014), while also displaying distinct neuroanatomical correlates (Ashar et al., 2017). However, this putative dissociation between personal distress and empathic concern is not widely consensual as conflicting findings also exist. Personal distress and empathic concern were similarly associated with greater closeness towards another person experiencing pain (Grynberg \& Konrath, 2020) and emotional regulation when observing someone in distress (Grynberg \& López-Pérez, 2018). Moreover, there is evidence suggesting that both constructs are associated with insula-related activations during empathy tasks (Singer et al., 2004; Saarela et al., 2007). Thus, personal distress and empathic concern should be at least partially correlated, representing a common latent factor which is likely emotional reactivity to others' distress.

Despite the underlying subcomponents of cognitive and affective empathy not being widely consensual, it is reasonable to argue that psychopathy dimensions may be differentially associated with these constructs. For instance, the negative association between boldnessrelated traits and affective empathy could be related to reduced personal distress driven by 
enhanced stress immunity, and not due to an affective-sharing inability per se. Maladaptive interpersonal traits were negatively associated with cognitive empathy, although it is feasible to postulate whether these deficits can be observed in both cognitive and affective theory of mind tasks. Thus, future studies should keep up with recent behavioral and neuroscientific evidence on additional empathy subcomponents. The dimensional nature of empathy has been explored within other social brain disorders such as autism (Song et al., 2019) and schizophrenia (Bonfils et al., 2017). Similar endeavors in psychopathy should be accomplished.

There are also a few issues that need to be addressed regarding the way self-reports assess empathy. Studies mainly used the Interpersonal Reactivity Index to assess empathy in both group-based and correlation analyses in psychopathy (45\% and 38.19\%, respectively). This was one of the first questionnaires that truly proposed a multidimensional framework of empathy (Davis, 1983), but in the last decades, poor fit two-factorial solutions had been reported for a wide array of scoring alternatives (Wang et al., 2020) (Chrysikou \& Thompson, 2016). For instance, the construct validity of the personal distress subscale is questionable (Murphy et al., 2020) and the fantasy subscale is not always conceived as a proxy for cognitive empathy (Murphy \& Lilienfeld, 2019). As a result, recent questionnaires such as the Questionnaire of Cognitive and Affective Empathy (Reniers et al., 2011) or the Basic Empathy Scale (Jolliffe \& Farrington, 2006) propose more refined alternatives to dissociate the neurobiological processes underlying the cognitive and affective domains of empathy. Another interesting approach to measure empathy, especially in this research field, asks for evaluating affective responses that are dissonant with the expected emotional states for a given situation (e.g., sadism, schadenfreude) rather than uniquely assessing congruent affectiveempathic experiences (e.g., sympathy, compassion) as proposed by the Affective and Cognitive Measure of Empathy (Vachon \& Lynam, 2016). 
Regarding issues around empathy measurements, it was possible to unveil that cognitive empathy deficits in antisocial groups were larger in performance-based vs. self-report measures, whilst an oppositive pattern was observed in high psychopathy groups (smaller effects on performance-based cognitive empathy than self-report measures). Furthermore, larger effects (on both empathy domains) were found for self-report measures across several psychopathy analyses. To address these findings, it is important to consider the relationship between self-reported psychopathy traits and distorted response styles. Despite some historically questioning about using self-report measures to assess psychopathy, there is metaanalytical evidence suggesting that psychopathy is not related to the willingness to self-report socially undesirable traits, with the lifestyle-antisocial dimension actually being negatively associated with these faking good tendencies (Ray et al., 2013). Ray et al. (2013) actually found a positive association between psychopathy and negative impression management across several psychopathy subscales. Hence, it is feasible to postulate that the reduced effect sizes for performance-based measures reported here may be mostly driven by method variance (psychopathy self-report vs. empathy tasks) and, in some analyses, by the reduced number of studies using performance-based tasks. Regardless, even if the influence of psychopathy on self-report questionnaires is somewhat overstated, using performance-based measures closely mimicking real-world empathic behaviors can be a more reliable and ecological alternative to assess empathy. Further studies that examine how performance-based measures moderate the association between psychopathy and empathy are still needed.

\subsubsection{Lessons learned for psychopathic personality assessment}

From the current findings, 4-facets and 3-dimensional models were more informative than the 2-factors one. For example, facet 2 displayed larger effect sizes in comparison to facet 1 for both empathy domains, and they are both comprised in Factor 1. As such, 3-dimensional 
and 4-facets models provide more fine-grained solutions to unravel the differences between psychopathic traits, at least regarding empathy.

Another important issue that should be addressed when interpreting the current results is the clear difference in sample types across each analysis. For psychopathy groupbased analyses, more than $50 \%$ of the samples were recruited from criminal settings, with PCL-R being the most widely used measure. Conversely, for correlation analyses, almost $80 \%$ of the included samples were from the community and the use of 3-dimensional questionnaires becomes more expressive. Thus, findings should be interpreted considering historical differences between the two main conceptual frameworks. Specifically, the discrepant findings in the interpersonal dimension (facet 1 vs. boldness) should be interpreted with caution since the adaptive interpersonal traits are probably more represented within community samples, while maladaptive interpersonal behaviors are more prevalent in criminal and clinical settings. Even so, this does not conceal the fact that facet 1 and boldness are inherently distinct operationalizations of the interpersonal dimension of psychopathy. Facet 1 stems from the interpersonal dimension proposed by the PCL (and SRP and LSRP that can be used in community samples) in which adaptive characteristics were largely ruled out (Hare, 1980), while boldness aims to measure several of Cleckley's (1941/1988) positive adjustment behaviors that were originally excluded from psychopathy scales. A major future direction for the field calls for conducting large-scale studies including measures encompassing both adaptive and maladaptive traits. Looking at the role of empathy in psychopathy without fully contemplating its dimensional and heterogeneous nature will likely be insufficient.

Remarkably, the differential role of cognitive and affective empathy in antisocial behavior and psychopathy can inform future studies and classification diagnosis systems. The Antisocial Personality Disorder diagnosis includes specific criteria on affective empathy (e.g., 
DSM-5: lack of concern for feelings, needs, or suffering of others; lack of remorse after hurting or mistreating another). Therefore, it is quite surprising that cognitive empathy stands as the core feature of the most severe expressions of antisocial behavior. This may require revising diagnostic criteria in an era where the field is moving towards empirically informed classification systems. In turn, affective empathy was more clearly associated with psychopathy, which unveils a possible route for dissociating the two constructs and avoiding the overlap between psychopathy and antisocial personalities. Nonetheless, diagnostic criteria should not rely on broad, unitary descriptions. Total scores of psychopathy only provided a limited overview of its association with empathy, which highlights that it is necessary to target specific psychopathic traits.

Finally, it is also important to acknowledge some additional limitations of the current work regarding psychopathy assessment. First, this meta-analysis did not retrieve descriptive statistics on psychopathy scores. It remains possible that effect sizes would be larger in more heterogeneous samples capturing the full spectrum of psychopathy traits. The same reasoning could be made for empathy and antisocial behavior scores. Secondly, the issue of collinearity between psychopathy dimensions should be discussed, particularly when considering available knowledge about the 3-dimensional model. Several studies have provided evidence for a clear positive association between meanness and disinhibition, while boldness is also positively correlated with meanness (e.g., Blagov et al. 2016; Drislane et al., 2014; Stanley et al., 2013; Fanti et al., 2016). These interactions across psychopathy dimensions can influence the association between empathy and psychopathy. For instance, the small but significant associations between empathy and antisocial expressions of psychopathy (Factor 2, Facets 3 and 4, disinhibition) may be driven by the shared variance between these traits and the affective dimension of psychopathy (meanness and callous-unemotional traits). Similarly, the small affective empathy deficits observed in boldness-related traits may be linked to its shared 
variance with meanness. Hence, although this endeavor would be quite challenging, future meta-analytical work controlling for the collinearity between dimensions of psychopathy could provide valuable contributions to the field (e.g., partial correlations from regression models).

\subsection{Perspectives for clinical practice: adaptive and antisocial expressions of}

\section{psychopathy}

As an attempt to conciliate different perspectives around the role of antisocial behavior in psychopathy, it is now widely accepted that the heterogeneity in psychopathy can be explained by two etiological pathways - externalizing vulnerability and dispositional fearlessness.

Externalizing vulnerability is described as a common transdiagnostic feature across externalizing disorders such as antisocial personality, alcohol, and drug abuse (Kotov et al., 2017; Krueger et al., 2002; Krueger et al., 2007). That way, psychopathy dimensions linked to antisocial behavior map onto externalizing vulnerability, while dispositional fearlessness is more closely connected with adaptive boldness manifestations (Fowles \& Dindo, 2006; Nelson \& Foell, 2018; Patrick \& Bernat, 2009). The affective-meanness dimension is quite complex as it shares both externalizing and fearless dispositions. This probably helps to explain why affective traits are the core component of empathic deficits.

The body of literature dissociating externalizing vulnerability from low-fear dispositions of psychopathy provides indeed valuable insights and opens new possibilities for clinical interventions. The next section will address how etiological paths of psychopathy can relate to its maladaptive and adaptive expressions when evaluating aggression and antisocial behavior a clinical outcome of Gao and Raine's model that is inherently connected to empathy deficits. We argue that a differential approach to psychopathy and empathy has the potential to inform targeted interventions, namely when considering its developmental roots.

\subsubsection{Reactive aggression and impulsive-disinhibition traits of psychopathy}


Cognitive empathy was the nuclear deficit in antisocial groups, although correlational analysis only yielded small effects. Thus, individuals higher in externalizing might not entirely fail to empathize with others, at least affectively. Research reveals indeed that these individuals are not emotionally detached and can feel remorse, shame, and guilt (Campbell \& Elison, 2005; Gudjonsson \& Roberts, 1983; Miller \& Eisenberg, 1988; Morrison \& Gilbert, 2001; Prado et al., 2016; Skeem et al., 2007).

Still, externalizing is a close attribute of antisocial behavior, so we need to search for alternative hypotheses that can explain this link beyond empathy. At this point, one should bear in mind that reactive aggression is the most expected outcome when talking about externalizing expressions of behavior (Blais et al., 2014; Brennan \& Baskin-Sommers, 2020b; Long et al., 2014; Paiva et al., 2020a; Patrick et al., 2009; Woodworth \& Porter, 2002). Reactive aggression incorporates two main features: deficits in inhibitory control and hypervigilance towards threat. The rationale is that impulsive-disinhibited individuals are likely to interpret a negative stimulus as having hostile content (even if they are ambiguous) and to exhibit an emotion-driven response towards that stimulus (e.g., anger outbursts) which will not be suppressed because they exhibit deficits in inhibitory control and emotional regulation (Patrick et al., 2009; Vitale et al., 2005; Wilkowski \& Robinson, 2012). From a developmental perspective, research links disinhibition, hostile tendencies, reactive aggression and abusive experiences during growth in a common framework (Blair, 2018; Brennan \& Baskin-Sommers, 2020a, 2020b; Dodge, 2006; Paiva et al., 2020a; Richey et al., 2016). Growing up in abusive environments interferes with children's ability to identify hostile cues and is likely to increase physiological arousal levels, since infants need to be capable of continuously detecting social cues that convey signals of potential danger (e.g., anger displays). Hence, antisocial behavior within the impulsive-disinhibition dimension of psychopathy may not be critically driven by empathy impairment, but rather by a proneness to reactive aggression driven by 
hostility attribution biases as well as deficits in inhibitory control and emotional regulation. Importantly, these mechanisms appear to be specific of disinhibition-impulsivity traits, as they do not relate substantially with fearlessness (Donahue et al., 2014; Long et al., 2014; Paiva et al., 2020b; Weidacker et al., 2017).

\subsubsection{Predatory aggression and affective-meanness traits of psychopathy}

Affective traits emerged as the core dimension of psychopathy linked to empathic deficits. Although affective traits of psychopathy share the externalizing etiological pathway with disinhibition-impulsive traits, these dimensions correspond to two distinct factors of the externalizing spectrum (Nelson \& Foell, 2018). Affective-meanness traits are specifically related to callous-aggression and agentic disaffiliation in most interpersonal relations, while disinhibition is framed within the purest externalizing factor (Nelson \& Foell, 2018; Palumbo et al., 2020).

Affective-meanness traits are, therefore, best conceived as an affiliative deficit combined with a motivational style in which excitement through cruelty is actively pursued without any regard for others (Patrick et al., 2009). This may predispose to a different form of aggression: premeditated aggression. Individuals high in affective-meanness traits will probably tend to exploit and resort to intimidation to control others in a context of emotional indifference and to exhibit a callous pattern of aggression that is more predatory, premeditated, and instrumental in nature (Paiva et al., 2020a; Palumbo et al., 2020; Patrick et al., 2009; van Dongen et al., 2017).

The origins of these conducts can be traced back to early socialization processes since early deviations in the child's affiliative motivations influence empathy (Frick \& Kemp, 2020; Patrick et al., 2009). The failure of secure attachments is thought to be a risk factor for some of the aspects embodied in these traits and sets the stage for possible failures in the development of positive relationships (Patrick et al., 2009). Notably, attachment styles differ between 
disinhibition-impulsive and affective-meanness traits, revealing differences on these dimensions that may relate to distinct patterns of aggression as mediated by empathic processes. Both dimensions are associated with suboptimal parenting (Craig et al., 2013), but disinhibition-impulsive traits are associated with an anxious attachment style, while affectivemeanness traits relate to an avoidant one. Thus, anxious attachment styles will explain the intense irritability and emotion regulation difficulties in disinhibition-impulsive traits, while avoidance styles in meanness-affective traits may shape relationships marked by a limited concern for others (Christian et al., 2017; Craig et al., 2013). Taking the perspective of others may be more difficult for a child with high callousunemotional traits because he/she is not motivated to do so, and he/she does not experience the expected level of emotional arousal to others' distress (Frick \& Kemp, 2020).

\subsubsection{Adaptive and non-adaptive interpersonal traits: the fine line between prosocial and antisocial behavior}

PCL-based interpersonal traits were associated with broad empathy impairments. In turn, boldness correlated with intact cognitive empathy and to (small) deficits in affective empathy. These two results are not mutually exclusive and yield direct implications to the understanding of adaptive and maladaptive behavior in psychopathy.

Intact cognitive empathy in boldness can compensate for affective deficits, capturing the emotion paradox. Bold individuals might be good at manipulating others without the accompanying affective response - and especially because of that - since they will be more cognitively aware of others' mental states and expectations and are not clouded by affective interferences. As a result, while non-adaptive interpersonal traits of psychopathy may predispose individuals for disruptive outcomes - as they are not able to effectively conceal their lack of affiliative capacity - adaptive interpersonal-boldness traits may allow individuals to retain their masks and to successfully navigate the social world. 
One can even argue that this can lead to nuanced variations of antisocialprosocial manifestations in boldness. Antisocial and prosocial behaviors do not necessarily lie on opposite poles (Costello et al., 2018; Smith et al., 2013), especially when talking about fearlessness features of psychopathy that relate to everyday altruistic behavior (Bronchain et al., 2019; Costello et al., 2018; Patton et al., 2018; Smith et al., 2013). Lykken (1995, p. 118) contended that "the hero and the psychopath may be twigs on the same genetic branch," sharing a fearlessness predisposition that could manifest in either socially praiseworthy or socially blameworthy behaviors depending on yet unknown variables (Patton et al., 2018). Empathy relates to different types of prosocial behavior as well (Batson et al., 2011; Eisenberg et al., 2010). Empathy plays a stronger role in altruistic and anonymous prosocial behavior, whereas prosocial behaviors performed in front of others are thought to be driven by more egoistic (self-serving) motives. From this perspective, White (2014) found that interpersonal-affective psychopathy scores were positively associated with empathic behaviors in the real world, but only when others were watching. One might postulate that intact cognitive empathy in boldness make these individuals more able to read and formulate cognitive schemas of others' mental states and, consequently, may exhibit more deliberative prosocial acts that are primarily motivated by dominance and reputation. In turn, meanness and disinhibition traits are both uncorrelated or negatively associated with prosocial acts and altruism (Costello et al., 2018; Patton et al., 2018; Smith et al., 2013).

Yet, one might be aware that boldness-related traits co-occur with affective-meanness traits (Patrick \& Bernat, 2009; Drislane et al., 2014; Pasion et al., 2018a; van Dongen et al., 2017). However, several differences exist between them. Boldness correlates positively with care experiences in infancy and secure attachment styles, and negatively with avoidant and anxious attachment (Christian et al., 2017; Craig et al., 2013). Hence, a lowfear disposition does not inevitably lead to a failure of conscience development as seen in 
affective-meanness traits. Warm and responsive environments will probably reverse or attenuate dispositional low-fear deficits by fostering the internalization of social norms and the development of cognitive empathic skills - aspects that are implicated in successful interpersonal interactions by means of promoting trust in others and emotional stability (Christian et al., 2017; Frick \& Kemp, 2020; Patrick et al., 2009). Moreover, boldness can be distinguished from impulsive-disinhibition dimensions: boldness traits are associated with improved brain functioning (Bresin et al., 2014; Maes \& Brazil, 2013; Pasion et al., 2016; Pasion et al., 2018b) and are unrelated to hostile attribution biases and difficulties in anger regulation (Donahue et al., 2014; Hicks \& Patrick, 2006; Long et al., 2014; Paiva et al., 2020a).

Altogether, it sounds reasonable to argue that boldness is essentially adaptive and will probably reflect on adequate social functioning via preserved cognitive empathy, whilst attenuating antisocial expressions that characterize meanness and disinhibition (and facet 1).

\section{Closing remarks}

Gao and Raine (2010) conceived a framework for dissociating psychopathic manifestations differentially associated with antisocial expressions. In this model, empathy was framed as an important mediator. Thus, the current meta-analysis provides a compelling opportunity to revisit Gao and Raine's model in its updated version (2020) and to conciliate different theoretical frameworks of psychopathy in the field.

The first major conclusion of the current review was that antisocial and high psychopathy groups display distinct empathic profiles, suggesting that these constructs should be clearly differentiated. Cognitive empathy was more clearly impaired in antisocial groups, while psychopathy groups were more strongly associated with affective empathy deficits.

The second major set of findings shows differential associations between empathy and psychopathy dimensions when integrating the main theoretical models in the field. Affective (facet 2) and meanness traits were strongly associated with affective empathic 
deficits, which supports H1. However, cognitive empathy was also moderately impaired - a finding that should be added to further refine Gao and Raine's model. Moreover, contrary to what was foreseen by the evidence in the field (cf. H2), impulsive-antisocial traits of psychopathy do not seem to be majorly related to empathic impairment. It seems that these traits are not the main driver in psychopathy-empathy interplay and should be rethought in the model. Only disinhibition showed a moderate association with affective empathy after adjusting for publication bias. Finally, the conflicting associations in the interpersonal domain should be considered. In contrast to the authors' hypothesis (cf. H3), findings from facet 1 resembled the results reported for the affective traits (facet 2) - albeit the magnitude of the effect sizes was smaller. In this sense, boldness-related traits better fit the authors' proposal regarding the role of preserved cognitive empathy in the adaptive expressions of psychopathy.

Altogether, these findings are a compelling opportunity for advancing knowledge on the complex interactions between psychopathy and empathy and are systematized in Figure 3. In fact, Gao and Raine's proposals were coincident with the growing dissemination of dimensional approaches, and, consequently, the current work constitutes a unique opportunity for updating a set of postulates that can now be empirically based.

[insert Figure 3 about here] 
Table 1

Operationalization of the different conceptual frameworks of psychopathy

\section{Psychopathy Models}

\begin{tabular}{|c|c|c|}
\hline 2-Factors & 4-Facets & 3-Dimensions \\
\hline $\begin{array}{c}\text { Psychopathy Checklist } \\
\text { Self-Report Psychopathy Scale } \\
\text { Levenson Self-Report Psychopathy } \\
\text { Antisocial Process Screening Device } \\
\text { Child Psychopathy Scale }\end{array}$ & $\begin{array}{c}\text { Psychopathy Checklist } \\
\text { Self-Report Psychopathy Scale }\end{array}$ & $\begin{array}{l}\text { Triarchic Psychopathy Measure } \\
\text { Psychopathic Personality Inventory } \\
\text { Youth Psychopathic Traits Inventory }\end{array}$ \\
\hline $\begin{array}{l}\text { Notes: Egocentricity (Levenson Self-Report } \\
\text { subscale of the respective measure. Measu } \\
\text { Unemotional) were included in all three mo } \\
\text { Traits Questionnaire was developed as an e } \\
\text { Child Problematic Traits Inventory was dev } \\
\text { Some subscales of the Personality Inventory }\end{array}$ & $\begin{array}{l}\text { m (Antisocial Process Screening) } \\
\text { to assess callous-unemotional tri } \\
\text { Facet 2, and Meanness) because t } \\
\text { irless Dominance and Boldness at } \\
\text { ure a childhood version of the 3- } \\
\text { e recently framed according to the }\end{array}$ & $\begin{array}{l}\text { Factor } 1 \text { analysis with the Callous-Unemotional } \\
\text { ychopathy model (e.g., Inventory of Callous- } \\
\text { mensions. The Durand Adaptive Psychopathic } \\
\text { was included in the 3-dimensional model. The } \\
\text { ly to the Youth Psychopathic Traits Inventory. } \\
\text { were also included in the 3-dimensions analysis. }\end{array}$ \\
\hline
\end{tabular}


PSYCHOPATHY, ANTISOCIAL BEHAVIOR, AND EMPATHY

Table 2

Group-based analyses for antisocial behavior

\begin{tabular}{|c|c|c|c|c|c|c|c|c|c|c|c|c|c|c|c|c|c|}
\hline & & \multicolumn{5}{|c|}{ Effect size statistics } & \multicolumn{3}{|c|}{ Heterogeneity Statistics } & \multicolumn{2}{|c|}{ Publication bias } & \multicolumn{3}{|c|}{ Categorical Moderators } & \multicolumn{3}{|c|}{ Meta-regression } \\
\hline & $k$ & $n$ & & $g$ & $95 \% \mathrm{CI}$ & $p$ & $Q$ & $p$ & $I^{2}$ & $B$ & $\bar{p}$ & $g$ & $95 \% \mathrm{CI}$ & $\bar{p}$ & $\bar{b}$ & $95 \% \mathrm{CI}$ & $p$ \\
\hline & & antisocial & controls & & & & & & & & & & & & & & \\
\hline $\begin{array}{l}\text { Antisocial/ } \\
\text { Total Empathy }\end{array}$ & 44 & 2,772 & 4,625 & -0.37 & {$[-0.47,-0.27]$} & $<.001$ & 136.1 & $<.001$ & 68.4 & -2.06 & .005 & & & & & & \\
\hline Self-report & 42 & & & & & & & & & & & -0.34 & {$[-0.44,-0.25]$} & $<.001$ & & & \\
\hline Performance & 2 & & & & & & & & & & & -1.04 & {$[-1.58,-0.50]$} & $<.001$ & & & \\
\hline Age $(M)$ & 44 & & & & & & & & & & & & & & -0.002 & {$[-0.013,0.008]$} & .696 \\
\hline Females (\%) & 43 & & & & & & & & & & & & & & 0.002 & {$[-0.001,0.004]$} & .178 \\
\hline $\begin{array}{l}\text { Antisocial/ } \\
\text { Affective Empathy }\end{array}$ & 96 & 6,293 & 7,162 & -0.13 & {$[-0.21,-0.05]$} & .001 & 384.5 & $<.001$ & 75.3 & 1.28 & .010 & & & & & & \\
\hline Self-report & 89 & & & & & & & & & & & -0.12 & {$[-0.20,-0.04]$} & .003 & & & \\
\hline Performance & 17 & & & & & & & & & & & -0.11 & {$[-0.35,0.14]$} & .404 & & & \\
\hline Age $(M)$ & 95 & & & & & & & & & & & & & & 0.012 & {$[0.005,0.019]$} & $<.001$ \\
\hline Females $(\%)$ & 96 & & & & & & & & & & & & & & -0.003 & {$[-0.005,-0.0003]$} & .030 \\
\hline $\begin{array}{l}\text { Antisocial/ } \\
\text { Cognitive Empathy }\end{array}$ & 110 & 7292 & 7776 & -0.43 & {$[-0.51,-0.34]$} & $<.001$ & 579.4 & $<.001$ & 81.2 & -0.53 & .312 & & & & & & \\
\hline Self-report & 89 & & & & & & & & & & & -0.34 & {$[-0.43,-0.26]$} & $<.001$ & & & \\
\hline Performance & 38 & & & & & & & & & & & -0.58 & {$[-0.75,-0.41]$} & $<.001$ & & & \\
\hline Age $(M)$ & 108 & & & & & & & & & & & & & & 0.002 & {$[-0.006,0.010]$} & .708 \\
\hline Females (\%) & 109 & & & & & & & & & & & & & & 0.003 & {$[-0.0002,0.005]$} & .069 \\
\hline
\end{tabular}


PSYCHOPATHY, ANTISOCIAL BEHAVIOR, AND EMPATHY

Table 3

Correlational analyses for antisocial behavior

\begin{tabular}{|c|c|c|c|c|c|c|c|c|c|c|c|c|c|c|c|c|}
\hline & & \multicolumn{4}{|c|}{ Effect size statistics } & \multicolumn{3}{|c|}{ Heterogeneity Statistics } & \multicolumn{2}{|c|}{ Publication bias } & \multicolumn{3}{|c|}{ Categorical Moderators } & \multicolumn{3}{|c|}{ Meta-regression } \\
\hline & $k$ & $n$ & $r$ & $95 \% \mathrm{CI}$ & $p$ & $Q$ & $p$ & $I^{2}$ & $b$ & $p$ & $r$ & $95 \% \mathrm{CI}$ & $p$ & $b$ & $95 \% \mathrm{CI}$ & $p$ \\
\hline $\begin{array}{l}\text { Antisocial/ } \\
\text { Total Empathy }\end{array}$ & 73 & 36,106 & -.16 & {$[-.18,-.14]$} & $<.001$ & 231.5 & $<.001$ & 68.9 & 0.13 & .707 & & & & & & \\
\hline $\begin{array}{l}\text { Self-report } \\
\text { Performance }\end{array}$ & $\begin{array}{c}71 \\
4\end{array}$ & & & & & & & & & & $\begin{array}{l}-.16 \\
-.03\end{array}$ & $\begin{array}{l}{[-.18,-.14]} \\
{[-.15, .08]}\end{array}$ & $<.001$ & & & \\
\hline Age $(M)$ & 71 & & & & & & & & & & & & & 0.0004 & {$[-0.002,0.003]$} & .749 \\
\hline Females $(\%)$ & 73 & & & & & & & & & & & & & 0.002 & {$[0.001,0.002]$} & .001 \\
\hline $\begin{array}{l}\text { Antisocial/ } \\
\text { Affective Empathy }\end{array}$ & 112 & 28,806 & -.12 & {$[-.14,-.10]$} & $<.001$ & 295.9 & $<.001$ & 62.5 & 0.06 & .858 & & & & & & \\
\hline $\begin{array}{l}\text { Self-report } \\
\text { Performance }\end{array}$ & $\begin{array}{c}104 \\
13\end{array}$ & & & & & & & & & & $\begin{array}{l}-.12 \\
-.07\end{array}$ & $\begin{array}{l}{[-.15,-.10]} \\
{[-.16, .02]}\end{array}$ & $\begin{array}{l}<.001 \\
.132\end{array}$ & & & \\
\hline $\operatorname{Age}(M)$ & 112 & & & & & & & & & & & & & 0.0004 & {$[-0.002,0.003]$} & .786 \\
\hline Females $(\%)$ & 112 & & & & & & & & & & & & & 0.001 & {$[0.0001,0.002]$} & .035 \\
\hline $\begin{array}{l}\text { Antisocial/ } \\
\text { Cognitive Empathy }\end{array}$ & 97 & 24,395 & -.11 & {$[-.14,-.07]$} & $<.001$ & 551.0 & $<.001$ & 82.6 & 0.76 & .072 & & & & & & \\
\hline Self-report & 71 & & & & & & & & & & -.13 & {$[-.17,-.09]$} & $<.001$ & & & \\
\hline Performance & 36 & & & & & & & & & & -.06 & {$[-.11,-.01]$} & .029 & & & \\
\hline Age $(M)$ & 97 & & & & & & & & & & & & & 0.001 & {$[-0.002,0.005]$} & .385 \\
\hline Females $(\%)$ & 97 & & & & & & & & & & & & & -0.0001 & {$[-0.001,0.001]$} & .946 \\
\hline
\end{tabular}


PSYCHOPATHY, ANTISOCIAL BEHAVIOR, AND EMPATHY

Table 4

Group-based analyses for psychopathy

\begin{tabular}{|c|c|c|c|c|c|c|c|c|c|c|c|c|c|c|c|c|c|}
\hline & & \multicolumn{5}{|c|}{ Effect size statistics } & \multicolumn{3}{|c|}{ Heterogeneity Statistics } & \multicolumn{2}{|c|}{ Publication bias } & \multicolumn{3}{|c|}{ Categorical Moderators } & \multicolumn{3}{|c|}{ Meta-regression } \\
\hline & $k$ & $n$ & & $g$ & $95 \% \mathrm{CI}$ & $p$ & $Q$ & $p$ & $I^{2}$ & $b$ & $p$ & $g$ & $95 \% \mathrm{CI}$ & $p$ & $b$ & $95 \% \mathrm{CI}$ & $p$ \\
\hline $\begin{array}{l}\text { Psychopathy / } \\
\text { Total Empathy }\end{array}$ & 13 & $\begin{array}{l}\text { psychopathy } \\
922\end{array}$ & $\begin{array}{c}\text { controls } \\
938\end{array}$ & -0.54 & {$[-0.85,-0.24]$} & .001 & 85.9 & $<.001$ & 86.0 & 0.13 & .938 & & & & & & \\
\hline $\begin{array}{l}\text { Self-report } \\
\text { Performance }\end{array}$ & $\begin{array}{c}13 \\
0\end{array}$ & & & & & & & & & & & -0.54 & {$[-0.85,-0.24]$} & .001 & & & \\
\hline $\operatorname{Age}(M)$ & 13 & & & & & & & & & & & & & & 0.013 & {$[-0.013,0.040]$} & .324 \\
\hline Females $(\%)$ & 13 & & & & & & & & & & & & & & -0.007 & {$[-0.017,0.004]$} & .218 \\
\hline $\begin{array}{l}\text { Psychopathy/ } \\
\text { Affective Empathy }\end{array}$ & 31 & 1,610 & 1,662 & -0.40 & {$[-0.55,-0.25]$} & $<.001$ & 102.7 & $<.001$ & 70.8 & 0.52 & .543 & & & & & & \\
\hline $\begin{array}{l}\text { Self-report } \\
\text { Performance }\end{array}$ & $\begin{array}{c}28 \\
9\end{array}$ & & & & & & & & & & & $\begin{array}{l}-0.39 \\
-0.35\end{array}$ & $\begin{array}{l}{[-0.58,-0.21]} \\
{[-0.52,-0.19]}\end{array}$ & $\begin{array}{l}<.001 \\
<.001\end{array}$ & & & \\
\hline Age $(M)$ & 31 & & & & & & & & & & & & & & 0.011 & {$[-0.003,0.025]$} & .112 \\
\hline Females (\%) & 31 & & & & & & & & & & & & & & -0.002 & {$[-0.007,0.003]$} & .438 \\
\hline $\begin{array}{l}\text { Psychopathy/ } \\
\text { Cognitive Empathy }\end{array}$ & 36 & 1,831 & 1,916 & -0.22 & {$[-0.32,-0.12]$} & $<.001$ & 62.5 & .003 & 44.0 & -0.38 & .476 & & & & & & \\
\hline Self-report & 25 & & & & & & & & & & & -0.28 & {$[-0.40,-0.16]$} & $<.001$ & & & \\
\hline Performance & 20 & & & & & & & & & & & -0.16 & {$[-0.29,-0.03]$} & .019 & & & \\
\hline Age $(M)$ & 36 & & & & & & & & & & & & & & 0.008 & {$[-0.002,0.018]$} & .104 \\
\hline Females (\%) & 36 & & & & & & & & & & & & & & -0.002 & {$[-0.006,0.001]$} & .217 \\
\hline
\end{tabular}




\section{PSYCHOPATHY, ANTISOCIAL BEHAVIOR, AND EMPATHY}

\section{Table 5}

Correlational analyses for psychopathy total scores

\begin{tabular}{|c|c|c|c|c|c|c|c|c|c|c|c|c|c|c|c|c|}
\hline & & \multicolumn{4}{|c|}{ Effect size statistics } & \multicolumn{3}{|c|}{ Heterogeneity Statistics } & \multicolumn{2}{|c|}{ Publication bias } & \multicolumn{3}{|c|}{ Categorical Moderators } & \multicolumn{3}{|c|}{ Meta-regression } \\
\hline & $k$ & $n$ & $r$ & $95 \% \mathrm{CI}$ & $p$ & $Q$ & $p$ & $I^{2}$ & $b$ & $p$ & $r$ & $95 \% \mathrm{CI}$ & $p$ & $b$ & $95 \% \mathrm{CI}$ & $p$ \\
\hline $\begin{array}{l}\text { Psychopathy/ } \\
\text { Total Empathy }\end{array}$ & 87 & 28,365 & -.29 & {$[-.33,-.25]$} & $<.001$ & 916.6 & $<.001$ & 90.6 & 0.33 & .614 & & & & & & \\
\hline $\begin{array}{l}\text { Self-report } \\
\text { Performance }\end{array}$ & $\begin{array}{c}85 \\
2\end{array}$ & & & & & & & & & & -.30 & {$[-.34,-.26]$} & $<.001$ & & & \\
\hline $\operatorname{Age}(M)$ & 87 & & & & & & & & & & -.03 & {$[-.18, .12]$} & & -0.003 & {$[-0.007,0.002]$} & .268 \\
\hline Females (\%) & 87 & & & & & & & & & & & & & -0.0003 & {$[-0.002,0.001]$} & .612 \\
\hline $\begin{array}{l}\text { Psychopathy/ } \\
\text { Affective Empathy }\end{array}$ & 113 & 32,229 & -.29 & {$[-.32,-.25]$} & $<.001$ & 1000.9 & $<.001$ & 88.8 & 0.39 & .459 & & & & & & \\
\hline $\begin{array}{l}\text { Self-report } \\
\text { Performance }\end{array}$ & $\begin{array}{c}106 \\
24\end{array}$ & & & & & & & & & & -.31 & {$[-.34,-.27]$} & $<.001$ & & & \\
\hline $\begin{array}{l}\text { Performance } \\
\text { Age }(M)\end{array}$ & 24 & & & & & & & & & & -.15 & {$[-.21,-.09]$} & $<.001$ & & & \\
\hline $\begin{array}{l}\text { Age }(M) \\
\text { Females }(\%)\end{array}$ & 113 & & & & & & & & & & & & & $\begin{array}{l}-0.004 \\
-0.001\end{array}$ & $\begin{array}{l}{[-0.009,0.0001]} \\
{[-0.002,0.0003]}\end{array}$ & $\begin{array}{l}.056 \\
.166\end{array}$ \\
\hline $\begin{array}{l}\text { Psychopathy/ } \\
\text { Cognitive Empathy }\end{array}$ & 106 & 29,797 & -.19 & {$[-.22,-.16]$} & $<.001$ & 533.7 & $<.001$ & 80.3 & 0.10 & .808 & & & & & & \\
\hline Self-report & 92 & & & & & & & & & & -.20 & {$[-.23,-.17]$} & $<.001$ & & & \\
\hline Performance & 28 & & & & & & & & & & -.12 & {$[-.16,-.07]$} & $<.001$ & & & \\
\hline Age $(M)$ & 103 & & & & & & & & & & & & & 0.0003 & {$[-0.004,0.004]$} & .871 \\
\hline Females (\%) & 106 & & & & & & & & & & & & & -0.001 & {$[-0.001,0.0004]$} & 303 \\
\hline
\end{tabular}




\section{PSYCHOPATHY, ANTISOCIAL BEHAVIOR, AND EMPATHY}

\section{Table 6}

\section{Correlational analyses for the 2-factor model}

\begin{tabular}{|c|c|c|c|c|c|c|c|c|c|c|c|c|c|c|c|c|}
\hline \multirow[b]{2}{*}{$\begin{array}{l}\text { Factor 1/ } \\
\text { Total Empathy }\end{array}$} & \multirow[b]{2}{*}{$\begin{array}{c}k \\
86\end{array}$} & \multicolumn{4}{|c|}{ Effect size statistics } & \multicolumn{3}{|c|}{ Heterogeneity Statistics } & \multicolumn{2}{|c|}{ Publication bias } & \multicolumn{3}{|c|}{ Categorical Moderators } & \multicolumn{3}{|c|}{ Meta-regression } \\
\hline & & $\begin{array}{c}n \\
22,276\end{array}$ & $\begin{array}{c}r \\
-.38\end{array}$ & $\begin{array}{c}95 \% \text { CI } \\
{[-.42,-34]}\end{array}$ & $\begin{array}{l}p \\
<.001\end{array}$ & $\begin{array}{c}Q \\
973.9\end{array}$ & $\begin{array}{c}p \\
<.001\end{array}$ & $\begin{array}{c}I^{2} \\
91.3\end{array}$ & $\begin{array}{c}b \\
0.09\end{array}$ & $\begin{array}{c}p \\
.894\end{array}$ & $r$ & $95 \% \mathrm{CI}$ & $p$ & $b$ & $95 \% \mathrm{CI}$ & $p$ \\
\hline $\begin{array}{l}\text { Self-report } \\
\text { Performance }\end{array}$ & $\begin{array}{c}86 \\
0\end{array}$ & & & & & & & & & & $\begin{array}{l}-.38 \\
-\end{array}$ & {$[-.42,-34]$} & $<.001$ & & & \\
\hline Age $(M)$ & 84 & & & & & & & & & & & & & -0.003 & {$[-0.007,0.002]$} & .282 \\
\hline Females (\%) & 84 & & & & & & & & & & & & & -0.001 & {$[-0.002,0.0001]$} & .061 \\
\hline $\begin{array}{l}\text { Factor 1/ } \\
\text { Affective Empathy }\end{array}$ & 137 & 30.564 & -.33 & {$[-.36,-.30]$} & $<.001$ & 1101.0 & $<.001$ & 87.6 & 0.68 & .170 & & & & & & \\
\hline $\begin{array}{l}\text { Self-report } \\
\text { Performance }\end{array}$ & $\begin{array}{c}125 \\
31\end{array}$ & & & & & & & & & & -.36 & {$[-.39,-.32]$} & $<.001$ & & & \\
\hline Age $(M)$ & 134 & & & & & & & & & & -.19 & {$[-.25,-.13]$} & $<.001$ & -0.006 & {$[-0.010,-0.002]$} & .002 \\
\hline Females (\%) & 135 & & & & & & & & & & & & & -0.001 & {$[-0.002,0.0001]$} & .092 \\
\hline $\begin{array}{l}\text { Factor 1/ } \\
\text { Cognitive Empathy }\end{array}$ & 128 & 28.463 & -.26 & {$[-.29,-.23]$} & $<.001$ & 685.5 & $<.001$ & 81.5 & 0.91 & .022 & & & & & & \\
\hline $\begin{array}{l}\text { Self-report } \\
\text { Performance }\end{array}$ & $\begin{array}{c}107 \\
38\end{array}$ & & & & & & & & & & -.29 & {$[-.32,-.26]$} & $<.001$ & & & \\
\hline $\begin{array}{l}\text { Performance } \\
\text { Age }(M)\end{array}$ & $\begin{array}{c}38 \\
124\end{array}$ & & & & & & & & & & -.12 & {$[-.17,-.06]$} & $<.001$ & & {$[-0.00400002]$} & \\
\hline $\begin{array}{l}\text { Age }(M) \\
\text { Females (\%) }\end{array}$ & $\begin{array}{l}124 \\
126\end{array}$ & & & & & & & & & & & & & $\begin{array}{l}-0.001 \\
-0.001\end{array}$ & $\begin{array}{c}{[-0.004,0.002]} \\
{[-0.002,-0.0004]}\end{array}$ & $\begin{array}{l}.774 \\
.004\end{array}$ \\
\hline $\begin{array}{l}\text { Factor 2/ } \\
\text { Total Empathy }\end{array}$ & 49 & 15,167 & -.17 & {$[-.23,-.12]$} & $<.001$ & 457.1 & $<.001$ & 89.5 & -0.07 & .937 & & & & & & \\
\hline Self-report & 44 & & & & & & & & & & -.17 & {$[-.23,-.12]$} & $<.001$ & & & \\
\hline $\begin{array}{l}\text { Performance } \\
\text { Age }(M)\end{array}$ & $\begin{array}{c}0 \\
49\end{array}$ & & & & & & & & & & - & & & -0.002 & {$[-0.008,0.004]$} & .462 \\
\hline Females (\%) & 49 & & & & & & & & & & & & & -0.001 & {$[-0.002,0.001]$} & .436 \\
\hline $\begin{array}{l}\text { Factor 2/ } \\
\text { Affective Empathy }\end{array}$ & 76 & 19,529 & -.09 & {$[-.14,-.05]$} & $<.001$ & 534.8 & $<.001$ & 86.0 & 0.86 & .153 & & & & & & \\
\hline $\begin{array}{l}\text { Self-report } \\
\text { Performance }\end{array}$ & 69 & & & & & & & & & & -.10 & {$[-.15,-.06]$} & $<.001$ & & & \\
\hline $\begin{array}{l}\text { Performance } \\
\text { Age }(M)\end{array}$ & $\begin{array}{l}16 \\
75\end{array}$ & & & & & & & & & & -.06 & {$[-.10,-.01]$} & .012 & -0.001 & {$[-0.007,0.005]$} & .756 \\
\hline Females $(\%)$ & 76 & & & & & & & & & & & & & -0.001 & {$[-0.002,0.001]$} & .388 \\
\hline $\begin{array}{l}\text { Factor 2/ } \\
\text { Cognitive Empathy }\end{array}$ & 73 & 18,571 & -.15 & {$[-.18,-.11]$} & $<.001$ & 339.3 & $<.001$ & 78.8 & -0.06 & .906 & & & & & & \\
\hline Self-report & 61 & & & & & & & & & & -.16 & {$[-.20,-.12]$} & $<.001$ & & & \\
\hline Performance & $\begin{array}{l}18 \\
71\end{array}$ & & & & & & & & & & -.10 & {$[-.15,-.04]$} & $<.001$ & & & 091 \\
\hline $\begin{array}{l}\text { Age }(M) \\
\text { Females }(\%)\end{array}$ & $\begin{array}{l}71 \\
73\end{array}$ & & & & & & & & & & & & & $\begin{array}{l}-0.004 \\
-0.001\end{array}$ & $\begin{array}{c}{[-0.008,0.001]} \\
{[-0.002,0.0004]}\end{array}$ & $\begin{array}{l}.091 \\
.249\end{array}$ \\
\hline
\end{tabular}




\section{PSYCHOPATHY, ANTISOCIAL BEHAVIOR, AND EMPATHY}

\section{Table 7}

\section{Correlational analyses for the 4-facets model}

\begin{tabular}{|c|c|c|c|c|c|c|c|c|c|c|c|c|c|c|c|c|}
\hline & \multicolumn{5}{|c|}{ Effect size statistics } & \multicolumn{3}{|c|}{ Heterogeneity Statistics } & \multicolumn{2}{|c|}{ Publication bias } & \multicolumn{3}{|c|}{ Categorical Moderators } & \multicolumn{3}{|c|}{ Meta-regression } \\
\hline & $k$ & $n$ & $r$ & $95 \% \mathrm{CI}$ & $p$ & $Q$ & $p$ & $I^{2}$ & $b$ & $p$ & $r$ & $95 \% \mathrm{CI}$ & $p$ & $b$ & $95 \% \mathrm{CI}$ & $p$ \\
\hline $\begin{array}{l}\text { Interpersonal (f1)/ } \\
\text { Total Empathy }\end{array}$ & 20 & 6036 & -.25 & {$[-.30,-.20]$} & $<.001$ & 53.1 & $<.001$ & 64.2 & 0.21 & .744 & & & & & & \\
\hline $\begin{array}{l}\text { Self-report } \\
\text { Performance }\end{array}$ & $\begin{array}{c}18 \\
0\end{array}$ & & & & & & & & & & -.25 & {$[-.30,-.20]$} & $<.001$ & & & \\
\hline Age $(M)$ & 20 & & & & & & & & & & & & & 0.006 & {$[-0.004,0.016]$} & .259 \\
\hline Females (\%) & 20 & & & & & & & & & & & & & -0.0001 & {$[-0.002,0.002]$} & .965 \\
\hline $\begin{array}{l}\text { Interpersonal (f1)/ } \\
\text { Affective Empathy }\end{array}$ & 29 & 9,476 & -.25 & {$[-.31,-.19]$} & $<.001$ & 222.4 & $<.001$ & 87.4 & -1.08 & .225 & & & & & & \\
\hline $\begin{array}{l}\text { Self-report } \\
\text { Performance }\end{array}$ & $\begin{array}{l}25 \\
10\end{array}$ & & & & & & & & & & $\begin{array}{l}-.30 \\
-.07\end{array}$ & $\begin{array}{l}{[-.36,-.23]} \\
{[-.14,-.01]}\end{array}$ & $<.001$ & & & \\
\hline Age $(M)$ & 27 & & & & & & & & & & & & & 0.004 & {$[-0.007,0.016]$} & 480 \\
\hline Females (\%) & 29 & & & & & & & & & & & & & -0.001 & {$[-0.004,0.001]$} & .287 \\
\hline $\begin{array}{l}\text { Interpersonal (f1)/ } \\
\text { Cognitive Empathy }\end{array}$ & 25 & 8,823 & -.16 & {$[-.21,-.10]$} & $<.001$ & 94.7 & $<.001$ & 74.6 & 1.75 & .004 & & & & & & \\
\hline $\begin{array}{l}\text { Self-report } \\
\text { Performance }\end{array}$ & $\begin{array}{l}21 \\
10\end{array}$ & & & & & & & & & & $\begin{array}{l}-.17 \\
-.07\end{array}$ & $\begin{array}{l}{[-.22,-.12]} \\
{[-.12,-.01]}\end{array}$ & $\begin{array}{l}<.001 \\
.013\end{array}$ & & & \\
\hline Age $(M)$ & 24 & & & & & & & & & & & & & 0.005 & {$[-0.004,0.014]$} & .276 \\
\hline Females (\%) & 25 & & & & & & & & & & & & & -0.002 & {$[-0.003,-0.0004]$} & .014 \\
\hline $\begin{array}{l}\text { Affective (f2)/ } \\
\text { Total Empathy }\end{array}$ & 58 & 12,893 & -.40 & {$[-.45,-.35]$} & $<.001$ & 562.0 & $<.001$ & 89.9 & 2.07 & .021 & & & & & & \\
\hline Self-report & 53 & & & & & & & & & & $\begin{array}{c}-.40 \\
-\end{array}$ & {$[-.45,-.35]$} & $<.001$ & & & \\
\hline $\begin{array}{l}\text { Performance } \\
\text { Age }(M)\end{array}$ & 55 & & & & & & & & & & & & & -0.005 & {$[-0.012,0.002]$} & .157 \\
\hline Females (\%) & 55 & & & & & & & & & & & & & -0.001 & {$[-0.003,0.001]$} & .293 \\
\hline $\begin{array}{l}\text { Affective (f2)/ } \\
\text { Affective Empathy }\end{array}$ & 87 & 19,949 & -.34 & {$[-.38,-.29]$} & $<.001$ & 731.7 & $<.001$ & 88.2 & 0.31 & .627 & & & & & & \\
\hline Self-report & 78 & & & & & & & & & & -.37 & {$[-.41,-.33]$} & $<.001$ & & & \\
\hline $\begin{array}{l}\text { Performance } \\
\text { Age }(M)\end{array}$ & $\begin{array}{l}22 \\
82\end{array}$ & & & & & & & & & & & & & -0.002 & {$[-0.008,0.003]$} & .370 \\
\hline Females (\%) & 84 & & & & & & & & & & & & & -0.0002 & {$[-0.002,0.001]$} & .742 \\
\hline $\begin{array}{l}\text { Affective (f2)/ } \\
\text { Cognitive Empathy }\end{array}$ & 84 & 18,940 & -.27 & {$[-.31,-.23]$} & $<.001$ & 629.0 & $<.001$ & 86.8 & 0.11 & .860 & & & & & & \\
\hline Self-report & 72 & & & & & & & & & & -.31 & {$[-.36,-.27]$} & $<.001$ & & & \\
\hline Performance & 28 & & & & & & & & & & -.08 & {$[-.12,-.04]$} & $<.001$ & & & \\
\hline Age $(M)$ & 80 & & & & & & & & & & & & & -0.0001 & {$[-0.005,0.005]$} & .967 \\
\hline Females (\%) & 81 & & & & & & & & & & & & & -0.001 & {$[-0.003,-0.0001]$} & .050 \\
\hline
\end{tabular}




\begin{tabular}{|c|c|c|c|c|c|c|c|c|c|c|c|c|c|c|c|c|}
\hline $\begin{array}{l}\text { Impulsive Lifestyle (f3)/ } \\
\text { Total Empathy }\end{array}$ & 19 & 5,972 & -.12 & {$[-.17,-.07]$} & $<.001$ & 47.2 & $<.001$ & 61.9 & -0.46 & .481 & & & & & & \\
\hline Self-report & 19 & & & & & & & & & & -.12 & {$[-.17,-.07]$} & $<.001$ & & & \\
\hline Performance & 0 & & & & & & & & & & - & - & - & & & \\
\hline Age $(M)$ & 19 & & & & & & & & & & & & & 0.014 & {$[0.005,0.024]$} & .003 \\
\hline Females (\%) & 19 & & & & & & & & & & & & & 0.0003 & {$[-0.001,0.002]$} & .758 \\
\hline $\begin{array}{l}\text { Impulsive Lifestyle (f3)/ } \\
\text { Affective Empathy }\end{array}$ & 29 & 9,472 & -.12 & {$[-.17,-.07]$} & $<.001$ & 110.7 & $<.001$ & 74.7 & -1.33 & .029 & & & & & & \\
\hline Self-report & 25 & & & & & & & & & & -.14 & {$[-.19,-.09]$} & $<.001$ & & & \\
\hline Performance & 10 & & & & & & & & & & -.05 & {$[-.12, .01]$} & .100 & & & \\
\hline $\operatorname{Age}(M)$ & 27 & & & & & & & & & & & & & -0.001 & {$[-0.008,0.007]$} & .830 \\
\hline Females $(\%)$ & 29 & & & & & & & & & & & & & 0.001 & {$[-0.001,0.002]$} & .570 \\
\hline $\begin{array}{l}\text { Impulsive Lifestyle (f3)/ } \\
\text { Cognitive Empathy }\end{array}$ & 25 & 8.799 & -.10 & {$[-.15,-.05]$} & $<.001$ & 101.8 & $<.001$ & 76.4 & 1.06 & .113 & & & & & & \\
\hline Self-report & 21 & & & & & & & & & & -.10 & {$[-.16,-.04]$} & $<.001$ & & & \\
\hline Performance & 10 & & & & & & & & & & -.10 & {$[-.15,-.04]$} & $<.001$ & & & \\
\hline Age $(M)$ & 24 & & & & & & & & & & & & & 0.011 & {$[0.007,0.016]$} & $<.001$ \\
\hline Females (\%) & 25 & & & & & & & & & & & & & -0.001 & {$[-0.003,0.001]$} & .302 \\
\hline $\begin{array}{l}\text { Antisocial (f4)/ } \\
\text { Total Empathy }\end{array}$ & 16 & 3,197 & -.14 & {$[-.21,-.07]$} & $<.001$ & 49.7 & $<.001$ & 69.8 & 0.18 & .869 & & & & & & \\
\hline Self-report & 16 & & & & & & & & & & -.14 & {$[-.21,-.07]$} & $<.001$ & & & \\
\hline Performance & 0 & & & & & & & & & & - & - & - & & & \\
\hline Age $(M)$ & 16 & & & & & & & & & & & & & 0.018 & {$[0.005,0.030]$} & .006 \\
\hline Females $(\%)$ & 16 & & & & & & & & & & & & & -0.001 & {$[-0.003,0.002]$} & .644 \\
\hline $\begin{array}{l}\text { Antisocial (f4)/ } \\
\text { Affective Empathy }\end{array}$ & 26 & 6,461 & -.12 & {$[-.17,-.08]$} & $<.001$ & 59.0 & $<.001$ & 57.6 & 0.12 & .830 & & & & & & \\
\hline Self-report & 22 & & & & & & & & & & -.14 & {$[-.19,-.09]$} & $<.001$ & & & \\
\hline Performance & 10 & & & & & & & & & & -.05 & {$[-.11, .02]$} & .155 & & & \\
\hline Age $(M)$ & 24 & & & & & & & & & & & & & 0.004 & {$[-0.002,0.010]$} & .163 \\
\hline Females (\%) & 26 & & & & & & & & & & & & & -0.001 & {$[-0.003,0.001]$} & .487 \\
\hline $\begin{array}{l}\text { Antisocial (f4)/ } \\
\text { Cognitive Empathy }\end{array}$ & 22 & 6039 & -.11 & {$[-.17,-.05]$} & .001 & 94.5 & $<.001$ & 77.8 & -0.76 & .360 & & & & & & \\
\hline Self-report & 18 & & & & & & & & & & -.12 & {$[-.19,-.05]$} & .001 & & & \\
\hline Performance & 10 & & & & & & & & & & -.08 & {$[-.15,-.01]$} & .020 & & & \\
\hline Age $(M)$ & 21 & & & & & & & & & & & & & 0.011 & {$[0.001,0.022]$} & .037 \\
\hline Females $(\%)$ & 22 & & & & & & & & & & & & & -0.001 & {$[-0.003,0.001]$} & .255 \\
\hline
\end{tabular}




\section{PSYCHOPATHY, ANTISOCIAL BEHAVIOR, AND EMPATHY}

\section{Table 8}

Correlational analyses for the 3-dimensions model

\begin{tabular}{|c|c|c|c|c|c|c|c|c|c|c|c|c|c|c|c|c|}
\hline & & \multicolumn{4}{|c|}{ Effect size statistics } & \multicolumn{3}{|c|}{ Heterogeneity Statistics } & \multicolumn{2}{|c|}{ Publication bias } & \multicolumn{3}{|c|}{ Categorical Moderators } & \multicolumn{3}{|c|}{ Meta-regression } \\
\hline & $k$ & $n$ & $r$ & $95 \% \mathrm{CI}$ & $p$ & $Q$ & $p$ & $I^{2}$ & $b$ & $p$ & $r$ & $95 \% \mathrm{CI}$ & $p$ & $b$ & $95 \% \mathrm{CI}$ & $p$ \\
\hline $\begin{array}{l}\text { Boldness/ } \\
\text { Total Empathy }\end{array}$ & 33 & 10,649 & -.14 & {$[-.21,-.06]$} & .001 & 458.4 & $<.001$ & 93.0 & 0.29 & .823 & & & & & & \\
\hline Self-report & 32 & & & & & & & & & & -.14 & {$[-.22,-.06]$} & .001 & & & \\
\hline Performance & 1 & & & & & & & & & & -.01 & {$[-.10, .09]$} & .887 & & & \\
\hline Age $(M)$ & 33 & & & & & & & & & & & & & -0.004 & {$[-0.013,0.005]$} & .412 \\
\hline Females (\%) & 33 & & & & & & & & & & & & & -0.001 & {$[-0.003,0.001]$} & .351 \\
\hline $\begin{array}{l}\text { Boldness/ } \\
\text { Affective Empathy }\end{array}$ & 51 & 14,541 & -.17 & {$[-.22,-.12]$} & $<.001$ & 357.8 & $<.001$ & 86.0 & 0.31 & .700 & & & & & & \\
\hline Self-report & 50 & & & & & & & & & & -.19 & {$[-.24,-.15]$} & $<.001$ & & & \\
\hline Performance & 8 & & & & & & & & & & .01 & {$[-.15, .17]$} & .877 & & & \\
\hline Age $(M)$ & 50 & & & & & & & & & & & & & -0.006 & {$[-0.012,-0.0002]$} & .044 \\
\hline Females (\%) & 51 & & & & & & & & & & & & & -0.001 & {$[-0.002,0.001]$} & .311 \\
\hline $\begin{array}{l}\text { Boldness/ } \\
\text { Cognitive Empathy }\end{array}$ & 51 & 14,467 & .03 & {$[-.02, .08]$} & .200 & 354.6 & $<.001$ & 85.9 & 0.116 & .875 & & & & & & \\
\hline Self-report & 45 & & & & & & & & & & .03 & {$[-.02, .08]$} & .251 & & & \\
\hline Performance & 11 & & & & & & & & & & .01 & {$[-.06, .08]$} & .735 & & & \\
\hline Age $(M)$ & 50 & & & & & & & & & & & & & 0.004 & {$[-0.001,0.010]$} & .105 \\
\hline Females (\%) & 51 & & & & & & & & & & & & & -0.0003 & {$[-0.002,0.001]$} & .754 \\
\hline $\begin{array}{l}\text { Meanness/ } \\
\text { Total Empathy }\end{array}$ & 73 & 19,277 & -.41 & {$[-.46,-.35]$} & $<.001$ & 1288.8 & $<.001$ & 94.4 & 1.26 & .194 & & & & & & \\
\hline Self-report & 72 & & & & & & & & & & -.41 & {$[-.46,-.36]$} & $<.001$ & & & \\
\hline Performance & 1 & & & & & & & & & & -.15 & {$[-.24,-.05]$} & .003 & & & \\
\hline Age $(M)$ & 71 & & & & & & & & & & & & & -0.009 & {$[-0.015,-0.003]$} & .003 \\
\hline Females (\%) & 71 & & & & & & & & & & & & & -0.001 & {$[-0.003,0.001]$} & .300 \\
\hline $\begin{array}{l}\text { Meanness / } \\
\text { Affective Empathy }\end{array}$ & 100 & 23,225 & -.35 & {$[-.40,-.31]$} & $<.001$ & 1433.1 & $<.001$ & 93.1 & 1.84 & .018 & & & & & & \\
\hline Self-report & 95 & & & & & & & & & & -.38 & {$[-.42,-.33]$} & $<.001$ & & & \\
\hline Performance & 19 & & & & & & & & & & -.20 & {$[-.26,-.13]$} & $<.001$ & & & \\
\hline Age $(M)$ & 97 & & & & & & & & & & & & & -0.009 & {$[-0.014,-0.004]$} & .001 \\
\hline Females (\%) & 98 & & & & & & & & & & & & & -0.001 & {$[-0.003,0.001]$} & .296 \\
\hline $\begin{array}{l}\text { Meanness/ } \\
\text { Cognitive Empathy }\end{array}$ & 102 & 22,884 & -.26 & {$[-.30,-.22]$} & $<.001$ & 875.0 & $<.001$ & 88.5 & 0.20 & .730 & & & & & & \\
\hline Self-report & 89 & & & & & & & & & & -.31 & {$[-.35,-.27]$} & $<.001$ & & & \\
\hline Performance & 28 & & & & & & & & & & -.07 & {$[-.11,-.02]$} & .003 & & & \\
\hline Age $(M)$ & 99 & & & & & & & & & & & & & -0.002 & {$[-0.007,0.002]$} & .329 \\
\hline Females (\%) & 100 & & & & & & & & & & & & & -0.001 & {$[-0.002,0.0002]$} & .111 \\
\hline
\end{tabular}


PSYCHOPATHY, ANTISOCIAL BEHAVIOR, AND EMPATHY

\begin{tabular}{|c|c|c|c|c|c|c|c|c|c|c|c|c|c|c|c|c|}
\hline $\begin{array}{l}\text { Disinhibition/ } \\
\text { Total Empathy }\end{array}$ & 35 & 10,822 & -.14 & {$[-.21,-.06]$} & $<.001$ & 457.8 & $<.001$ & 92.6 & 1.95 & .096 & & & & & & \\
\hline Self-report & 34 & & & & & & & & & & -.14 & {$[-.22,-.06]$} & $<.001$ & & & \\
\hline Performance & 1 & & & & & & & & & & -.08 & {$[-.18, .01]$} & .089 & & & \\
\hline Age $(M)$ & 35 & & & & & & & & & & & & & -0.008 & {$[-0.015,-0.0004]$} & .038 \\
\hline Females (\%) & 35 & & & & & & & & & & & & & 0.001 & {$[-0.001,0.003]$} & .484 \\
\hline $\begin{array}{l}\text { Disinhibition/ } \\
\text { Affective Empathy }\end{array}$ & 52 & 15,059 & -.08 & {$[-.14,-.03]$} & .005 & 594.2 & $<.001$ & 91.4 & 2.16 & .028 & & & & & & \\
\hline Self-report & 51 & & & & & & & & & & -.09 & {$[-.15,-.03]$} & .005 & & & \\
\hline Performance & $\begin{array}{c}8 \\
51\end{array}$ & & & & & & & & & & .01 & {$[-.09, .12]$} & .787 & & & \\
\hline $\begin{array}{l}\text { Age }(M) \\
\text { Females (\%) }\end{array}$ & $\begin{array}{l}51 \\
52\end{array}$ & & & & & & & & & & & & & $\begin{array}{c}-0.009 \\
-0.0001\end{array}$ & $\begin{array}{c}{[-0.015,-0.003]} \\
{[-0.002,0.002]}\end{array}$ & $\begin{array}{l}.006 \\
.9996\end{array}$ \\
\hline $\begin{array}{l}\text { Disinhibition/ } \\
\text { Cognitive Empathy }\end{array}$ & 53 & 14,601 & -.10 & {$[-.15,-.05]$} & $<.001$ & 349.0 & $<.001$ & 85.1 & 0.37 & .597 & & & & & & \\
\hline Self-report & 46 & & & & & & & & & & -.11 & {$[-.16,-.06]$} & $<.001$ & & & \\
\hline Performance & 12 & & & & & & & & & & -.01 & {$[-.08, .05]$} & .720 & & & \\
\hline $\operatorname{Age}(M)$ & 52 & & & & & & & & & & & & & -0.006 & {$[-0.012,-0.001]$} & .022 \\
\hline Females (\%) & 53 & & & & & & & & & & & & & 0.0002 & {$[-0.001,0.002]$} & .759 \\
\hline
\end{tabular}


PSYCHOPATHY, ANTISOCIAL BEHAVIOR, AND EMPATHY

Figure 1

Conceptual Frameworks and hypotheses

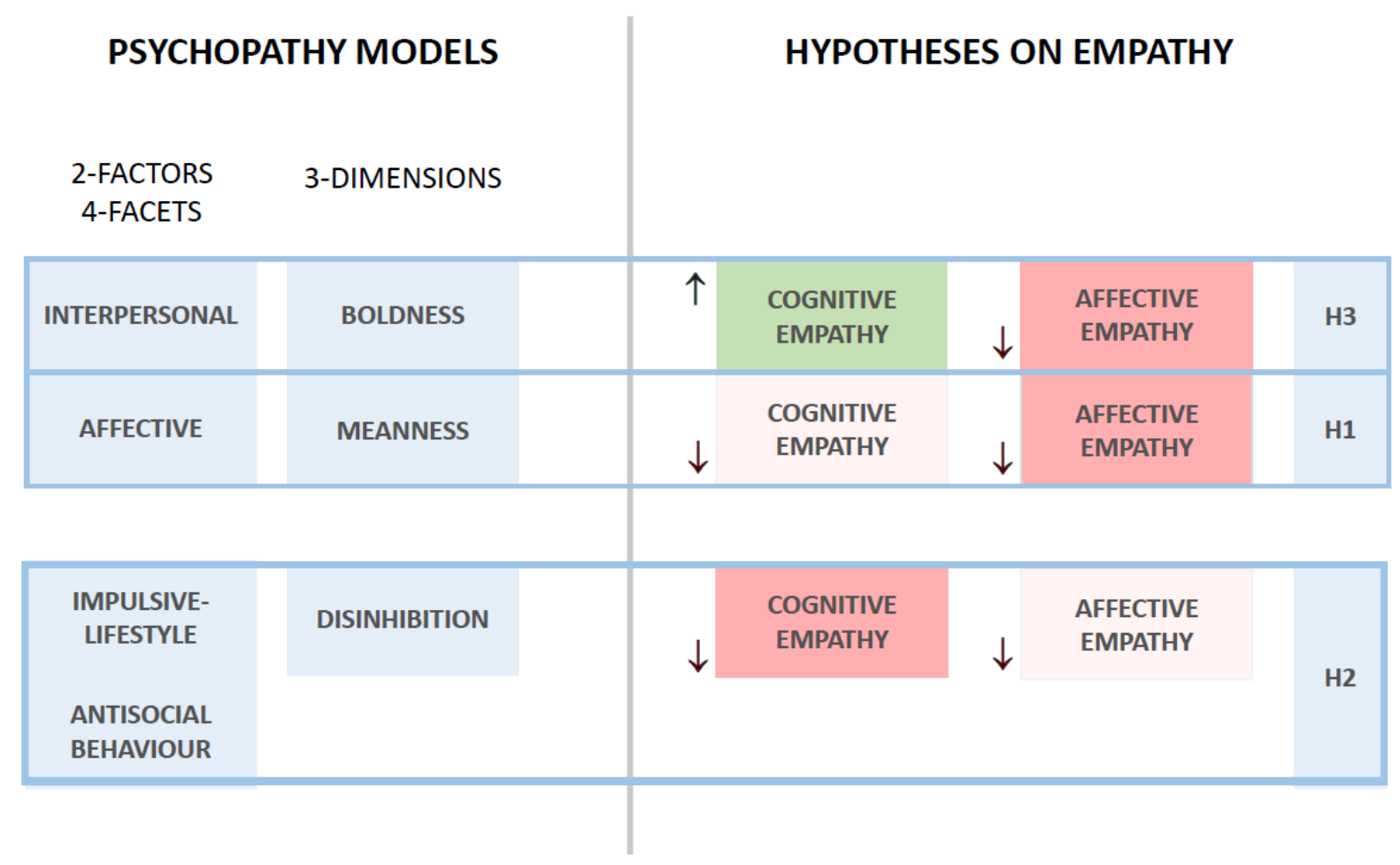


Figure 2

Study selection flow diagram adapted from the PRISMA guidelines (Page et al., 2021)

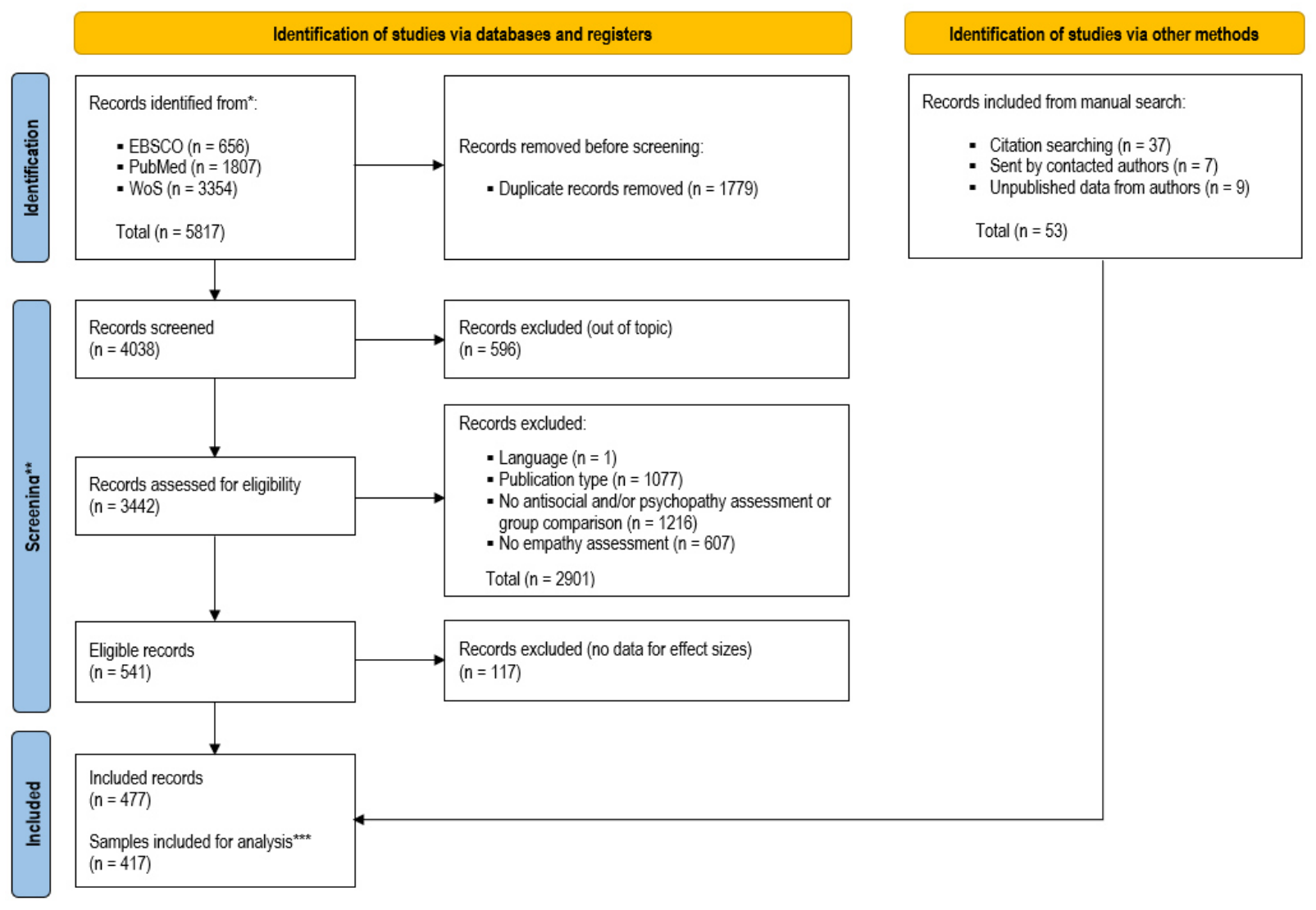

^EBSCO (Psychology and Behavioral Sciences Collection, APA PsycArticles, and Open Dissertations), PubMed (Medline), WoS (Web of Science Core Collection) ** Initial screening to remove out of topic records was performed using title and abstract only. Record assessment for eligibility was conducted using full text screening 


\section{Figure 3}

The interplay of cognitive and affective empathy across psychopathic traits

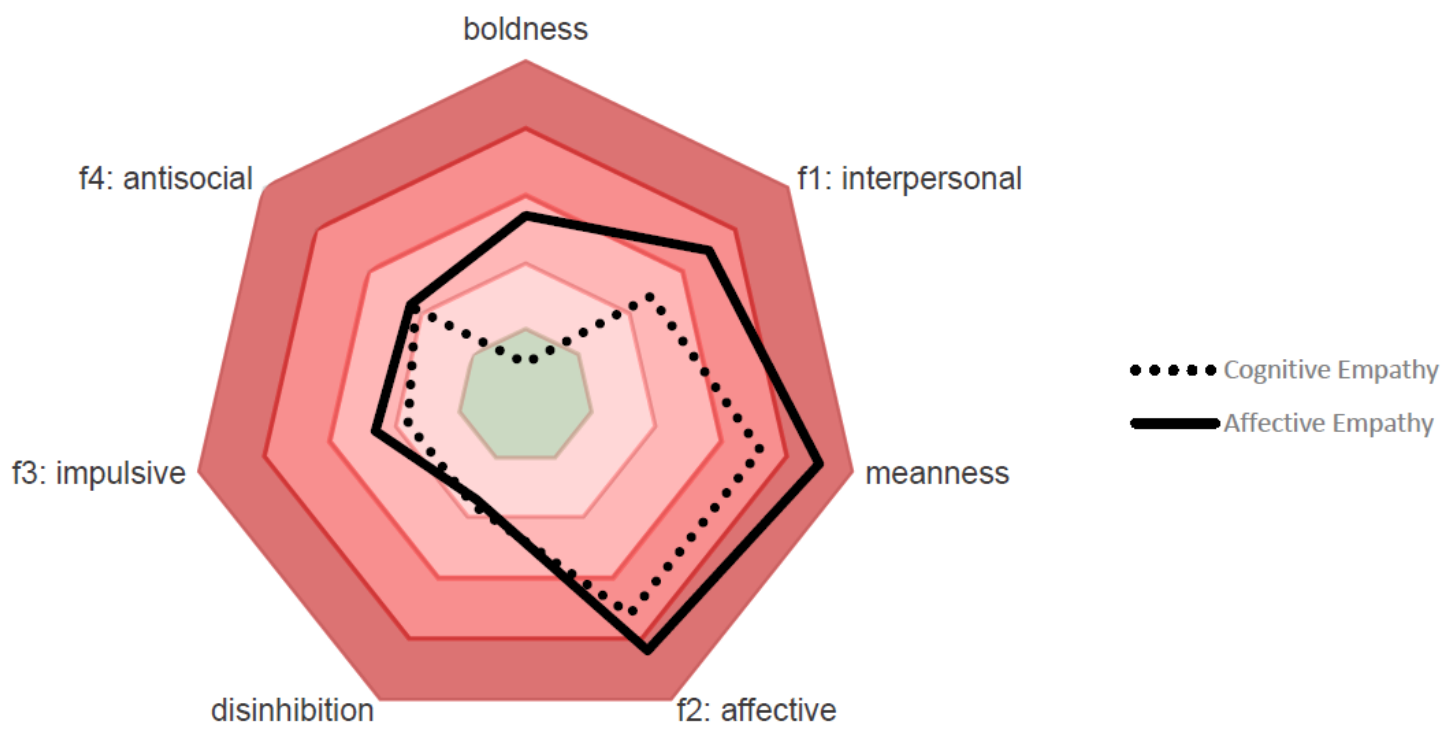

Note: Red layers represent negative correlations, with outer and darker layers equating to larger negative correlations (from the inner to the outer layer: residual, $r=-.01$ to -.09 ; small, $r=-.10$ to -.19 ; medium, $r=-.20$ to -.29 ; large: $r<-.30$ ). Green layer represents residual positive correlations ( $r=.01$ to .09$)$. Effects adjusted for publication bias are reported. 


\section{References}

Andershed, H., Hodgins, S., \& Tengström, A. (2007). Convergent validity of the Youth Psychopathic Traits Inventory (YPI): Association with the Psychopathy Checklist: Youth Version (PCL:YV). Assessment, 14(2), 144-154. https://doi.org/10.1177/1073191106298286

Andershed, H., Kerr, M., Stattin, H., \& Levander, S. (2002). Psychopathic traits in non-referred youths: A new assessment tool. In E. Blaauw \& L. Sheridan (Eds.), Psychopaths: Current International Perspectives (pp. 131-158). Elsevier.

Ashar, Y. K., Andrews-Hanna, J. R., Dimidjian, S., \& Wager, T. D. (2017). Empathic Care and Distress: Predictive Brain Markers and Dissociable Brain Systems. Neuron, 94(6), 1263-1273.e4. https://doi.org/10.1016/j.neuron.2017.05.014

Babiak, P., Neumann, C. S., \& Hare, R. D. (2010). Corporate psychopathy: Talking the walk. Behavioral Sciences \& the Law, 28(2), 174-193. https://doi.org/10.1002/bsl.925

Baskin-Sommers, A. R., Brazil, I. A., Ryan, J., Kohlenberg, N. J., Neumann, C. S., \& Newman, J. P. (2015). Mapping the association of global executive functioning onto diverse measures of psychopathic traits. Personality Disorders: Theory, Research, and Treatment, 6(4), 336-346. https://doi.org/10.1037/per0000125

Batson, C. D., Ahmad, N., \& Stocks, E. L. (2011). Four forms of prosocial motivation: Egoism, altruism, collectivism, and principlism. In Social motivation. (pp. 103-126). Psychology Press.

Benjamini, Y., Krieger, A. M., \& Yekutieli, D. (2006). Adaptive linear step-up procedures that control the false discovery rate. Biometrika, 93(3), 491-507. https://doi.org/DOI 10.1093/biomet/93.3.491

Benning, S. D., Patrick, C. J., Blonigen, D. M., Hicks, B. M., \& lacono, W. G. (2005). 
Estimating Facets of Psychopathy From Normal Personality Traits: A Step Toward Community Epidemiological Investigations. Assessment, 12(1), 3-18. https://doi.org/10.1177/1073191104271223

Benning, S. D., Patrick, C. J., Hicks, B. M., Blonigen, D. M., \& Krueger, R. F. (2003). Factor Structure of the Psychopathic Personality Inventory: Validity and Implications for Clinical Assessment. Psychological Assessment, 15(3), 340-350. https://doi.org/10.1037/1040-3590.15.3.340

Blackburn, R., \& Coid, J. W. (1998). Psychopathy and the dimensions of personality disorders in violent offenders. Personality and Individual Differences, 25(1), 129-145. https://doi.org/10.1016/s0191-8869(98)00027-0

Blagov, P. S., Patrick, C. J., Oost, K. M., Goodman, J. A., \& Pugh, A. T. (2015). Triarchic Psychopathy Measure: Validity in Relation to Normal-Range Traits, Personality Pathology, and Psychological Adjustment. J Pers Disord, 30(1), 71-81. https://doi.org/10.1521/pedi_2015_29_182

Blair, R. J. (2005). Responding to the emotions of others: dissociating forms of empathy through the study of typical and psychiatric populations. Conscious Cogn, 14(4), 698718. https://doi.org/10.1016/j.concog.2005.06.004

Blair, R. J. R. (2018). Traits of empathy and anger: implications for psychopathy and other disorders associated with aggression. Philosophical Transactions of the Royal Society B-Biological Sciences, 373(1744). https://doi.org/10.1098/rstb.2017.0155

Blais, J., Solodukhin, E., \& Forth, A. E. (2014). A meta-analysis exploring the relationship between psychopathy and instrumental versus reactive violence. Criminal Justice and Behavior, 41(7), 797-821. https://doi.org/10.1177/0093854813519629

Boduszek, D., Debowska, A., \& Willmott, D. (2017). Latent profile analysis of psychopathic traits among homicide, general violent, property, and white-collar offenders. Journal of 
Criminal Justice, 51, 17-23. https://doi.org/10.1016/j.jcrimjus.2017.06.001

Boduszek, D., Debowska, A., Sherretts, N., Willmott, D., Boulton, M., Kiełkiewicz, K., Popiolek, K., \& Hyland, P. (2019). Are Prisoners More Psychopathic than Non-forensic Populations? Profiling Psychopathic Traits among Prisoners, Community Adults, University Students, and Adolescents. Deviant Behavior. https://doi.org/10.1080/01639625.2019.1665221

Bonfils, K. A., Lysaker, P. H., Minor, K. S., \& Salyers, M. P. (2017). Empathy in schizophrenia: A meta-analysis of the Interpersonal Reactivity Index. Psychiatry Research, 249, 293-303. https://doi.org/10.1016/j.psychres.2016.12.033

Bons, D., van den Broek, E., Scheepers, F., Herpers, P., Rommelse, N., \& Buitelaaar, J. K. (2013). Motor, Emotional, and Cognitive Empathy in Children and Adolescents with Autism Spectrum Disorder and Conduct Disorder. Journal of Abnormal Child Psychology, 41(3), 425-443. https://doi.org/10.1007/s10802-012-9689-5

Borenstein, M., Hedges, L. V., J.P.T., H., \& Rothstein, H. R. (2009). Introduction to MetaAnalysis. John Wiley \& Sons. https://doi.org/https://doi.org/10.1002/9780470743386.ch1

Brennan, G. M., \& Baskin-Sommers, A. R. (2020a). Aggressive Realism: More Efficient Processing of Anger in Physically Aggressive Individuals. Psychological Science, 31(5), 568-581. https://doi.org/10.1177/0956797620904157

Brennan, G. M., \& Baskin-Sommers, A. R. (2020b). Cognitive mechanisms influencing facial emotion processing in psychopathy and externalizing. Personality Disorders: Theory, Research, and Treatment. https://doi.org/10.1037/per0000473

Bresin, K., Finy, M. S., Sprague, J., \& Verona, E. (2014). Response monitoring and adjustment: differential relations with psychopathic traits. Journal of Abnormal Psychology, 123(3), 634-649. https://doi.org/10.1037/a0037229 
Brinkley, C. A., Diamond, P. M., Magaletta, P. R., \& Heigel, C. P. (2008). Cross-validation of Levenson's Psychopathy Scale in a sample of federal female inmates. Assessment, 15(4), 464-482. https://doi.org/10.1177/1073191108319043

Brislin, S. J., Venables, N. C., Drislane, L. E., Blonigen, D. M., Iacono, W. G., Tellegen, A., Edens, J. F., \& Patrick, C. J. (2017). Further Validation of Triarchic Psychopathy Scales From the Multidimensional Personality Questionnaire: Setting the Stage for Large-Sample Etiological Studies. Assessment, 24(5), 575-590. https://doi.org/10.1177/1073191115621790

Bronchain, J., Chabrol, H., \& Raynal, P. (2019). Adaptive psychopathic traits: Positive outcomes in a college student sample. Current Psychology. https://doi.org/10.1007/s12144-019-00434-3

Burt, S. A. (2012). How do we optimally conceptualize the heterogeneity within antisocial behavior? An argument for aggressive versus non-aggressive behavioral dimensions. Clinical Psychology Review, 32(4), 263-279. https://doi.org/10.1016/j.cpr.2012.02.006

Burt, S. A., Donnellan, M. B., \& Tackett, J. L. (2012). Should Social Aggression be Considered "Antisocial”? Journal of Psychopathology and Behavioral Assessment, 34(2), 153-163. https://doi.org/10.1007/s10862-011-9267-0

Cale, E. M., \& Lilienfeld, S. O. (2002). Sex differences in psychopathy and antisocial personality disorder. A review and integration. Clin Psychol Rev, 22(8), 1179-1207. https://doi.org/10.1016/s0272-7358(01)00125-8

Campbell, J. S., \& Elison, J. (2005). Shame coping styles and psychopathic personality traits. Journal of Personality Assessment, 84(1), 96-104. https://doi.org/DOI 10.1207/s15327752jpa8401_16

Christian, E., Sellbom, M., \& Wilkinson, R. B. (2017). Clarifying the associations between individual differences in general attachment styles and psychopathy. Personality 
Disorders: Theory, Research, and Treatment, 8(4), 329-339. https://doi.org/10.1037/per0000206

Christov-Moore, L., Simpson, E. A., Coude, G., Grigaityte, K., Iacoboni, M., \& Ferrari, P. F. (2014). Empathy: gender effects in brain and behavior. Neurosci Biobehav Rev, $46 \mathrm{Pt}$ 4, 604-627. https://doi.org/10.1016/j.neubiorev.2014.09.001

Chrysikou, E. G., \& Thompson, W. J. (2016). Assessing Cognitive and Affective Empathy Through the Interpersonal Reactivity Index:An Argument Against a Two-Factor Model. Assessment, 23(6), 769-777. https://doi.org/10.1177/1073191115599055

Cleckley. (1988). The Mask of Sanity (5th ed.). Mosby.

Cochran, W. G. (1954). The Combination of Estimates from Different Experiments. Biometrics, 10(1), 101-129. https://doi.org/Doi 10.2307/3001666

Cooke, D. J., \& Michie, C. (2001). Refining the construct of psychopathy: Towards a hierarchical model. Psychological Assessment, 13(2), 171-188. https://doi.org/10.1037/1040-3590.13.2.171

Cooke, D. J., Michie, C., \& Hart, S. D. (2006). Facets of Clinical Psychopathy: Toward Clearer Measurement. In Handbook of psychopathy. (pp. 91-106). The Guilford Press.

Copestake, S., Gray, N. S., \& Snowden, R. J. (2011). A comparison of a self-report measure of psychopathy with the Psychopathy Checklist-revised in a UK sample of offenders. Journal of Forensic Psychiatry \& Psychology, 22(2), 169-182. https://doi.org/10.1080/14789949.2010.545134

Corradi-Dell'Acqua, C., Ronchi, R., Thomasson, M., Bernati, T., Saj, A., \& Vuilleumier, P. (2020). Deficits in cognitive and affective theory of mind relate to dissociated lesion patterns in prefrontal and insular cortex. Cortex, 128, 218-233. https://doi.org/10.1016/j.cortex.2020.03.019

Cosgrove, V. E., Rhee, S. H., Gelhorn, H. L., Boeldt, D., Corley, R. C., Ehringer, M. A., 
Young, S. E., \& Hewitt, J. K. (2011). Structure and etiology of co-occurring internalizing and externalizing disorders in adolescents. Journal of Abnormal Child Psychology, 39(1), 109-123. https://doi.org/10.1007/s10802-010-9444-8

Costello, T. H., Unterberger, A., Watts, A. L., \& Lilienfeld, S. O. (2018). Psychopathy and Pride: Testing Lykken's Hypothesis Regarding the Implications of Fearlessness for Prosocial and Antisocial Behavior. Frontiers in Psychology, 9. https://doi.org/10.3389/fpsyg.2018.00185

Craig, R. L., Gray, N. S., \& Snowden, R. J. (2013). Recalled parental bonding, current attachment, and the triarchic conceptualisation of psychopathy. Personality and Individual Differences, 55(4), 345-350. https://doi.org/https://doi.org/10.1016/j.paid.2013.03.012

Davis, M. H. (1983). Measuring individual differences in empathy: Evidence for a multidimensional approach. Journal of Personality and Social Psychology, 44(1), 113126. https://doi.org/10.1037/0022-3514.44.1.113

de Vignemont, F., \& Singer, T. (2006). The empathic brain: How, when and why? Trends in Cognitive Sciences, 10(10), 435-441. https://doi.org/10.1016/j.tics.2006.08.008 de Waal, F. B. M., \& Preston, S. D. (2017). Mammalian empathy: behavioural manifestations and neural basis. Nature Reviews Neuroscience, 18(8), 498-509. https://doi.org/10.1038/nrn.2017.72

Decety, J., Lewis, K. L., \& Cowell, J. M. (2015). Specific electrophysiological components disentangle affective sharing and empathic concern in psychopathy. Journal of Neurophysiology, 114(1), 493-504. https://doi.org/10.1152/jn.00253.2015

Dodge, K. A. (2006). Translational science in action: Hostile attributional style and the development of aggressive behavior problems. Development and Psychopathology, 18(3), 791-814. https://doi.org/10.1017/S0954579406060391 
Donahue, J. J., McClure, K. S., \& Moon, S. M. (2014). The Relationship Between Emotion Regulation Difficulties and Psychopathic Personality Characteristics. Personality Disorders-Theory Research and Treatment, 5(2), 186-194. https://doi.org/10.1037/per0000025

Drislane, L. E., Brislin, S. J., Kendler, K. S., Andershed, H., Larsson, H., \& Patrick, C. J. (2015). A Triarchic Model Analysis of the Youth Psychopathic Traits Inventory. Journal of Personality Disorders, 29(1), 15-41. https://doi.org/DOI10.1521/pedi_2014_28_144

Drislane, L. E., Patrick, C. J., \& Arsal, G. (2014). Clarifying the Content Coverage of Differing Psychopathy Inventories Through Reference to the Triarchic Psychopathy Measure. Psychological Assessment, 26(2), 350-362. https://doi.org/10.1037/a0035152

Duval, S., \& Tweedie, R. (2000). Trim and fill: A simple funnel-plot-based method of testing and adjusting for publication bias in meta-analysis. Biometrics, 56(2), 455-463. https://doi.org/10.1111/j.0006-341x.2000.00455.x

Dvash, J., \& Shamay-Tsoory, S. G. (2014). Theory of mind and empathy as multidimensional constructs: Neurological foundations. Topics in Language Disorders, 34(4), 282-295. https://doi.org/10.1097/tld.0000000000000040

Egger, M., Davey Smith, G., Schneider, M., \& Minder, C. (1997). Bias in meta-analysis detected by a simple, graphical test. BMJ, 315(7109), 629-634. https://doi.org/10.1136/bmj.315.7109.629

Eisenberg, N., Eggum, N. D., \& Di Giunta, L. (2010). Empathy-related Responding: Associations with Prosocial Behavior, Aggression, and Intergroup Relations. Soc Issues Policy Rev, 4(1), 143-180. https://doi.org/10.1111/j.1751-2409.2010.01020.x

Eklund, H. J., \& Meranius, S. M. (2020). Toward a consensus on the nature of empathy: A review of reviews. Patient Educ Couns. https://doi.org/10.1016/j.pec.2020.08.022 
Evans, J. S. (2008). Dual-processing accounts of reasoning, judgment, and social cognition. Annu Rev Psychol, 59, 255-278. https://doi.org/10.1146/annurev.psych.59.103006.093629

Evans, L., \& Tully, R. J. (2016). The Triarchic Psychopathy Measure (TriPM): Alternative to the PCL-R? Aggression and Violent Behavior, 27, 79-86. https://doi.org/10.1016/j.avb.2016.03.004

Fairchild, G., Hawes, D. J., Frick, P. J., Copeland, W. E., Odgers, C. L., Franke, B., Freitag, C. M., \& De Brito, S. A. (2019). Conduct disorder. Nature Reviews Disease Primers, 5(1), 43. https://doi.org/10.1038/s41572-019-0095-y

Fanti, K. A., Kyranides, M. N., Drislane, L. E., Colins, O. F., \& Andershed, H. (2016). Validation of the Greek Cypriot Translation of the Triarchic Psychopathy Measure. Journal of Personality Assessment, 98(2), 146-154. https://doi.org/10.1080/00223891.2015.1077452

Forth, A. E., Kosson, D. S., \& Hare, R. D. (1994). The Psychopathy Checklist: Youth Version (PCL:YV). Multi-Health Systems.

Fowles, D. C., \& Dindo, L. (2006). A Dual-Deficit Model of Psychopathy. In Handbook of psychopathy. (pp. 14-34). The Guilford Press.

Frick, P. J., \& Hare, R. D. (2001). Antisocial process screening device. . Multi-Health Systems. Frick, P. J., \& Kemp, E. C. (2020). Conduct Disorders and Empathy Development. Annual Review of Clinical Psychology. https://doi.org/10.1146/annurev-clinpsy-081219105809

Frith, C. D., \& Frith, U. (2007). Social cognition in humans. Curr Biol, 17(16), R724-732. https://doi.org/10.1016/j.cub.2007.05.068

Funder, D. C., \& Ozer, D. J. (2019). Evaluating Effect Size in Psychological Research: Sense and Nonsense. Advances in Methods and Practices in Psychological Science, 2(2), 156- 
PSYCHOPATHY, ANTISOCIAL BEHAVIOR, AND EMPATHY

168. https://doi.org/10.1177/2515245919847202

Gao, Y., \& Raine, A. (2010). Successful and unsuccessful psychopaths: a neurobiological model. Behav Sci Law, 28(2), 194-210. https://doi.org/10.1002/bsl.924

Gao, Y., Schug, R. A., Huang, Y., \& Raine, A. (2020). Successful and Unsuccessful Psychopathy. In A. R. Felthous \& H. Saß (Eds.), The Wiley International Handbook on Psychopathic Disorders and the Law (2nd ed., pp. 591-605). John Wiley \& Sons Ltd. https://doi.org/https://doi.org/10.1002/9781119159322.ch26

Gignac, G. E., \& Szodorai, E. T. (2016). Effect size guidelines for individual differences researchers. Personality and Individual Differences, 102, 74-78. https://doi.org/10.1016/j.paid.2016.06.069

Glenn, A. L., Efferson, L. M., Kastner, R. M., Johnson, A. K., \& Remmel, R. J. (2022). Psychopathy and the perception of the genuineness of facial expressions. Personality and Individual Differences, 187, 111439. https://doi.org/10.1016/j.paid.2021.111439

Grynberg, D., \& Konrath, S. (2020). The closer you feel, the more you care: Positive associations between closeness, pain intensity rating, empathic concern and personal distress to someone in pain. Acta Psychologica, 210, 103175. https://doi.org/10.1016/j.actpsy.2020.103175

Grynberg, D., \& López-Pérez, B. (2018). Facing others' misfortune: Personal distress mediates the association between maladaptive emotion regulation and social avoidance. PloS One, 13(3), e0194248. https://doi.org/10.1371/journal.pone.0194248

Guay, J. P., Ruscio, J., Knight, R. A., \& Hare, R. D. (2007). A taxometric analysis of the latent structure of psychopathy: evidence for dimensionality. Journal of Abnormal Psychology, 116(4), 701-716. https://doi.org/10.1037/0021-843X.116.4.701

Gudjonsson, G. H., \& Roberts, J. C. (1983). Guilt and Self-Concept in Secondary Psychopaths. Personality and Individual Differences, 4(1), 65-70. https://doi.org/Doi 10.1016/0191- 
PSYCHOPATHY, ANTISOCIAL BEHAVIOR, AND EMPATHY

8869(83)90053-3

Hall, J. A., \& Schwartz, R. (2019). Empathy present and future. The Journal of Social Psychology, 159(3), 225-243. https://doi.org/10.1080/00224545.2018.1477442

Hall, J. R., Drislane, L. E., Patrick, C. J., Morano, M., Lilienfeld, S. O., \& Poythress, N. G. (2014). Development and Validation of Triarchic Construct Scales from the Psychopathic Personality Inventory. Psychological assessment, 26(2), 447-461. https://doi.org/10.1037/a0035665

Hare, R. D. (1980). A research scale for the assessment of psychopathy in criminal populations. Personality and Individual Differences, 1(2), 111-119. https://doi.org/10.1016/0191-8869(80)90028-8

Hare, R. D. (1999). Psychopathy as a risk factor for violence. Psychiatr Q, 70(3), 181-197. https://doi.org/10.1023/a:1022094925150

Hare, R. D. (2003). Manual for the revised psychopathy checklist (2nd ed.). Multi-Health Systems.

Hare, R. D., \& Neumann, C. S. (2008). Psychopathy as a clinical and empirical construct. Annu Rev Clin Psychol, 4, 217-246. https://doi.org/10.1146/annurev.clinpsy.3.022806.091452

Hare, R. D., Harpur, T. J., Hakstian, A. R., Forth, A. E., Hart, S. D., \& Newman, J. P. (1990). The revised Psychopathy Checklist: Reliability and factor structure. Psychological Assessment: A Journal of Consulting and Clinical Psychology, 2(3), 338-341. https://doi.org/10.1037/1040-3590.2.3.338

Hartmann, D., \& Schwenck, C. (2020). Emotion Processing in Children with Conduct Problems and Callous-Unemotional Traits: An Investigation of Speed, Accuracy, and Attention. Child Psychiatry Hum Dev, 51(5), 721-733. https://doi.org/10.1007/s10578020-00976-9 
Hedges, L. V. (1981). Distribution Theory for Glass's Estimator of Effect size and Related Estimators. Journal of Educational Statistics, 6(2), 107-128. https://doi.org/10.3102/10769986006002107

Hedges, L. V., \& Vevea, J. L. (1998). Fixed- and random-effects models in meta-analysis. Psychological Methods, 3(4), 486-504. https://doi.org/Doi 10.1037/1082-989x.3.4.486

Hemphill, J. F., Hare, R. D., \& Wong, S. (1998). Psychopathy and recidivism: A review. Legal and Criminological Psychology, 3(Part 1), 139-170. https://doi.org/10.1111/j.20448333.1998.tb00355.x

Hicks, B. M., \& Patrick, C. J. (2006). Psychopathy and negative emotionality: Analyses of suppressor effects reveal distinct relations with emotional distress, fearfulness, and anger-hostility. Journal of Abnormal Psychology, 115(2), 276-287. https://doi.org/10.1037/0021-843x.115.2.276

Higgins, J. P. T., Thomas, J., Chandler, J., Cumpston, M., Li, T., Page, M. J., \& Welch, V. A. (2019). Cochrane Handbook for Systematic Reviews of Interventions. John Wiley \& Sons.

Hoppenbrouwers, S. S., Bulten, B. H., \& Brazil, I. A. (2016). Parsing fear: A reassessment of the evidence for fear deficits in psychopathy. Psychol Bull, 142(6), 573-600. https://doi.org/10.1037/bul0000040

Israelashvili, J., Sauter, D., \& Fischer, A. (2020). Two facets of affective empathy: concern and distress have opposite relationships to emotion recognition. Cognition and Emotion, 34(6), 1112-1122. https://doi.org/10.1080/02699931.2020.1724893

Jolliffe, D., \& Farrington, D. P. (2004). Empathy and offending: A systematic review and meta-analysis. Aggression and Violent Behavior, 9(5), 441-476. https://doi.org/10.1016/j.avb.2003.03.001

Jolliffe, D., \& Farrington, D. P. (2006). Development and validation of the Basic Empathy 
PSYCHOPATHY, ANTISOCIAL BEHAVIOR, AND EMPATHY

Scale. Journal of Adolescence, 29(4), 589-611.

https://doi.org/10.1016/j.adolescence.2005.08.010

Kalbe, E., Schlegel, M., Sack, A. T., Nowak, D. A., Dafotakis, M., Bangard, C., Brand, M., Shamay-Tsoory, S., Onur, O. A., \& Kessler, J. (2010). Dissociating cognitive from affective theory of mind: A TMS study. Cortex, 46(6), 769-780. https://doi.org/10.1016/j.cortex.2009.07.010

Karpman, B. (1941). On the need of separating psychopathy into two distinct clinical types: The symptomatic and the idiopathic. Journal of Criminal Psychopathology, 3, 112-137.

Kendler, K. S., \& Myers, J. (2014). The boundaries of the internalizing and externalizing genetic spectra in men and women. Psychological Medicine, 44(3), 647-655. https://doi.org/10.1017/S0033291713000585

Kennealy, P. J., Skeem, J. L., Walters, G. D., \& Camp, J. (2010). Do core interpersonal and affective traits of PCL-R psychopathy interact with antisocial behavior and disinhibition to predict violence? Psychological Assessment, 22(3), 569-580. https://doi.org/10.1037/a0019618

Kimonis, E. R., Frick, P. J., Skeem, J. L., Marsee, M. A., Cruise, K., Munoz, L. C., Aucoin, K. J., \& Morris, A. S. (2008). Assessing callous-unemotional traits in adolescent offenders: Validation of the Inventory of Callous-Unemotional Traits. International Journal of Law and Psychiatry, 31(3), 241-252. https://doi.org/10.1016/j.ijlp.2008.04.002

Klimecki, O. M., Leiberg, S., Ricard, M., \& Singer, T. (2014). Differential pattern of functional brain plasticity after compassion and empathy training. Social Cognitive and Affective Neuroscience, 9(6), 873-879. https://doi.org/10.1093/scan/nst060

Kogler, L., Müller, V. I., Werminghausen, E., Eickhoff, S. B., \& Derntl, B. (2020). Do I feel or do I know? Neuroimaging meta-analyses on the multiple facets of empathy. Cortex, 
129, 341-355. https://doi.org/10.1016/j.cortex.2020.04.031

Kotov, R., Krueger, R. F., Watson, D., Achenbach, T. M., Althoff, R. R., Bagby, R. M., Brown, T. A., Carpenter, W. T., Caspi, A., Clark, L. A., Eaton, N. R., Forbes, M. K., Forbush, K. T., Goldberg, D., Hasin, D., Hyman, S. E., Ivanova, M. Y., Lynam, D. R., Markon, K., Miller, J. D., Moffitt, T. E., Morey, L. C., Mullins-Sweatt, S. N., Ormel, J., Patrick, C. J., Regier, D. A., Rescorla, L., Ruggero, C. J., Samuel, D. B., Sellbom, M., Simms, L. J., Skodol, A. E., Slade, T., South, S. C., Tackett, J. L., Waldman, I. D., Waszczuk, M. A., Widiger, T. A., Wright, A. G. C., \& Zimmerman, M. (2017). The Hierarchical Taxonomy of Psychopathology (HiTOP): A dimensional alternative to traditional nosologies. Journal of Abnormal Psychology, 126(4), 454-477. https://doi.org/10.1037/abn0000258

Krueger, R. F. (1999). The structure of common mental disorders. Archives of General Psychiatry, 56(10), 921-926. https://doi.org/DOI 10.1001/archpsyc.56.10.921

Krueger, R. F., Caspi, A., Moffitt, T. E., \& Silva, P. A. (1998). The structure and stability of common mental disorders (DSM-III-R): A longitudinal-epidemiological study. Journal of Abnormal Psychology, 107(2), 216-227. https://doi.org/Doi 10.1037/0021$843 x .107 .2 .216$

Krueger, R. F., Hicks, B. M., Patrick, C. J., Carlson, S. R., Iacono, W. G., \& McGue, M. (2002). Etiologic connections among substance dependence, antisocial behavior and personality: Modeling the externalizing spectrum. Journal of Abnormal Psychology, 111(3), 411-424. https://doi.org/10.1037/0021-843x.111.3.411

Krueger, R. F., Markon, K. E., Patrick, C. J., Benning, S. D., \& Kramer, M. D. (2007). Linking antisocial behavior, substance use, and personality: An integrative quantitative model of the adult externalizing spectrum. Journal of Abnormal Psychology, 116(4), 645-666. https://doi.org/10.1037/0021-843x.116.4.645 
Levenson, M. R., Kiehl, K. A., \& Fitzpatrick, C. M. (1995). Assessing psychopathic attributes in a noninstitutionalized population. Journal of Personality and Social Psychology, 68(1), 151-158. https://doi.org/10.1037/0022-3514.68.1.151

Lieberman, M. D. (2007). Social Cognitive Neuroscience: A Review of Core Processes. Annual Review of Psychology, 58, 259-289. https://doi.org/10.1146/annurev.psych.58.110405.085654

Lilienfeld, S. O. (2018). The Multidimensional Nature of Psychopathy: Five Recommendations for Research. Journal of Psychopathology and Behavioral Assessment, 40(1), 79-85. https://doi.org/10.1007/s10862-018-9657-7

Lilienfeld, S. O., \& Andrews, B. P. (1996). Development and preliminary validation of a selfreport measure of psychopathic personality traits in noncriminal populations. Journal of Personality Assessment, 66(3), 488-524. https://doi.org/10.1207/s15327752jpa6603_3

Lilienfeld, S. O., \& Andrews, B. P. (1996). Development and Preliminary Validation of a SelfReport Measure of Psychopathic Personality Traits in Noncriminal Population. Journal of Personality Assessment, 66(3), 488-524. https://doi.org/10.1207/s15327752jpa6603_3

Lilienfeld, S. O., Waldman, I. D., Landfield, K., Watts, A. L., Rubenzer, S., \& Faschingbauer, T. R. (2012). Fearless dominance and the U.S. presidency: Implications of psychopathic personality traits for successful and unsuccessful political leadership. Journal of Personality and Social Psychology, 103(3), 489-505. https://doi.org/10.1037/a0029392

Long, K., Felton, J. W., Lilienfeld, S. O., \& Lejuez, C. W. (2014). The role of emotion regulation in the relations between psychopathy factors and impulsive and premeditated aggression. Personality Disorders: Theory, Research, and Treatment, 5(4), 390-396. https://doi.org/10.1037/per0000085 
Lorenz, A. R., \& Newman, J. P. (2002). Deficient response modulation and emotion processing in low-anxious Caucasian psychopathic offenders: results from a lexical decision task. Emotion, 2(2), 91-104. https://doi.org/10.1037/1528-3542.2.2.91

Lykken, D. T. (1995). The antisocial personalities. Lawrence Erlbaum Associates, Inc.

Maes, J. H. R., \& Brazil, I. A. (2013). No clear evidence for a positive association between the interpersonal-affective aspects of psychopathy and executive functioning. Psychiatry Research, 210(3), 1265-1274. https://doi.org/10.1016/j.psychres.2013.09.028

Main, A., \& Kho, C. (2020). A Relational Framework for Integrating the Study of Empathy in Children and Adults. Emotion Review, 12(4), 280-290. https://doi.org/10.1177/1754073919868755

Marsden, J., Glazebrook, C., Tully, R., \& Völlm, B. (2019). Do adult males with antisocial personality disorder (with and without co-morbid psychopathy) have deficits in emotion processing and empathy? A systematic review. Aggression and Violent Behavior, 48, 197-217. https://doi.org/https://doi.org/10.1016/j.avb.2019.08.009 Mathieu, C., Babiak, P., \& Hare, R. D. (2020). Psychopathy in the Workplace. In A. R. Felthous \& H. Saß (Eds.), The Wiley International Handbook on Psychopathic Disorders and the Law (pp. 607-644). John Wiley \& Sons Ltd. https://doi.org/https://doi.org/10.1002/9781119159322.ch27

McCord, W., \& McCord, J. (1964). The psychopath: An essay on the criminal mind (pp. xi, 223). D. Van Nostrand.

Miller, P. A., \& Eisenberg, N. (1988). The relation of empathy to aggressive and externalizing/antisocial behavior. Psychological Bulletin, 103(3), 324-344. https://doi.org/10.1037/0033-2909.103.3.324

Morrison, D., \& Gilbert, P. (2001). Social rank, shame and anger in primary and secondary psychopaths. Journal of Forensic Psychiatry, 12(2), 330-356. https://doi.org/Doi 


\section{$10.1080 / 09585180110056867$}

Morrow, E. P. (2020). Cognitive, Affective, and General Empathy in Individuals Convicted of a Sexual Offense: A Meta-Analysis. Sexual Abuse-a Journal of Research and Treatment, 32(8), 883-906. https://doi.org/10.1177/1079063219858062

Murphy, B. A., \& Lilienfeld, S. O. (2019). Are self-report cognitive empathy ratings valid proxies for cognitive empathy ability? Negligible meta-analytic relations with behavioral task performance. Psychological Assessment, 31(8), 1062-1072. https://doi.org/10.1037/pas0000732

Murphy, B. A., Costello, T. H., Watts, A. L., Cheong, Y. F., Berg, J. M., \& Lilienfeld, S. O. (2020). Strengths and Weaknesses of Two Empathy Measures: A Comparison of the Measurement Precision, Construct Validity, and Incremental Validity of Two Multidimensional Indices. Assessment, 27(2), 246-260. https://doi.org/10.1177/1073191118777636

Nelson, L. D., \& Foell, J. (2018). Externalizing proneness and psychopathy. In Handbook of psychopathy, 2nd ed. (pp. 127-143). The Guilford Press.

Neumann, C. S., \& Hare, R. D. (2008). Psychopathic traits in a large community sample: Links to violence, alcohol use, and intelligence. Journal of Consulting and Clinical Psychology, 76(5), 893-899. https://doi.org/10.1037/0022-006x.76.5.893

Neumann, C. S., Hare, R. D., \& Newman, J. P. (2007). The super-ordinate nature of the psychopathy checklist-revised. J Pers Disord, 21(2), 102-117. https://doi.org/10.1521/pedi.2007.21.2.102

Northam, J. C., \& Dadds, M. R. (2020). Is Callous Always Cold? A Critical Review of the Literature on Emotion and the Development of Callous-Unemotional Traits in Children. Clinical Child and Family Psychology Review, 23(2), 265-283. https://doi.org/10.1007/s10567-019-00309-w 
Page, M. J., McKenzie, J. E., Bossuyt, P. M., Boutron, I., Hoffmann, T. C., Mulrow, C. D., Shamseer, L., Tetzlaff, J. M., Akl, E. A., Brennan, S. E., Chou, R., Glanville, J., Grimshaw, J. M., Hróbjartsson, A., Lalu, M. M., Li, T., Loder, E. W., Mayo-Wilson, E., McDonald, S., ... Moher, D. (2021). The PRISMA 2020 statement: An updated guideline for reporting systematic reviews. $B M J, \mathrm{n} 71$. https://doi.org/10.1136/bmj.n71

Paiva, T. O., Almeida, P. R., Coelho, R. C., Pasion, R., Barbosa, F., Ferreira-Santos, F., Bastos-Leite, A. J., \& Marques-Teixeira, J. (2020b). The neurophysiological correlates of the triarchic model of psychopathy: An approach to the basic mechanisms of threat conditioning and inhibitory control. Psychophysiology, 57(8), e13567. https://doi.org/10.1111/psyp.13567

Paiva, T. O., Pasion, R., Patrick, C. J., Moreira, D., Almeida, P. R., \& Barbosa, F. (2020a). Further evaluation of the Triarchic Psychopathy Measure: Evidence from community adult and prisoner samples from Portugal. Psychological Assessment, 32(3), e1-e14. https://doi.org/10.1037/pas0000797

Palumbo, I. M., Perkins, E. R., Yancey, J. R., Brislin, S. J., Patrick, C. J., \& Latzman, R. D. (2020). Toward a multimodal measurement model for the neurobehavioral trait of affiliative capacity. Personality Neurosciences, 3, e11. https://doi.org/10.1017/pen.2020.9

Pasion, R., Cruz, A. R., \& Barbosa, F. (2016). Dissociation of boldness and disinhibition psychopathic traits in ERN modulation. Personality and Individual Differences, 95, 610. https://doi.org/10.1016/j.paid.2016.02.017

Pasion, R., Cruz, A. R., \& Barbosa, F. (2018a). Dissociable effects of psychopathic traits on executive functioning: Insights from the triarchic model. Frontiers in Psychology, 9. https://doi.org/10.3389/fpsyg.2018.01713

Pasion, R., Fernandes, C., Pereira, M. R., \& Barbosa, F. (2018b). Antisocial behaviour and 
psychopathy: Uncovering the externalizing link in the P3 modulation. Neuroscience and Biobehavioral Reviews, 91, 170-186. https://doi.org/10.1016/j.neubiorev.2017.03.012

Pasion, R., Prata, C., Fernandes, M., Almeida, R., Garcez, H., Araujo, C., \& Barbosa, F. (2019). N2 amplitude modulation across the antisocial spectrum: a meta-analysis. Reviews in the Neurosciences. https://doi.org/10.1515/revneuro-2018-0116

Patrick, C. (2010). Operationalizing the Triarchic Conceptualization of Psychopathy: Preliminary Description of Brief Scales for Assessment of Boldness, Meanness, and Disinhibition.

Patrick, C. J. (2006). Back to the Future: Cleckley as a Guide to the Next Generation of Psychopathy Research. In Handbook of psychopathy. (pp. 605-617). The Guilford Press.

Patrick, C. J., \& Bernat, E. M. (2009). Neurobiology of psychopathy: A two process theory. In Handbook of neuroscience for the behavioral sciences, Vol 2. (pp. 1110-1131). John Wiley \& Sons Inc. https://doi.org/10.1002/9780470478509.neubb002057

Patrick, C. J., \& Drislane, L. E. (2015). Triarchic Model of Psychopathy: Origins, Operationalizations, and Observed Linkages with Personality and General Psychopathology. J Pers, 83(6), 627-643. https://doi.org/10.1111/jopy.12119

Patrick, C. J., Fowles, D. C., \& Krueger, R. F. (2009). Triarchic conceptualization of psychopathy: developmental origins of disinhibition, boldness, and meanness. Dev Psychopathol, 21(3), 913-938. https://doi.org/10.1017/s0954579409000492

Patrick, C. J., Hicks, B. M., Krueger, R. F., \& Lang, A. R. (2005). Relations between Psychopathy Facets and Externalizing in a Criminal Offender Sample. Journal of Personality Disorders, 19(4), 339-356. https://doi.org/10.1521/pedi.2005.19.4.339 Patrick, C.J., Drislane, L. E., \& Strickland, C. (2012). Conceptualizing Psychopathy in 
Triarchic Terms: Implications for Treatment. International Journal of Forensic Mental Health, 11(4), 253-266. https://doi.org/10.1080/14999013.2012.746761

Patton, C. L., Smith, S. F., \& Lilienfeld, S. O. (2018). Psychopathy and heroism in first responders: Traits cut from the same cloth? Personal Disord, 9(4), 354-368. https://doi.org/10.1037/per0000261

Paulhus, D. L., Neumann, C. S., \& Hare, R. D. (2016). The SRP-4: Self-report psychopaty scale. Multi-Health Systems.

Pike, N. (2011). Using false discovery rates for multiple comparisons in ecology and evolution. Methods in Ecology and Evolution, 2(3), 278-282. https://doi.org/10.1111/j.2041-210X.2010.00061.x

Poythress, N. G., Edens, J. F., \& Lilienfeld, S. O. (1998). Criterion-related validity of the Psychopathic Personality Inventory in a prison sample. Psychological Assessment, 10(4), 426-430. https://doi.org/10.1037/1040-3590.10.4.426

Prado, C. E., Treeby, M. S., \& Crowe, S. F. (2016). Examining the relationships between subclinical psychopathic traits with shame, guilt and externalisation response tendencies to everyday transgressions. Journal of Forensic Psychiatry \& Psychology, 27(4), 569-585. https://doi.org/10.1080/14789949.2016.1167933

Ray, J. V., Hall, J., Rivera-Hudson, N., Poythress, N. G., Lilienfeld, S. O., \& Morano, M. (2013). The relation between self-reported psychopathic traits and distorted response styles: A meta-analytic review. Personality Disorders: Theory, Research, and Treatment, 4(1), 1-14. https://doi.org/10.1037/a0026482

Reniers, R. L., Corcoran, R., Drake, R., Shryane, N. M., \& Völlm, B. A. (2011). The QCAE: a Questionnaire of Cognitive and Affective Empathy. Journal of Personality Assessment, 93(1), 84-95. https://doi.org/10.1080/00223891.2010.528484

Richey, A., Brown, S., Fite, P. J., \& Bortolato, M. (2016). The Role of Hostile Attributions in 
the Associations Between Child Maltreatment and Reactive and Proactive Aggression. Journal of Aggression Maltreatment \& Trauma, 25(10), 1043-1057. https://doi.org/10.1080/10926771.2016.1231148

Rijnders, R. J. P., Terburg, D., Bos, P. A., Kempes, M. M., \& van Honk, J. (2021). Unzipping empathy in psychopathy: Empathy and facial affect processing in psychopaths. Neuroscience \& Biobehavioral Reviews, 131, 1116-1126. https://doi.org/10.1016/j.neubiorev.2021.10.020

Rosenthal, R. (1994). Parametric measures of effect size. In The handbook of research synthesis. (pp. 231-244). Russell Sage Foundation.

Saarela, M. V., \& Hari, R. (2008). Listening to humans walking together activates the social brain circuitry. Social Neuroscience, 3(3-4), 401-409. https://doi.org/10.1080/17470910801897633

Saarela, M. V., Hlushchuk, Y., Williams, A. C. de C., Schürmann, M., Kalso, E., \& Hari, R. (2007). The compassionate brain: Humans detect intensity of pain from another's face. Cerebral Cortex (New York, N.Y.: 1991), 17(1), 230-237. https://doi.org/10.1093/cercor/bhj141

Sacco, D. F., Merold, S. J., Lui, J. H. L., Lustgraaf, C. J. N., \& Barry, C. T. (2016). Social and emotional intelligence moderate the relationship between psychopathy traits and social perception. Personality and Individual Differences, 95, 95-104. https://doi.org/10.1016/j.paid.2016.02.031

Schlaffke, L., Lissek, S., Lenz, M., Juckel, G., Schultz, T., Tegenthoff, M., Schmidt-Wilcke, T., \& Brüne, M. (2015). Shared and nonshared neural networks of cognitive and affective theory-of-mind: A neuroimaging study using cartoon picture stories. Human Brain Mapping, 36(1), 29-39. https://doi.org/10.1002/hbm.22610

Schurz, M., Radua, J., Tholen, M. G., Maliske, L., Margulies, D. S., Mars, R. B., Sallet, J., \& 
Kanske, P. (2020). Toward a hierarchical model of social cognition: A neuroimaging meta-analysis and integrative review of empathy and theory of mind. Psychological Bulletin. https://doi.org/10.1037/bul0000303

Sebastian, C. L., Fontaine, N. M. G., Bird, G., Blakemore, S.-J., De Brito, S. A., McCrory, E. J. P., \& Viding, E. (2012). Neural processing associated with cognitive and affective Theory of Mind in adolescents and adults. Social Cognitive and Affective Neuroscience, 7(1), 53-63. https://doi.org/10.1093/scan/nsr023

Sedgwick, O., Young, S., Baumeister, D., Greer, B., Das, M., \& Kumari, V. (2017). Neuropsychology and emotion processing in violent individuals with antisocial personality disorder or schizophrenia: The same or different? A systematic review and meta-analysis. Australian and New Zealand Journal of Psychiatry, 51(12), 1178-1197. https://doi.org/10.1177/0004867417731525

Sellbom, M. (2011). Elaborating on the construct validity of the Levenson self-report psychopathy scale in incarcerated and non-incarcerated samples. Law and Human Behavior, 35(6), 440-451. https://doi.org/10.1007/s10979-010-9249-x

Sellbom, M., \& Drislane, L. E. (2021). The classification of psychopathy. Aggression and Violent Behavior, 59, 101473. https://doi.org/10.1016/j.avb.2020.101473

Sellbom, M., \& Phillips, T. R. (2013). An examination of the triarchic conceptualization of psychopathy in incarcerated and nonincarcerated samples. Journal of Abnormal Psychology, 122(1), 208-214. https://doi.org/10.1037/a0029306

Sellbom, M., \& Verona, E. (2007). Neuropsychological correlates of psychopathic traits in a non-incarcerated sample. Journal of Research in Personality, 41(2), 276-294. https://doi.org/10.1016/j.jrp.2006.04.001

Shamay-Tsoory, S. G., \& Aharon-Peretz, J. (2007). Dissociable prefrontal networks for cognitive and affective theory of mind: A lesion study. Neuropsychologia, 45(13), 
3054-3067. https://doi.org/10.1016/j.neuropsychologia.2007.05.021

Singer, T., Seymour, B., O’Doherty, J., Kaube, H., Dolan, R. J., \& Frith, C. D. (2004).

Empathy for Pain Involves the Affective but not Sensory Components of Pain. Science, 303(5661), 1157-1162. https://doi.org/10.1126/science.1093535

Skeem, J. L., \& Cooke, D. J. (2010). Is criminal behavior a central component of psychopathy? Conceptual directions for resolving the debate. Psychological Assessment, 22(2), 433445. https://doi.org/10.1037/a0008512

Skeem, J. L., \& Cooke, D. J. (2010). Is criminal behavior a central component of psychopathy? Conceptual directions for resolving the debate. Psychological Assessment, 22(2), 433445. https://doi.org/10.1037/a0008512

Skeem, J. L., Polaschek, D. L., Patrick, C. J., \& Lilienfeld, S. O. (2011). Psychopathic Personality: Bridging the Gap Between Scientific Evidence and Public Policy. Psychol Sci Public Interest, 12(3), 95-162. https://doi.org/10.1177/1529100611426706

Skeem, J., Johansson, P., Andershed, H., Kerr, M., \& Louden, J. E. (2007). Two subtypes of psychopathic violent offenders that parallel primary and secondary variants. Journal of Abnormal Psychology, 116(4), 853-853. https://doi.org/10.1037/0021-843x.116.4.853

Skilling, T. A., Harris, G. T., Rice, M. E., \& Quinsey, V. L. (2002). Identifying persistently antisocial offenders using the Hare Psychopathy Checklist and DSM antisocial personality disorder criteria. Psychological Assessment, 14(1), 27-38. https://doi.org/10.1037/1040-3590.14.1.27

Smith, S. F., Lilienfeld, S. O., Coffey, K., \& Dabbs, J. M. (2013). Are psychopaths and heroes twigs off the same branch? Evidence from college, community, and presidential samples. Journal of Research in Personality, 47(5), 634-646. https://doi.org/https://doi.org/10.1016/j.jrp.2013.05.006

Somma, A., Fossati, A., Patrick, C., Maffei, C., \& Borroni, S. (2014). The three-factor 
structure of the Levenson self-report psychopathy scale: Fool's gold or true gold? A study in a sample of Italian adult non-clinical participants. Personality and Mental Health, 8(4), 337-347. https://doi.org/10.1002/pmh.1267

Song, Y. M., Nie, T. T., Shi, W. D., Zhao, X. D., \& Yang, Y. Y. (2019). Empathy Impairment in Individuals With Autism Spectrum Conditions From a Multidimensional Perspective: A Meta-Analysis. Frontiers in Psychology, 10. https://doi.org/10.3389/fpsyg.2019.01902

Spunt, R. P., \& Lieberman, M. D. (2013). The busy social brain: evidence for automaticity and control in the neural systems supporting social cognition and action understanding. Psychol Sci, 24(1), 80-86. https://doi.org/10.1177/0956797612450884

Stanley, J. H., Wygant, D. B., \& Sellbom, M. (2013). Elaborating on the construct validity of the Triarchic Psychopathy Measure in a criminal offender sample. Journal of Personality Assessment, 95(4), 343-350. https://doi.org/10.1080/00223891.2012.735302

Steinert, S. W., Lishner, D. A., Vitacco, M. J., \& Hong, P. Y. (2017). Conceptualizing successful psychopathy: An elaboration of the moderated-expression model. Aggression and Violent Behavior, 36, 44-51. https://doi.org/10.1016/j.avb.2017.07.005

Stevens, F., \& Taber, K. (2021). The neuroscience of empathy and compassion in pro-social behavior. Neuropsychologia, 159. https://doi.org/10.1016/j.neuropsychologia.2021.107925

Sun, B., Luo, Z., Zhang, W., Li, W., \& Li, X. (2018). Age-related differences in affective and cognitive empathy: self-report and performance-based evidence. Neuropsychology, Development, and Cognition. Section B, Aging, Neuropsychology and Cognition, 25(5), 655-672. https://doi.org/10.1080/13825585.2017.1360835

Tesar, B., Deckert, M., Schmoeger, M., \& Willinger, U. (2020). Electrophysiological 
Correlates of Basic and Higher Order Cognitive and Affective Theory of Mind Processing in Emerging and Early Adulthood-An Explorative Event-Related Potentials Study to Investigate First-, Second-, and Third-Order Theory of Mind Processing Based on Visual Cues. Frontiers in Human Neuroscience, 14, 79. https://doi.org/10.3389/fnhum.2020.00079

Vachon, D. D. (2019). Antagonism in psychopathy. Em The Handbook of Antagonism (pp. 199-220). Elsevier. https://doi.org/10.1016/B978-0-12-814627-9.00014-1

Vachon, D. D., \& Lynam, D. R. (2016). Fixing the Problem With Empathy: Development and Validation of the Affective and Cognitive Measure of Empathy. Assessment, 23(2), 135-149. https://doi.org/10.1177/1073191114567941

Vachon, D. D., Lynam, D. R., \& Johnson, J. A. (2014). The (non)relation between empathy and aggression: Surprising results from a meta-analysis. Psychological Bulletin, 140(3), 751-773. https://doi.org/10.1037/a0035236

van Dongen, J. D. M. (2020). The Empathic Brain of Psychopaths: From Social Science to Neuroscience in Empathy. Frontiers in Psychology, 11, 695. https://doi.org/10.3389/fpsyg.2020.00695

van Dongen, J. D. M., Drislane, L. E., Nijman, H., Soe-Agnie, S. E., \& van Marle, H. J. C. (2017). Further Evidence for Reliability and Validity of the Triarchic Psychopathy Measure in a Forensic Sample and a Community Sample. Journal of Psychopathology and Behavioral Assessment, 39(1), 58-66. https://doi.org/10.1007/s10862-016-9567-5 van Langen, M. A. M., Wissink, I. B., van Vugt, E. S., Van der Stouwe, T., \& Stams, G. J. J. M. (2014). The relation between empathy and offending: A meta-analysis. Aggression and Violent Behavior, 19(2), 179-189. https://doi.org/10.1016/j.avb.2014.02.003

Venables, N. C., Hall, J. R., \& Patrick, C. J. (2014). Differentiating psychopathy from antisocial personality disorder: a triarchic model perspective. Psychol Med, 44(5), 
1005-1013. https://doi.org/10.1017/s003329171300161x

Verona, E., \& Vitale, J. (2018). Psychopathy in women: Assessment, manifestations, and etiology. In Handbook of psychopathy, 2nd ed. (pp. 509-528). The Guilford Press.

Vitacco, M. J., Rogers, R., \& Neumann, C. S. (2003). The antisocial process screening device: An examination of its construct and criterion-related validity. Assessment, 10(2), 143150. https://doi.org/10.1177/1073191103010002005

Vitale, J. E., Newman, J. P., Serin, R. C., \& Bolt, D. M. (2005). Hostile attributions in incarcerated adult male offenders: An exploration of diverse pathways. Aggressive Behavior, 31(2), 99-115. https://doi.org/10.1002/ab.20050

Vitale, J., Kosson, D. S., Resch, Z., \& Newman, J. P. (2018). Speed-Accuracy Tradeoffs on an Affective Lexical Decision Task: Implications for the Affect Regulation Theory of Psychopathy. Journal of Psychopathology and Behavioral Assessment, 40(3), 412-418. https://doi.org/10.1007/s10862-018-9652-z

Wall, T. D., Wygant, D. B., \& Sellbom, M. (2015). Boldness explains a key difference between psychopathy and antisocial personality disorder. Psychiatry, Psychology and Law, 22(1), 94-105. https://doi.org/10.1080/13218719.2014.919627

Waller, R., Wagner, N. J., Barstead, M. G., Subar, A., Petersen, J. L., Hyde, J. S., \& Hyde, L. W. (2020). A meta-analysis of the associations between callous-unemotional traits and empathy, prosociality, and guilt. Clin Psychol Rev, 75, 101809. https://doi.org/10.1016/j.cpr.2019.101809

Wang, Y., Li, Y., Xiao, W., Fu, Y., \& Jie, J. (2020). Investigation on the Rationality of the Extant Ways of Scoring the Interpersonal Reactivity Index Based on Confirmatory Factor Analysis [Original Research]. Frontiers in Psychology, 11(1086). https://doi.org/10.3389/fpsyg.2020.01086

Weidacker, K., Whiteford, S., Boy, F., \& Johnston, S. J. (2017). Response inhibition in the 
parametric go/no-go task and its relation to impulsivity and subclinical psychopathy. Quarterly Journal of Experimental Psychology, 70(3), 473-487. https://doi.org/10.1080/17470218.2015.1135350

White, B. A. (2014). Who cares when nobody is watching? Psychopathic traits and empathy in prosocial behaviors. Personality and Individual Differences, 56, 116-121. https://doi.org/https://doi.org/10.1016/j.paid.2013.08.033

Wilkowski, B. M., \& Robinson, M. D. (2012). When Aggressive Individuals See the World More Accurately: The Case of Perceptual Sensitivity to Subtle Facial Expressions of Anger. Personality and Social Psychology Bulletin, 38(4), 540-553. https://doi.org/10.1177/0146167211430233

Williams, A., O’Driscoll, K., \& Moore, C. (2014). The influence of empathic concern on prosocial behavior in children. Frontiers in Psychology, 5, 425. https://doi.org/10.3389/fpsyg.2014.00425

Williams, K., Nathanson, C., Delroy, \& Paulhus, D. (2003). Structure and validity of the selfreport psychopathy scale-III in normal populations. 111th annual Convention of the American Psychological Association, 1-12.

Woodworth, M., \& Porter, S. (2002). In cold blood: Characteristics of criminal homicides as a function of psychopathy. Journal of Abnormal Psychology, 111(3), 436-445. https://doi.org/10.1037/0021-843x.111.3.436

Yan, Z., Hong, S., Liu, F., \& Su, Y. (2020). A meta-analysis of the relationship between empathy and executive function. PsyCh Journal, 9(1), 34-43. https://doi.org/10.1002/pchj.311

Zaki, J., \& Ochsner, K. N. (2012). The neuroscience of empathy: progress, pitfalls and promise. Nat Neurosci, 15(5), 675-680. https://doi.org/10.1038/nn.3085 


\section{Appendix A. Search Queries}

Bellow the search query for each electronic dataset:

\section{PubMed (Medline)}

(((antisocial personality disorder [MeSH] OR attention deficit and disruptive behavior disorders $[\mathrm{MeSH}]$ OR problem behavior [MeSH] OR disruptive, impulse control, and conduct disorders $[\mathrm{MeSH}] \mathrm{OR}$ juvenile delinquency $[\mathrm{MeSH}] \mathrm{OR}$ criminals $[\mathrm{MeSH}] \mathrm{OR}$ prisoners [MeSH] OR psychopath*[Title/Abstract] OR sociopath*[Title/Abstract] OR antisocial[Title/Abstract] OR anti-social[Title/Abstract] OR callous[Title/Abstract] OR unemotional[Title/Abstract] OR conduct disorder*[Title/Abstract] OR conduct problem*[Title/Abstract] OR disruptive behav*[Title/Abstract] OR "oppositional defiant"[Title/Abstract] OR oppositional behav*[Title/Abstract] OR defiant behav*[Title/Abstract] OR behavior problem*[Title/Abstract] OR offend*[Title/Abstract] OR criminal*[Title/Abstract] OR inmate*[Title/Abstract] OR prisoner*[Title/Abstract] OR delinquen*[Title/Abstract] OR violent[Title/Abstract]) AND (empathy $[\mathrm{MeSH}]$ OR theory of mind $[\mathrm{MeSH}]$ OR mentalization $[\mathrm{MeSH}] \mathrm{OR}$ empath*[Title/Abstract] OR "theory of mind"[Title/Abstract] OR mentali*[Title/Abstract] OR "perspective taking”[Title/Abstract] OR mindread*[Title/Abstract] $\mathrm{OR}$ mind read*[Title/Abstract] OR "mental states"[Title/Abstract]) NOT (psychopathol*[Title/Abstract])) AND English[lang])

Note: The legacy version of the PubMed website was retired after 31 October 2020. Thus, the final search update was already conducted on the new PubMed version. 


\section{Web of Science Core Collection}

TS=(psychopath* OR sociopath* OR antisocial OR anti-social OR callous OR unemotional OR "conduct disorder*" OR "conduct problem*" OR "disruptive behav*" OR "oppositional defiant" OR "oppositional behav*" OR "defiant behav*" OR "behavior problem*" OR offend* OR criminal* OR inmate* OR prisoner* OR delinquen* OR violent $)$ AND TS=(empath* OR "theory of mind" OR mentali* OR "perspective taking" OR mindread* OR "mind read*" OR "mental representation*" OR "mental states") NOT $\mathrm{TS}=$ psychopathol $*$

Note: Language Filter - English

EBSCO (Psychology and Behavioral Sciences Collection, APA PsycArticles, and Open Dissertations)

AB ( psychopath* OR sociopath* OR antisocial OR anti-social OR callous OR unemotional OR "conduct disorder*" OR "conduct problem*" OR "disruptive behav*" OR "oppositional defiant" OR "oppositional behav*" OR "defiant behav*" OR "behavior problem*" OR offend* OR criminal* OR inmate* OR prisoner* OR delinquen* OR violent ) AND AB ( empath* OR "theory of mind" OR mentali* OR "perspective taking" OR mindread* OR "mind read*" OR "mental representation*" OR "mental states" ) NOT AB psychopathol*

Note: Language Filter - English 


\section{Appendix B. List of Included Records}

1. Abbey, A., Parkhill, M. R., BeShears, R., Clinton-Sherrod, A. M., \& Zawacki, T. (2005). Cross-sectional predictors of sexual assault perpetration in a community sample of single African American and caucasian men. Aggressive Behavior, 32(1), 54-67. https://doi.org/10.1002/ab.20107

2. Abbey, A., Parkhill, M. R., Clinton-Sherrod, A. M., \& Zawacki, T. (2007). A comparison of men who committed different types of sexual assault in a community sample. Journal of Interpersonal Violence \& Victims, 22(12), 1567-1580. $\underline{\text { https://doi.org/10.1177/0886260507306489 }}$

3. Ackermann, K., Kirchner, M., Bernhard, A., Martinelli, A., Anomitri, C., Baker, R., Baumann, S., Dochnal, R., Fernandez-Rivas, A., Gonzalez-Madruga, K., HerpertzDahlmann, B., Hervas, A., Jansen, L., Kapornai, K., Kersten, L., Kohls, G., Limprecht, R., Lazaratou, H., McLaughlin, A., ... Freitag, C (2019). Relational aggression in adolescents with conduct disorder: sex differences and behavioral correlates. Journal of Abnormal Child Psychology, 47(10), 1625-1637. https://doi.org/10.1007/s10802-019-00541-6

4. Ackermann, K., Martinelli, A., Bernhard, A., Freitag, C. M., Büttner, G., \& Schwenck, C. (2019). Friendship quality in youth with and without disruptive behavior disorders: The role of empathy, aggression, and callousness. Child Psychiatry \& Human Development, 50(5), 776-788. https://doi.org/10.1007/s10578-019-00880-x

5. Adams, E. W., Bontemps, A. P., Decker, K., Tsang, S., \& Salekin, R. T. (2020). Model fit and convergent and discriminant validity of the Psychopathic Personality Inventory-Short form: A comparison of competing models. Journal of Psychopathology and Behavioral Assessment, 42(2), 647-665. https://doi.org/10.1007/s10862-020-09829-0 
6. Aghajani, M., Klapwijk, E. T., Andershed, H., Fanti, K. A., van der Wee, N. J. A., Vermeiren, R. R. J. M., \& Colins, O. F. (2020). Neural processing of socioemotional content in conduct-disordered juvenile offenders with limited prosocial emotions. Progress in Neuro-Psychopharmacology \& Biological Psychiatry, 105, 110045. https://doi.org/10.1016/j.pnpbp.2020.110045

7. Aghajani, M., Klapwijk, E. T., Colins, O. F., Ziegler, C., Domschke, K., Vermeiren, R. R. J. M., \& van der Wee, N. J. A. (2018). Interactions between oxytocin receptor gene methylation and callous-unemotional traits impact socioaffective brain systems in conductdisordered offenders. Biological Psychiatry: Cognitive Neuroscience and Neuroimaging, 3(4), 379-391. https://doi.org/10.1016/j.bpsc.2017.12.010

8. Akça, Ö. F., Wall, K., \& Sharp, C. (2021). Divergent mentalization types in adolescent borderline personality disorder and attention deficit/hyperactivity disorder. Nordic Journal of Psychiatry, 75(7), 479-486. https://doi.org/10.1080/08039488.2021.1887349

9. Ali, F., \& Chamorro-Premuzic, T. (2010). Investigating theory of mind deficits in nonclinical psychopathy and machiavellianism. Personality and Individual Differences, 49(3), 169-174. https://doi.org/10.1016/j.paid.2010.03.027

10. Ali, F., Amorim, I., \& Chamorro-Premuzic, T. (2009). Empathy deficits and trait emotional intelligence in psychopathy and machiavellianism. Personality and Individual Differences, 47(7), 758-762. https://doi.org/10.1016/j.paid.2009.06.016

11. Almeida, P. R., Seixas, M. J., Ferreira-Santos, F., Vieira, J. B., Paiva, T. O., Moreira, P. S., \& Costa, P. (2015). Empathic, moral and antisocial outcomes associated with distinct components of psychopathy in healthy individuals: a Triarchic model approach. Personality and Individual Differences, $\quad 85, \quad 205-211$. https://doi.org/10.1016/j.paid.2015.05.012 
12. Álvarez-García, D., González-Castro, P., Núñez, J. C., Rodríguez, C., \& Cerezo, R. (2019). Impact of family and friends on antisocial adolescent behavior: The mediating role of impulsivity and empathy. Frontiers in Psychology, 10, 2071. https://doi.org/10.3389/fpsyg.2019.02071

13. Álvarez-García, D., Núñez, J. C., García, T., \& Barreiro-Collazo, A. (2018). Individual, family, and community predictors of cyber-aggression among adolescents. European Journal of Psychology Applied to Legal Context, 10(2), 79-88. https://doi.org/10.5093/ejpalc2018a8

14. Anastassiou-Hadjicharalambous, X., \& Warden, D. (2008). Physiologically-indexed and self-perceived affective empathy in conduct-disordered children high and low on callousunemotional traits. Child Psychiatry \& Human Development, 39(4), 503-517. https://doi.org/10.1007/s10578-008-0104-y

15. Andretta, J. R., Ramirez, A. M., Barnes, M. E., Odom, T., Roberson-Adams, S., \& Woodland, M. H. (2015). Perceived parental security profiles in African American adolescents involved in the juvenile justice system. Journal of Family Psychology, 29(6), 884-894. https://doi.org/10.1037/fam0000105

16. Antoniadou, N., Kokkinos, C. M., \& Markos, A. (2016). Possible common correlates between bullying and cyber-bullying among adolescents. Psicologia Educativa, 22(1), 2738. https://doi.org/10.1016/j.pse.2016.01.003

17. Antoniadou, N., Kokkinos, C. M., \& Markos, A. (2019). Psychopathic traits and social anxiety in cyber-space: A context-dependent theoretical framework explaining online disinhibition. Computers in Human Behavior, 99, 228-234. https://doi.org/10.1016/j.chb.2019.05.025 
18. Armenti, N. A., \& Babcock, J. C. (2018). Psychophysiological reactivity profiles of partner-violent men with borderline or psychopathic personality features: The role of empathy. International Journal of Offender Therapy and Comparative, 62(11), 33373354. https://doi.org/10.1177/0306624X17740029

19. Austin, G., Bondu, R., \& Elsner, B. (2020). Executive function, theory of mind, and conduct-problem symptoms in middle childhood. Frontiers in Psychology, 11, 539. https://doi.org/10.3389/fpsyg.2020.00539

20. Azeredo et al. (Unpublished) Dating Violence: Influence of Psychopathic Traits and Social Cognition

21. Bacchini, D., De Angelis, G., \& Dragone, M. (2018). Empathy and utilitarian judgment in incarcerated and community control adolescents. Criminal Justice and Behavior, 45(7), 1093-1109. https://doi.org/10.1177/0093854818781438

22. Bacchini, D., De Angelis, G., Affuso, G., \& Brugman, D. (2016). The structure of selfserving cognitive distortions: A validation of the "how I think" questionnaire in a sample of Italian adolescents. Measurement and Evaluation in Counseling and Development, 49(2), 163-180. https://doi.org/10.1177/0748175615596779

23. Balash, J., \& Falkenbach, D. M. (2018). The ends justify the meanness: An investigation of psychopathic traits and utilitarian moral endorsement. Personality and Individual Differences, 127, 127-132. https://doi.org/10.1016/j.paid.2018.02.009

24. Barb, R. (2005). The relationship between attachment, empathy, and sociomoral reasoning and psychopathy in a male juvenile delinquent population (Publication No. 3224142) [Doctoral dissertation, College of Arts and Sciences]. ProQuest Information and Learning Company. 
25. Barhight, L. R., Hubbard, J. A., Grassetti, S. N., \& Morrow, M. M. T. (2017). Relations between actual group norms, perceived peer behavior, and bystander children's intervention to bullying. Journal of Clinical Child \& Adolescent Psychology, 46(3), 394400. https://doi.org/10.1080/15374416.2015.1046180

26. Beavin, L. (2014). Oxytocin and empathy in sexoffenders: A biological basis for deficiencies in empathix responding (Publication No. 3631057) [Doctoral dissertation, Faculty of Claremont Graduate University]. ProQuest LLC.

27. Berenguer Forner, C., Miranda, B., Fortea, I., Castellar, R., Diago, C., \& Casas, A. (2017). ADHD symptoms and peer problems: Mediation of executive function and theory of mind. Psicothema, 29(4), 514-519. https://doi.org/10.7334/psicothema2016.376

28. Berenguer, C., Rosello, B., Colomer, C., Baixauli, I., \& Miranda, A. (2018). Children with autism and Attention Deficit Hyperactivity Disorder. relationships between symptoms and executive function, theory of mind, and behavioral problems. Research in Developmental Disabilities, 83, 260-269. https://doi.org/10.1016/j.ridd.2018.10.001

29. Bertone, M. S., Díaz Granados, E. A., Vallejos, M., \& Muniello, J. (2017). Differences in social cognition between male prisoners with antisocial personality or psychotic disorder. International Journal of Psychological Research, 10(2), 15-24. https://doi.org/10.21500/20112084.2903

30. Beussink, C. N., Hackney, A. A., \& Vitacco, M. J. (2017). The effects of perspective taking on empathy-related responses for college students higher in callous traits. Personality and Individual Differences, 119, 86-91. https://doi.org/10.1016/j.paid.2017.07.005

31. Blair, J., Sellars, C., Strickland, I., Clark, F., Williams, A., Smith, M., \& Jones, L. (1996). Theory of mind in the psychopath. Journal of Forensic Psychiatry, 7(1), 15-25. https://doi.org/10.1080/09585189608409914 
32. Bodde, P. (2014). A comparison study between male juvenile sex offenders and juvenile non-offenders regarding cognitive and affective empathy [Unpublished master's thesis]. Universiteit van Amsterdam.

33. Bono, G., Froh, J., Disabato, D., Blalock, D., McKnight, P., \& Bausert, S. (2017). Gratitude's role in adolescent antisocial and prosocial behavior: A 4-year longitudinal investigation. The Journal of Positive Psychology, 14(2), 230-243. https://doi.org/10.1080/17439760.2017.1402078

34. Book, A. S., \& Quinsey, V. L. (2004). Psychopaths: Cheaters or warrior-hawks? Personality and Individual Differences, 36(1), 33-45. https://doi.org/10.1016/S0191$\underline{8869(03) 00049-7}$

35. Boza, M., \& Medimond. (2014). Emotional mind reading and emotional callousness in aggressive and non-aggressive young people with antisocial behavior.

36. Broidy, L., Cauffman, E., Espelage, D. L., Mazerolle, P., \& Piquero, A. (2003). Sex differences in empathy and its relation to juvenile offending. Violence \& Victims, 18(5), 503-516. https://doi.org/10.1891/vivi.2003.18.5.503

37. Brook, M., \& Kosson, D. S. (2013). Impaired cognitive empathy in criminal psychopathy: Evidence from a laboratory measure of empathic accuracy. Journal of Abnormal Psychology, 122(1), 156-166. https://doi.org/10.1037/a0030261

38. Brouns, B. H. J., de Wied, M. A., Keijsers, L., Branje, S., van Goozen, S. H. M., \& Meeus, W. H. J. (2013). Concurrent and prospective effects of psychopathic traits on affective and cognitive empathy in a community sample of late adolescents. Journal of Child Psychology and Psychiatry, 54(9), 969-976. https://doi.org/10.1111/jcpp.12052 
39. Burke, D. M. (2001). Empathy in sexually offending and nonoffending adolescent males. Journal of Interpersonal Violence, $\quad 16(3), \quad 222-233$. https://doi.org/10.1177/088626001016003003

40. Bush, C. A., Mullis, R. L., \& Mullis, A. K. (2000). Differences in empathy between offender and nonoffender youth. Journal of Youth and Adolescence, 29(4), 467-478. https://doi.org/10.1023/A:1005162526769

41. Campos, C., Barbosa, F., \& Rocha, N. (2020, June 29). The Complex Interaction Between Psychopathy, Empathy and Interoception. Retrieved from osf.io/5jhcw

42. Campos, C., Rocha, N., \& Barbosa, F. (2021, July 7). Self-other distinction and individual differences: evidence from the Imitation-Inhibition Task. Retrieved from osf.io/w4qt6

43. Cardona-Isaza, A. de J., Jiménez, S. V., \& Montoya-Castilla, I. (2021). Decision-making Styles in Adolescent Offenders and Non-offenders: Effects of Emotional Intelligence and Empathy. Anuario de Psicología Jurídica. https://doi.org/10.5093/apj2021a23

44. Carlo, G., Roesch, S. C., \& Melby, J. (1998). The multiplicative relations of parenting and temperament to prosocial and antisocial behaviors in adolescence. Journal of Early Adolescence, 18(3), 266-290. https://doi.org/10.1177/0272431698018003003

45. Carr, M., \& Lutjemeier, J. (2005). The relation of facial affect recognition and empathy to delinquency in youth offenders. Adolescence, 40(159), 601-619.

46. Carrasco, M., Barker, E. D., Tremblay, R. E., \& Vitaro, F. (2006). Eysenck's personality dimensions as predictors of male adolescent trajectories of physical aggression, theft and vandalism. Personality and Individual Differences, 41(7), 1309-1320. https://doi.org/10.1016/j.paid.2006.05.005

47. Carré, J. M., Ortiz, T. L., Labine, B., Moreau, B. J. P., Viding, E., Neumann, C. S., \& Goldfarb, B. (2015). Digit ratio (2D:4D) and psychopathic traits moderate the effect of 
exogenous testosterone on socio-cognitive processes in men. Psychoneuroendocrinology, 62, 319-326. https://doi.org/10.1016/j.psyneuen.2015.08.023

48. Carroll, G. A., Montrose, V. T., \& Burke, T. (2021). Correlates of Social Cognition and Psychopathic Traits in a Community-Based Sample of Males. Frontiers in Psychology, 12, 1437. https://doi.org/10.3389/fpsyg.2021.656299

49. Carvalho, L. d. F., \& Machado, G. M. (2020). Differences in adherence to COVID-19 pandemic containment measures: Psychopathy traits, empathy, and sex. Trends Psychiatry Psychother, 1-4.

50. Castellino, N., Bosco, F. M., Marshall, W. L., Marshall, L. E., \& Veglia, F. (2011). Mindreading abilities in sexual offenders: An analysis of theory of mind processes. Consciousness and 20(4), Cognition, 1612-1624. https://doi.org/10.1016/j.concog.2011.08.011

51. Cavojova, V. (2012). Being Nice or Being Tough? Social Behavior and Social Cognition in Two Types of Popular Pre-Adolescents. Studia Psychologica, 54(4), 313-327.

52. Centifanti, L. C. M., Meins, E., \& Fernyhough, C. (2016). Callous-unemotional traits and impulsivity: Distinct longitudinal relations with mind-mindedness and understanding of others. Journal of Child Psychology and Psychiatry, 57(1), 84-92. https://doi.org/10.1111/jcpp.12445

53. Chandler, M. (1973). Egocentrism and antisocial behavior: The assessment and training of social perspective-taking skills. Developmental Psychology, 9(3), 326-332. https://doi.org/10.1037/h0034974

54. Chandler, M., \& Moran, T. (1990). Psychopathy and moral development: A comparative study of delinquent and nondelinquent youth. Development and Psychopathology, 2, 227246. 
55. Chaplin, T. C., Rice, M. E., \& Harris, G. T. (1995). Salient victim suffering and the sexual responses of child molesters. Journal of Consulting and Clinical Psychology, 63(2), 249255. https://doi.org/10.1037//0022-006x.63.2.249

56. Chen, C., Hung, A.-Y., Fan, Y.-T., Tan, S., Hong, H., \& Cheng, Y. (2017). Linkage between pain sensitivity and empathic response in adolescents with autism spectrum conditions and conduct disorder symptoms. Autism Research, 10(2), 267-275. https://doi.org/10.1002/aur.1653

57. Chen, F. R., Fung, A. L. C., \& Raine, A. (2019). The Cognitive, Affective, and Somatic Empathy scales (CASES): Cross-cultural replication and specificity to different forms of aggression and victimization. Journal of Personality Assessment, 103(1), 80-91. https://doi.org/10.1080/00223891.2019.1677246

58. Cheng, Y., Hung, A.-Y., \& Decety, J. (2012). Dissociation between affective sharing and emotion understanding in juvenile psychopaths. Development and Psychopathology, 24(2), 623-636. https://doi.org/10.1017/S095457941200020x

59. Choe, D. E., Lane, J. D., Grabell, A. S., \& Olson, S. L. (2013). Developmental precursors of young school-age children's hostile attribution bias. Developmental Psychology, 49(12), 2245-2256. https://doi.org/10.1037/a0032293

60. Choe, D. E., Shaw, D. S., \& Forbes, E. E. (2015). Maladaptive social information processing in childhood predicts young men's atypical amygdala reactivity to threat. Journal of Child Psychology and Psychiatry, 56(5), 549-557. https://doi.org/10.1111/jcpp.12316

61. Chong, A. M., Lee, P. G., Roslan, S., \& Baba, M. (2015). Emotional intelligence and atrisk students. Sage Open, 5(1), 1-8. https://doi.org/10.1177/2158244014564768 
62. Christian, E., \& Sellbom, M. (2015). Development and validation of an expanded version of the three-factor Levenson Self-Report Psychopathy scale. Journal of Personality Assessment, 98(2), 155-168. https://doi.org/10.1080/00223891.2015.1068176

63. Ciucci, E., \& Baroncelli, A. (2014). The emotional core of bullying: Further evidences of the role of callous-unemotional traits and empathy. Personality and Individual Differences, 67, 69-74. https://doi.org/10.1016/j.paid.2013.09.033

64. Ciucci, E., Baroncelli, A., Golmaryami, F. N., \& Frick, P. J. (2015). The emotional correlates to callous-unemotional traits in children. Journal of Child and Family Studies, 24(8), 2374-2387. https://doi.org/10.1007/s10826-014-0040-3

65. Cohen, D., \& Strayer, J. (1996). Empathy in conduct-disordered and comparison youth. Developmental Psychology, 32(6), 988-998. https://doi.org/10.1037/0012-1649.32.6.988

66. Cohen, T. R., Panter, A. T., Bhatia, N., Morse, L., \& Kim, Y. (2014). Moral character in the workplace. Journal of Personality and Social Psychology, 107(5), 943-963. https://doi.org/10.1037/a0037245

67. Cornelius, J. (2001). Empathy levels of child molesters compared to nonsexual offenders and nonoffenders [Unpublished master's thesis]. Emporia State University.

68. Coyne, S. M., Warburton, W. A., Essig, L. W., \& Stockdale, L. A. (2018). Violent video games, externalizing behavior, and prosocial behavior: A five-year longitudinal study during adolescence. Developmental Psychology, 54(10), 1868-1880. https://doi.org/10.1037/dev0000574

69. Cremer, J. (1996). Empathy and nurturance: A study of incest offenders (Publication No. 9634645) [Doctoral dissertation, California School of Professional Psychology at Alameda]. UMI Microform. 
70. Cristofani, C., Sesso, G., Cristofani, P., Fantozzi, P., Inguaggiato, E., Muratori, P., Narzisi, A., Pfanner, C., Pisano, S., Polidori, L., Ruglioni, L., Valente, E., Masi, G., \& Milone, A. (2020). The role of executive functions in the development of empathy and its association with externalizing behaviors in children with neurodevelopmental disorders and other $\begin{array}{llll}\text { psychiatric } & \text { comorbidities. } & \text { Brain } & \text { Sciences, }\end{array}$ $\underline{\text { https://doi.org/10.3390/brainsci10080489 }}$

71. Crocetti, E., Van der Graaff, J., Moscatelli, S., Keijsers, L., Koot, H. M., Rubini, M., Meeus, W., \& Branje, S. (2016). A longitudinal study on the effects of parental monitoring on adolescent antisocial behaviors: The moderating role of adolescent empathy. Frontiers in Psychology, 7, 1726. https://doi.org/10.3389/fpsyg.2016.01726

72. Cuevas, C. A. (2004). Obstacles to empathy in sex offenders: Recognition and interpretation of children's emotional cues. [Unpublished doctoral dissertation]. Alliant International University.

73. Curcio, A. L., Mak, A. S., \& George, A. M. (2017). Predictors of delinquency among adolescents and young adults: A new psychosocial control perspective. Australian and New Zealand Journal of Criminology, 50(2), 155-175. https://doi.org/10.1177/0004865816628594

74. Czarna, A. Z., Jonason, P. K., Dufner, M., \& Kossowska, M. (2016). The Dirty Dozen scale: validation of a polish version and extension of the nomological net. Frontiers in Psychology, 7, 445. https://doi.org/10.3389/fpsyg.2016.00445

75. Dadds, M. R., Hawes, D. J., Frost, A. D. J., Vassallo, S., Bunn, P., Hunter, K., \& Merz, S. (2009). Learning to 'talk the talk': the relationship of psychopathic traits to deficits in empathy across childhood. Journal of Child Psychology and Psychiatry, 50(5), 599-606. https://doi.org/10.1111/j.1469-7610.2008.02058.x 
76. Day, A., Mohr, P., Howells, K., Gerace, A., \& Lim, L. (2012). The role of empathy in anger arousal in violent offenders and university students. International Journal of Offender Therapy and Comparative Criminology, 56(4), 599-613. https://doi.org/10.1177/0306624X11431061

77. De Kemp, R. A. T., Overbeek, G., de Wied, M., Engels, R. C. M. E., \& Scholte, R. H. J. (2007). Early adolescent empathy, parental support, and antisocial behavior. The Journal of Genetic Psychology, 168(1), 5-18. https://doi.org/10.3200/GNTP.168.1.5-18

78. de la Rubia, J. M., H. (2012). Risk and protective factors of dissocial behavior in a probability sample. The Spanish Journal of Psychology, 15(2), 736-747. https://doi.org/10.5209/rev_SJOP.2012.v15.n2.38885

79. De Ruigh, E. L., Jansen, L. M. C., Vermeiren, R., \& Popma, A. (2019). Psychopathic traits and empathic functioning in detained juveniles: withdrawal response to empathic sadness. International Journal of Forensic Mental Health, 18(4), 336-349. https://doi.org/10.1080/14999013.2019.1577317

80. De Wied, M., van Boxtel, A., Matthys, W., \& Meeus, W. (2012). Verbal, facial and autonomic responses to empathy-eliciting film clips by disruptive male adolescents with high versus low callous-unemotional traits. Journal of Abnormal Child Psychology, 40(2), 211-223. https://doi.org/10.1007/s10802-011-9557-8

81. de Wied, M., van Boxtel, A., Zaalberg, R., Goudena, P., \& Matthys, W. (2006). Facial EMG responses to dynamic emotional facial expressions in boys with disruptive behavior disorders. Journal of Psychiatric Research, 40(2), 112-121. https://doi.org/10.1016/j.jpsychires.2005.08.003 
82. Deardorff, P. A., Finch, A. J., Kendall, P. C., Lira, F., \& Indrisano, V. (1975). Empathy and socialization in repeat offenders, first offenders, and normals. Journal of Counseling Psychology, 22(5), 453-455. https://doi.org/10.1037/h0077127

83. Decety, J., \& Yoder, K. J. (2016). Empathy and motivation for justice: Cognitive empathy and concern, but not emotional empathy, predict sensitivity to injustice for others. Social Neuroscience, 11(1), 1-14. https://doi.org/10.1080/17470919.2015.1029593

84. Decety, J., Lewis, K. L., \& Cowell, J. M. (2015). Specific electrophysiological components disentangle affective sharing and empathic concern in psychopathy. Journal of Neurophysiology, 114(1), 493-504. https://doi.org/10.1152/jn.00253.2015

85. Degue, S., \& DiLillo, D. (2004). Understanding perpetrators of nonphysical sexual coercion: Characteristics of those who cross the line. Violence \& Victims, 19(6), 673-688. https://doi.org/10.1891/vivi.19.6.673.66345

86. Degue, S., DiLillo, D., \& Scalora, M. (2010). Are all perpetrators alike? Comparing risk factors for sexual coercion and aggression. Sex Abuse, 22(4), 402-426. https://doi.org/10.1177/1079063210372140

87. Delhaye, M., Kempenaers, C., Stroobants, R., Goossens, L., \& Linkowski, P. (2013). Attachment and socio-emotional skills: A comparison of depressed inpatients, institutionalized delinquents and control adolescents. Clinical Psychology and Psychotherapy, 20(5), 424-433. https://doi.org/10.1002/cpp.1787

88. Delhove, M., \& Greitemeyer, T. (2020). The relationship between video game character preferences and aggressive and prosocial personality traits. Psychology of Popular Media, 9(1), 96-104. https://doi.org/10.1037/ppm0000211

89. Deming, P., Dargis, M., Haas, B. W., Brook, M., Decety, J., Harenski, C., Kiehl, K. A., Koenigs, M., \& Kosson, D. S. (2020). Psychopathy is associated with fear-specific 
reductions in neural activity during affective perspective-taking. NeuroImage, 223, 117342. https://doi.org/10.1016/j.neuroimage.2020.117342

90. Denardo Roney, J. L., Falkenbach, D. M., \& Aveson, O. (2018). Psychopathy and victim selection: Does nonverbal decoding or empathy impact vulnerability ratings? Journal of Interpersonal Violence, 1-22. https://doi.org/10.1177/0886260517742914

91. Deschamps, P. K. H., Schutter, D. J. L. G., Kenemans, J. L., \& Matthys, W. (2015). Empathy and prosocial behavior in response to sadness and distress in 6- to 7-year olds diagnosed with disruptive behavior disorder and Attention-Deficit Hyperactivity Disorder. European Child \& Adolescent Psychiatry, 24(1), 105-113. https://doi.org/10.1007/s00787$\underline{014-0535-\mathrm{X}}$

92. Deschamps, P. K., Verhulp, E. E., de Castro, B. O., \& Matthys, W. (2018). Proactive aggression in early school-aged children with externalizing behavior problems: A longitudinal study on the influence of empathy in response to distress. American Journal of Orthopsychiatry, 88(3), 346-353. https://doi.org/10.1037/ort0000319

93. Dietzel, B. J. (2008). Emotion recognition and the propensity to engage in sexually coercive behaviors: A study with college males. Dissertations, 764 . https://doi.org/https://scholarworks.wmich.edu/dissertations/764

94. Dinić, B. M., Milosavljević, M., \& Mandarić, J. (2020). Effects of Dark Tetrad traits on utilitarian moral judgement: the role of personal involvement and familiarity with the victim. Asian Journal of Social Psychology. https://doi.org/10.1111/ajsp.12422

95. Dinić, B. M., Petrović, B., \& Jonason, P. K. (2018). Serbian adaptations of the Dark Triad Dirty Dozen (DTDD) and Short Dark Triad (SD3). Personality and Individual Differences, 134, 321-328. https://doi.org/10.1016/j.paid.2018.06.018 
96. Dinolfo, C., \& Malti, T. (2013). Interpretive understanding, sympathy, and moral emotion attribution in Oppositional Defiant Disorder symptomatology. Child Psychiatry \& Human Development, 44(5), 633-645. https://doi.org/10.1007/s10578-013-0357-y

97. Dolan, M. C., \& Rennie, C. E. (2007). The relationship between psychopathic traits measured by the youth psychopathic trait inventory and psychopathology in a UK sample of conduct disordered boys. Journal of Adolescence, 30, 601-611. https://doi.org/https://doi.org/10.1016/j.adolescence.2006.07.002

98. Dolan, M., \& Fullam, R. (2004). Theory of mind and mentalizing ability in antisocial personality disorders with and without psychopathy. Psychological Medicine, 34(6), 10931102. https://doi.org/10.1017/s0033291704002028

99. Domes, G., Hollerbach, P., Vohs, K., Mokros, A., \& Habermeyer, E. (2013). Emotional empathy and psychopathy in offenders: An experimental study. Journal of Personality Disorders, 27(1), 67-84. https://doi.org/10.1521/pedi.2013.27.1.67

100. Dong, D., Jiang, Y., Gao, Y., Ming, Q., Wang, X., \& Yao, S. (2018). Atypical frontotemporal connectivity of cognitive empathy in male adolescents with conduct disorder. Frontiers in Psychology, 9, 2778. https://doi.org/10.3389/fpsyg.2018.02778

101. Dong, D., Ming, Q., Wang, X., Yu, W., Jiang, Y., Wu, Q., Gao, Y., \& Yao, S. (2016). Temporoparietal junction hypoactivity during pain-related empathy processing in adolescents with conduct disorder. Frontiers in Psychology, 7, 2085. https://doi.org/10.3389/fpsyg.2016.02085

102. Drayton, L. A., Santos, L. R., \& Baskin-Sommers, A. (2018). Psychopaths fail to automatically take the perspective of others. Proceedings of the National Academy of Sciences of the United States of America, 115(13), 3302-3307. https://doi.org/10.1073/pnas.1721903115 
103. Drislane, L. E., Sellbom, M., Brislin, S. J., Strickland, C. M., Christian, E., Wygant, D. B., Krueger, R., \& Patrick, C. J.(2019). Improving characterization of psychopathy within the diagnostic and statistical Manual of Mental Disorders, fifth edition (DSM-5), alternative model for personality disorders: Creation and validation of personality inventory for DSM5 triarchic scales. Personality Disorders: Theory, Research, and Treatment, 10(6), 511523. https://doi.org/10.1037/per0000345

104. Dryburgh, N. S. J., \& Vachon, D. D. (2019). Relating sex differences in aggression to three forms of empathy. Personality and Individual Differences, 151, 109526. https://doi.org/10.1016/j.paid.2019.109526

105. Duran, G., Cécillon, F.-X., Sansorgné, T., \& Michael, G. A. (2019). Cold-blooded women can detect lies with greater accuracy than other women. Journal of Forensic Psychiatry \& Psychology, 30(3), 510-529. https://doi.org/10.1080/14789949.2018.1560488

106. Duran, G., Dochez, S., Tapiero, I., \& Michael, G. A. (2020). Opinions, actions and emotions: Does the content of lies affect their detectability? Psychology, Crime \& Law, 26(10), 927-949. https://doi.org/10.1080/1068316x.2020.1742341

107. Durand, G. (2018). A French translation and validation of the durand adaptive psychopathic traits questionnaire: An investigation with community samples from France and Canada. PLoS $\quad$ One, Article e0204214. https://doi.org/10.1371/journal.pone.0204214

108. Eberly-Lewis, M. B., \& Coetzee, T. M. (2015). Dimensionality in adolescent prosocial tendencies: Individual differences in serving others versus serving the self. Personality and Individual Differences, 82, 1-6. https://doi.org/10.1016/j.paid.2015.02.032

109. Echeburua, E., \& Fernandez-Montalvo, J. (2007). Male batterers with and without psychopathy: An exploratory study in Spanish prisons. International Journal of Offender 
Therapy and Comparative Criminology, 51(3), 254-263. https://doi.org/10.1177/0306624X06291460

110. Eisenberg, N., Fabes, R. A., Murphy, B., Karbon, M., Smith, M., \& Maszk, P. (1996). The relations of children's depositional empathy-related responding to their emotionality, regulation, and social functioning. Developmental Psychology, 32(2), 195-209.

111. Ekerim-Akbulut, M., Sen, H. H., Besiroglu, B., \& Selcuk, B. (2020). The role of theory of mind, emotion knowledge and empathy in preschoolers' disruptive behavior. Journal of Child and Family Studies, 29(1), 128-143. https://doi.org/10.1007/s10826-019-01556-9

112. Ellis, P. L. (1982). Empathy: A factor in antisocial behavior. Journal of Abnormal Child Psychology, 10(1), 123-133. https://doi.org/10.1007/bf00915957

113. Elsegood, K. J., \& Duff, S. C. (2010). Theory of mind in men who have sexually offended against children: A UK comparison study between child sex offenders and nonoffender controls. Sexual Abuse-a Journal of Research and Treatment, 22(1), 112-131. https://doi.org/10.1177/1079063209359926

114. Erickson, J. M., \& Sagarin, B. J. (2021). The prosocial sadist? A comparison of BDSM sadism and everyday sadism. Personality and Individual Differences, 176, 110723. https://doi.org/10.1016/j.paid.2021.110723

115. Espelage, D. L., Van Ryzin, M. J., \& Holt, M. K. (2018). Trajectories of bully perpetration across early adolescence: Static risk factors, dynamic covariates, and longitudinal outcomes. Psychology of Violence, 8(2), 141-150. https://doi.org/10.1037/vio0000095

116. Euler, F., Steinlin, C., \& Stadler, C. (2017). Distinct profiles of reactive and proactive aggression in adolescents: Associations with cognitive and affective empathy. Child and Adolescent Psychiatry and Mental Health, 11(1), 1-14. https://doi.org/10.1186/s13034$\underline{016-0141-4}$ 
117. Fang, J., Wang, X., Yuan, K.-H., \& Wen, Z. (2020). Childhood psychological maltreatment and moral disengagement: A moderated mediation model of callous-unemotional traits and empathy. Personality and Individual Differences, $157,109814$. https://doi.org/10.1016/j.paid.2020.109814

118. Fang, J., Wang, X., Yuan, K.-H., Wen, Z., Yu, X., \& Zhang, G. (2020). Callousunemotional traits and cyberbullying perpetration: The mediating role of moral disengagement and the moderating role of empathy. Personality and Individual Differences, 157, 109829. https://doi.org/10.1016/j.paid.2020.109829

119. Fido, D., \& Richardson, M. (2019). Empathy mediates the relationship between nature connectedness and both callous and uncaring traits. Ecopsychology, 11(2), 130-137. https://doi.org/10.1089/eco.2018.0071

120. Fido, D., Harper, C. A., Davis, M., Petronzi, D., \& Worrall, S. G. M. (2019). Intrasexual competition as a predictor of women's judgments of revenge pornography offending. Sex Abuse, 1-26. https://doi.org/10.1177/1079063219894306

121. Figueiredo, P., Azeredo, A., Barroso, R., \& Barbosa, F. (2020). Psychometric Properties of Teacher Report of Social-Emotional Assets and Resilience Scale in Preschoolers and Elementary School Children. Journal of Psychopathology and Behavioral Assessment, 42, 799-807. https://doi.org/10.1007/s10862-020-09831-6

122. Figueiredo et al. (Unpublished). Precursors of antisocial behavior: association with potential risk and protective factors.

123. Fisher, D., Beech, A., \& Browne, K. (1999). Comparison of sex offenders to nonoffenders on selected psychological measures. International Journal of Offender Therapy and Comparative Criminology, 43(4), 473-491. https://doi.org/10.1177/0306624x99434006 
124. Fix, R. L., \& Fix, S. T. (2015). Trait psychopathy, emotional intelligence, and criminal thinking: Predicting illegal behavior among college students. International Journal of Law and Psychiatry, 42-43, 183-188. https://doi.org/10.1016/j.ijlp.2015.08.024

125. Fleischmann, A., Lammers, J., Conway, J., \& Galinsky, A. D. (2020). Kant be compared: People high in social comparison orientation make fewer-not more-deontological decisions in sacrificial dilemmas. Social Psychological and Personality Science, 1-12. https://doi.org/10.1177/1948550620947294

126. Flight, J. I., \& Forth, A. E. (2007). Instrumentally violent youths - The roles of psychopathic traits, empathy, and attachment. Criminal Justice and Behavior, 34(6), 739751. https://doi.org/10.1177/0093854807299462

127. Foell, J., Brislin, S. J., Drislane, L. E., Dziobek, I., \& Patrick, C. J. (2018). Creation and validation of an english-language version of the Multifaceted Empathy Test (MET). Journal of Psychopathology and Behavioral Assessment, 40(3), 431-439. https://doi.org/10.1007/s10862-018-9664-8

128. Francis, K. B., Gummerum, M., Ganis, G., Howard, I. S., \& Terbeck, S. (2019). Alcohol, empathy, and morality: Acute effects of alcohol consumption on affective empathy and moral decision-making. Psychopharmacology, 236, 3477-3496. https://doi.org/10.1007/s00213-019-05314-z

129. Friedman, A., Taraban, L., Sitnick, S., \& Shaw, D. S. (2021). Early Adolescent Predictors of Violent Behavior: Child and Contextual Risk, and Moderation by Rejecting Parenting. The Journal of Early Adolescence, 41(8), 1228-1254. https://doi.org/10.1177/02724316211002268 
130. Funk, J., Fox, C., Chan, M., \& Curtiss, K. (2008). The development of the children's empathic attitudes questionnaire using classical and rasch analyses. Journal of Applied Developmental Psychology, 29(3), 187-196. https://doi.org/10.1016/j.appdev.2008.02.005

131. Galán, C. A., Choe, D. E., Forbes, E. E., \& Shaw, D. S. (2017). Interactions between empathy and resting heart rate in early adolescence predict violent behavior in late adolescence and early adulthood. Journal of Child Psychology and Psychiatry, 58(12), 1370-1380. https://doi.org/10.1111/jepp.12771

132. Gamache, D., Savard, C., \& Maheux-Caron, V. (2018). French adaptation of the short dark triad: Psychometric properties and a head-to-head comparison with the Dirty Dozen. Personality and Individual Differences, 122, 164-170. https://doi.org/10.1016/j.paid.2017.10.027

133. Gano-Overway, L. A., Newton, M., Magyar, T. M., Fry, M. D., Kim, M.-S., \& Guivernau, M. R. (2009). Influence of caring youth sport contexts on efficacy-related beliefs and social behaviors. Developmental Psychology, 45(2), 329-340. https://doi.org/10.1037/a0014067

134. Garaigordobil, M. (2009). A comparative analysis of empathy in childhood and adolescence: Gender differences and associated socio-emotional variables. International Journal of Psychology and Psychological Therapy, 9(2), 217-235.

135. Garcia, O. F., Lopez-Fernandez, O., \& Serra, E. (2018). Raising Spanish children with an antisocial tendency: Do we know what the optimal parenting style is? Journal of Interpersonal Violence, 1-28. https://doi.org/10.1177/0886260518818426

136. Geng, Y., Xia, D., \& Qin, B. (2012). The Basic Empathy Scale: A Chinese validation of a measure of empathy in adolescents. Child Psychiatry \& Human Development, 43(4), 499510. https://doi.org/10.1007/s10578-011-0278-6 
137. Georgiou, G., \& Fanti, K. A. (2020). Physiological reactivity in children with high callousunemotional and autistic traits: Investigating unique and interactive effects. European Child \& Adolescent Psychiatry. https://doi.org/10.1007/s00787-020-01643-z

138. Georgiou, G., Demetriou, C. A., \& Fanti, K. A. (2019). Distinct empathy profiles in callous unemotional and autistic traits: Investigating unique and interactive associations with affective and cognitive empathy. Journal of Abnormal Child Psychology, 47(11), 18631873. https://doi.org/10.1007/s10802-019-00562-1

139. Georgiou, G., Kimonis, E. R., \& Fanti, K. A. (2018). What do others feel? Cognitive empathy deficits explain the association between callous-unemotional traits and conduct problems among preschool children. European Journal of Developmental Psychology, 16(6), 633-653. https://doi.org/10.1080/17405629.2018.1478810

140. Gery, I., Miljkovitch, R., Berthoz, S., \& Soussignan, R. (2009). Empathy and recognition of facial expressions of emotion in sex offenders, non-sex offenders and normal controls. Psychiatry Research, 165(3), 252-262. https://doi.org/10.1016/j.psychres.2007.11.006

141. Giammarco, E. A., \& Vernon, P. A. (2014). Vengeance and the Dark Triad: The role of empathy and perspective taking in trait forgivingness. Personality and Individual Differences, 67, 23-29. https://doi.org/10.1016/j.paid.2014.02.010

142. Gillen, C. T. A., Lee, Z., Salekin, K. L., Iselin, A.-M. R., Harrison, N. A., Clark, A., Colins, O., \& Salekin, R. T. (2018). Psychopathic traits in adolescence: The importance of examining components in face processing, voice processing, and emotional skill. Journal of Psychopathology and Behavioral Assessment, 40(1), 50-59. https://doi.org/10.1007/s10862-018-9656-8

143. Gillespie, S. M., Mitchell, I. J., \& Abu-Akel, A. (2017). Autistic traits and positive psychotic experiences modulate the association of psychopathic tendencies with theory of 
mind in opposite directions. Scientific Reports, 7(1), 6485. https://doi.org/10.1038/s41598-

\section{$\underline{017-06995-2}$}

144. Giroux, S., \& Guay, M.-C. (2021). Assessing the contribution of callous-unemotional traits and affective empathy to aggressive behaviour among teenagers hosted in a youth protection centre. Psychology, Crime \& Law, 1-12. https://doi.org/10.1080/1068316X.2021.1929977

145. Goering, M., \& Mrug, S. (2021). Empathy as a Mediator of the Relationship between Authoritative Parenting and Delinquent Behavior in Adolescence. Journal of Youth and Adolescence, 50(7), 1308-1318. https://doi.org/10.1007/s10964-021-01445-9

146. Goldstein, H., \& Higgins-D'alessandro, A. (2001). Empathy and attachment in relation to violent vs. non-violent offense history among jail inmates. Journal of Offender Rehabilitation, 32(4), 31-53. https://doi.org/http://dx.doi.org/10.1300/J076v32n04_03

147. Golubchik, P., \& Weizman, A. (2017). The possible effect of methylphenidate treatment on empathy in children diagnosed with Attention-Deficit/Hyperactivity Disorder, both with and without comorbid Oppositional Defiant Disorder. Journal of Child and Adolescent Psychopharmacology, 27(5), 429-432. https://doi.org/10.1089/cap.2016.0111

148. Gómez-Leal, R., Megías-Robles, A., Gutiérrez-Cobo, M., Cabello, R., Fernández-Abascal, E. G., \& Fernández-Berrocal, P. (2019). Spanish adaptation and validation of the 34-Item Self-Report Psychopathy Scale (SRP). Guilford Press Periodicals. https://doi.org/10.1521/pedi_2019_33_434

149. Gonsalves, V. M., McLawsen, J. E., Huss, M. T., \& Scalora, M. J. (2013). Factor structure and construct validity of the Psychopathic Personality Inventory in a forensic sample. International Journal of Law and Psychiatry, 36(2), 176-184. https://doi.org/10.1016/j.ijlp.2013.01.010 
150. Gonzalez-Gadea, M. L., Herrera, E., Parra, M., Gomez Mendez, P., Baez, S., Manes, F., \& Ibanez, A. (2014). Emotion recognition and cognitive empathy deficits in adolescent offenders revealed by context-sensitive tasks. Frontiers in Human Neuroscience, 8, 850. https://doi.org/10.3389/fnhum.2014.00850

151. Graham, S. (2002). Assessing emotional responses in sex offenders (Publication No. 3081080) [Doctoral dissertation, The University of Texas at Houstin]. ProQuest Information and Learning Company.

152. Grieve, R., \& Panebianco, L. (2013). Assessing the role of aggression, empathy, and selfserving cognitive distortions in trait emotional manipulation. Australian Journal of Psychology, 65(2), 79-88. https://doi.org/10.1111/j.1742-9536.2012.00059.x

153. Gummerum, M., \& Hanoch, Y. (2012). Altruism behind bars: Sharing, justice, perspective taking and empathy among inmates. Social Justice Research, 25(1), 61-78. https://doi.org/10.1007/s11211-012-0149-8

154. Gumustas, F., Yilmaz, I., Yulaf, Y., Gokce, S., \& Sabuncuoglu, O. (2017). Empathy and facial expression recognition in children with and without Attention-Deficit/Hyperactivity Disorder: Effects of stimulant medication on empathic skills in children with AttentionDeficit/Hyperactivity Disorder. Journal of Child and Adolescent Psychopharmacology, 27(5), 433-439. https://doi.org/10.1089/cap.2016.0052

155. Gvozden, T., Opacic, G., \& Mladenovic, I. (2015). Does empathy always inhibit amorality and offending? Psihologija, 48(3), 213-232. https://doi.org/10.2298/PSI1503213V

156. Happe, F., \& Frith, U. (1996). Theory of mind and social impairment in children with conduct disorder. British Journal of Developmental Psychology, 14(4), 385-398. https://doi.org/10.1111/j.2044-835X.1996.tb00713.x 
157. Harenski, C. L., Brook, M., Kosson, D. S., Bustillo, J. R., Harenski, K. A., Caldwell, M. F., Van Rybroek, G. J., Koenigs, M., Decety, J., Thornton, D. M., Calhoun, V. D., \& Kiehl, K. A. (2017). Socio-neuro risk factors for suicidal behavior in criminal offenders with psychotic disorders. Social Cognitive and Affective Neuroscience, 12(1), 70-80. https://doi.org/10.1093/scan/nsw164

158. Hartman, C., Hageman, T., Williams, J. H., Mary, J. S., \& Ascione, F. R. (2019). Exploring empathy and callous-unemotional traits as predictors of animal abuse perpetrated by children exposed to intimate partner violence. Journal of Interpersonal Violence, 34(12), 2419-2437. https://doi.org/10.1177/0886260516660971

159. Hawes, D., Kimonis, E., Mendoza Diaz, A., Frick, P., \& Dadds, M. (2020). The Clinical Assessment of Prosocial Emotions (CAPE 1.1): A multi-informant validation study. Psychological Assessment, 32(4), 348-357. https://doi.org/10.1037/pas0000792

160. Hayashino, D. S., Wurtele, S. K., \& Klebe, K. J. (1995). Child Molesters - An examination of cognitive-factors. Journal of Interpersonal Violence, 10(1), 106-116. https://doi.org/10.1177/088626095010001007

161. Heilbrun, A. (1982). Cognitive models of criminal violence based upon intelligence and psychopathy levels. Journal of Consulting and Clinical Psychology, 50(4), 546-557. https://doi.org/10.1037/0022-006x.50.4.546

162. Hepper, E. G., Hart, C. M., Meek, Cisek, S., \& Sedikides, C. (2014). Narcissism and empathy in young offenders and non-offenders. European Journal of Personality, 28(2), 201-210. https://doi.org/10.1002/per.1939

163. Heym, N., Ferguson, E., \& Lawrence, C. (2013). The P-psychopathy continuum: Facets of psychoticism and their associations with psychopathic tendencies. Personality and Individual Differences, 54(6), 773-778. https://doi.org/10.1016/j.paid.2012.12.001 
164. Heym, N., Firth, J. L., Kibowski, F., Sumich, A. L., Egan, V., \& Bloxsom, C. (2019). Empathy at the heart of darkness: Empathy deficits that bind the Dark Triad and those that mediate indirect relational aggression. Frontiers in Psychiatry, 10, 95. https://doi.org/10.3389/fpsyt.2019.00095

165. Heym, N., Firth, J., Sumich, A., Kibowski, F., Egan, V., \& Bloxsom, C. (2020). Push me, pull you: Psychopathy and affective empathy partially mediate the relationship between early and late attachment. Personality and Individual Differences, 157.

166. Heym, N., Kibowski, F., Bloxsom, C. A. J., Blanchard, A., Harper, A., Wallace, L., Firth, J., \& Sumich, A. (2021). The Dark Empath: Characterising dark traits in the presence of empathy. Personality and Individual Differences, 169, 110172. https://doi.org/10.1016/j.paid.2020.110172

167. Heynen, E. J. E., Van der Helm, G. H. P., Stams, G. J. J. M., \& Korebrits, A. M. (2016). Measuring empathy in a German youth prison: A validation of the German version of the Basic Empathy Scale (BES) in a sample of incarcerated juvenile offenders. Journal of Forensic Psychology $\quad$ Practice, 16(5), 336-346. https://doi.org/10.1080/15228932.2016.1219217

168. Hirtenlehner, H., Trivedi-Bateman, N., Baier, D., \& Strohmeier, D. (2021). Does Empathy Attenuate the Criminogenic Effect of Low Self-Control in Late Life? International Journal of Comparative and Applied Criminal Justice, 1-21. https://doi.org/10.1080/01924036.2021.1955219

169. Hoerold, D., \& Tranah, T. (2014). Correlates of adolescent fire setting: Examining the role of fire interest, fire-related attentional bias, impulsivity, empathy and callous-unemotional traits. Journal of Forensic Psychiatry \& Psychology, 25(4), 411-431. https://doi.org/10.1080/14789949.2014.925137 
170. Hogan, R. (1969). Development of an empathy scale. Journal of Consulting and Clinical Psychology, 33(3), 307-316.

171. Holl, A. K., Vetter, N. C., \& Elsner, B. (2021). Disentangling the relations of theory of mind, executive function and conduct problems. Journal of Applied Developmental Psychology, 72, 101233. https://doi.org/10.1016/j.appdev.2020.101233

172. Holmqvist, R. (2008). Psychopathy and affect consciousness in young criminal offenders. Journal of Interpersonal Violence, 23(2), 209-224. https://doi.org/10.1177/0886260507309341

173. House, S. J., Laan, J. M., Molden, R. K., Ritchie, J. C., \& Stowe, Z. N. (2017). Preliminary study of testosterone and empathy in determining recidivism and antisocial behavior. Journal of Forensic Sciences, 62(5), 1360-1365. https://doi.org/10.1111/1556-4029.13469

174. Huang, X., Li, W., Sun, B., Chen, H., \& Davis, M. (2012). The validation of the Interpersonal Reactivity Index for Chinese teachers from primary and middle schools. Journal of Psychoeducational Assessment, 30(2), 194-204. https://doi.org/10.1177/0734282911410588

175. Hudak, M., André, J., \& Allen, R. (1980). Delinquency and social values: Differences between delinquent and nondelinquent adolescents. Youth \& Society 11(3), 353-368. https://doi.org/https://doi.org/10.1177/0044118x8001100304

176. Hunnikin, L. M., Wells, A. E., Ash, D. P., \& van Goozen, S. H. M. (2020). The nature and extent of emotion recognition and empathy impairments in children showing disruptive behaviour referred into a crime prevention programme. European Child \& Adolescent Psychiatry, 29(3), 363-371. https://doi.org/10.1007/s00787-019-01358-w 
177. Jacobson, K. C., \& Chang, L. (2018). Associations between pet ownership and attitudes toward pets with youth socioemotional outcomes. Frontiers in Psychology, 9, 2304. https://doi.org/10.3389/fpsyg.2018.02304

178. Jameel, L., Vyas, K., Bellesi, G., Crawford, S., \& Channon, S. (2019). Thinking about other's mistakes: Contrasting patterns of performance in groups high or low in autistic or psychopathic traits. Cognitive Neuropsychiatry, 24(5), 369-385. https://doi.org/10.1080/13546805.2019.1667317

179. Javakhishvili, M., \& Vazsonyi, A. T. (2021). Empathy, Self-control, CallousUnemotionality, and Delinquency: Unique and Shared Developmental Antecedents. Child Psychiatry \& Human Development. https://doi.org/10.1007/s10578-021-01137-2

180. Jiang, S., Dong, L., \& Jiang, C. (2020). Examining the link between economic strain and adolescent social behavior: Roles of social bonds and empathy. Journal of Adolescent, 84, 1-10. https://doi.org/10.1016/j.adolescence.2020.07.015

181. Johnson, M. M., Caron, K. M., Mikolajewski, A. J., Shirtcliff, E. A., Eckel, L. A., \& Taylor, J. (2014). Psychopathic traits, empathy, and aggression are differentially related to cortisol awakening response. Journal of Psychopathology and Behavioral Assessment, 36(3), 380388. https://doi.org/10.1007/s10862-014-9412-7

182. Jolliffe, D., \& Farrington, D. P. (2007). Examining the relationship between low empathy and self-reported offending. Legal and Criminological Psychology, 12, 265-286. https://doi.org/10.1348/135532506x147413

183. Jonason, P. K., \& Krause, L. (2013). The emotional deficits associated with the Dark Triad traits: Cognitive empathy, affective empathy, and alexithymia. Personality and Individual Differences, 55(5), 532-537. https://doi.org/10.1016/j.paid.2013.04.027 
184. Jonason, P., \& Kroll, C. (2015). A multidimensional view of the relationship between empathy and the Dark Triad. Journal of Individual Differences, 36(3), 150-156. https://doi.org/10.1027/1614-0001/a000166

185. Jones, A. P., Forster, A. S., \& Skuse, D. (2007). What do you think you're looking at? Investigating social cognition in young offenders. Criminal Behaviour and Mental Health, 17(2), 101-106. https://doi.org/10.1002/cbm.641

186. Jones, A. P., Larsson, H., Ronald, A., Rijsdijk, F., Busfield, P., Mcmillan, A., Plomin, R., \&Viding, E. (2009). Phenotypic and aetiological associations between psychopathic tendencies, autistic traits, and emotion attribution. Criminal Justice and Behavior, 36(11), 1198-1212. https://doi.org/10.1177/0093854809342949

187. Jones, A., Happe, F. G. E., Gilbert, F., Burnett, S., \& Viding, E. (2010). Feeling, caring, knowing: Different types of empathy deficit in boys with psychopathic tendencies and autism spectrum disorder. Journal of Child Psychology and Psychiatry 51(11), 1188-1197. https://doi.org/10.1111/j.1469-7610.2010.02280.x

188. Ju, U., Kang, J., \& Wallraven, C. (2019). To brake or not to brake? Personality traits predict decision-making in an accident situation. Frontiers in Psychology, 10, 134. https://doi.org/10.3389/fpsyg.2019.00134

189. Ju, U., Kang, J., \& Wallraven, C. (2019). You or me? Personality traits predict sacrificial decisions in an accident situation / IEEE transactions on visualization and computer graphics. Transactions on Vizualization and Computer Graphics, 25(5), 1898-1907.

190. Ju, U., Kang, J., Wallraven, C., Hollerer, T., Interrante, V., Lecuyer, A., \& Suma, E. (2016). Personality differences predict decision-making in an accident situation in virtual driving. IEEE Virtual Reality (VR). https://doi.org/10.1109/vr.2016.7504690 
191. Kahane, G., Everett, J. A. C., Earp, B. D., Caviola, L., Faber, N. S., Crockett, M. J., \& Savulescu, J. (2018). Beyond sacrificial harm: A two-dimensional model of utilitarian psychology. Psychological Review, 125(2), 131-164. https://doi.org/10.1037/rev0000093

192. Kahane, G., Everett, J. A. C., Earp, B., Farias, M., \& Savulescu, J. (2015). 'Utilitarian' judgments in sacrificial moral dilemmas do not reflect impartial concern for the greater good. Cognition and Emotion, 134, 193-209. https://doi.org/http://dx.doi.org/10.1016/j.cognition.2014.10.005

193. Kahn, R. E., Frick, P. J., Golmaryami, F. N., \& Marsee, M. A. (2017). The moderating role of anxiety in the associations of callous-unemotional traits with self-report and laboratory measures of affective and cognitive empathy. Journal of Abnormal Child Psychology, 45(3), 583-596. https://doi.org/10.1007/s10802-016-0179-z

194. Kajonius, P. J., \& Björkman, T. (2020). Individuals with dark traits have the ability but not the disposition to empathize. Personality and Individual Differences, 155. https://doi.org/10.1016/j.paid.2019.109716

195. Kampfe, N., Penzhorn, J., Schikora, J., Dunzl, J., \& Schneidenbach, J. (2009). Empathy and social desirability: A comparison of delinquent and non-delinquent participants using direct and indirect measures. Psychology Crime \& Law, 15(1), 1-17. https://doi.org/10.1080/10683160802010640

196. Kendall, P. C., Deardorff, P. A., \& Finch, A. J. (1977). Empathy and socialization in first and repeat juvenile offenders and normals. Journal of Abnormal Child Psychology, 5(1), 93-97. https://doi.org/10.1007/BF00915764

197. Kimonis, E. R., Branch, J., Hagman, B., Graham, N., \& Miller, C. (2013). The psychometric properties of the Inventory of Callous-Unemotional traits in an 
undergraduate sample. Psychological Assessment, 25(1), 84-93. https://doi.org/10.1037/a0029024

198. Kimonis, E. R., Fanti, K. A., Anastassiou-Hadjicharalambous, X., Mertan, B., Goulter, N., \& Katsimicha, E. (2015). Can callous-unemotional traits be reliably measured in preschoolers? Journal of Abnormal Child Psychology, 44(4), 625-638. https://doi.org/10.1007/s10802-015-0075-y

199. Kimonis, E. R., Frick, P. J., Skeem, J. L., Marsee, M. A., Cruise, K., Munoz, L. C., Aucoin, K., \& Morris, A. S. (2008). Assessing callous-unemotional traits in adolescent offenders: Validation of the Inventory of Callous-Unemotional traits. International Journal of Law and Psychiatry, 31(3), 241-252. https://doi.org/10.1016/j.ijlp.2008.04.002

200. King, A. R., Breen, C. M., Russell, T. D., Nerpel, B. P., \& Pogalz, C. R. (2018). Selfreported executive functioning competencies and lifetime aggression. Applied Neuropsychology: $\quad$ Adult, $\quad$ 25(5), 400-409. https://doi.org/10.1080/23279095.2017.1320555

201. Klapwijk, E. T., Aghajani, M., Colins, O. F., Marijnissen, G. M., Popma, A., van Lang, N. D. J., van der Wee, N., \& Vermeiren, R. (2016). Different brain responses during empathy in autism spectrum disorders versus conduct disorder and callous-unemotional traits. Journal of Child Psychology and Psychiatry, 57(6), 737-747. https://doi.org/10.1111/jepp.12498

202. Klapwijk, E. T., Lelieveld, G.-J., Aghajani, M., Boon, A. E., van der Wee, N. J. A., Popma, A., Vermeiren, R., \& Colins, O. F. (2016). Fairness decisions in response to emotions: A functional MRI study among criminal justice-involved boys with conduct disorder. Social Cognitive and Affective Neuroscience, 11(4), 674-682. $\underline{\text { https://doi.org/10.1093/scan/nsv150 }}$ 
203. Kokkinos, C. M., Antoniadou, N., \& Markos, A. (2014). Cyber-bullying: An investigation of the psychological profile of university student participants. Journal of Applied Developmental Psychology, 35(3), 204-214. https://doi.org/10.1016/j.appdev.2014.04.001

204. Kokkinos, C. M., Kirpitsi, E., Voulgaridou, I., \& Markos, A. (2020). Reactive and proactive aggression subgroups in early adolescents and the interplay among callousunemotional traits, moral disengagement, empathy and functions of aggression. Current Psychology. https://doi.org/10.1007/s12144-020-00858-2

205. Kongerslev, M. T., Bo, S., Forth, A. E., \& Simonsen, E. (2015). Assessment of the affective dimensions of psychopathy with the Danish version of the Inventory of CallousUnemotional traits among incarcerated boys: A study of reliability, criterion validity, and construct validity. Scandinavian Journal of Child and Adolescent Psychiatry and Psychology, 3(1), 80-96. https://doi.org/10.21307/sjcapp-2015-008

206. Körner, A., Deutsch, R., \& Gawronski, B. (2020). Using the CNI model to investigate Individual differences in moral dilemma judgments. Personality and Social Psychology Bulletin, 46(9), 1392-1407. https://doi.org/10.1177/0146167220907203

207. Kostic, J., Nesikc, M., Stankovic, M., Zikic, O., \& Markovic, J. (2016). Evaluating empathy in adolescents with conduct disorders. Vojnosanitetski Pregled, 73(5), 429-434. $\underline{\text { https://doi.org/10.2298/vsp150121031k }}$

208. Kristof, Z., Kresznerits, S., Olah, M., Gyollai, A., Lukacs-Miszler, K., Halmai, T., Fountoulakis, K. N., Tenyi, T., Dome, P., \& Gonda, X. (2018). Mentalization and empathy as predictors of violence in schizophrenic patients: Comparison with nonviolent schizophrenic patients, violent controls and nonviolent controls. Psychiatry Research, 268, 198-205. https://doi.org/10.1016/j.psychres.2018.07.021 
209. Kurtines, W., \& Hogan, R. (1972). Sources of conformity in unsocialized college students. Journal of Abnormal Psychology, 80(1), 49-51. https://doi.org/10.1037/h0033391

210. Kurtines, W., Hogan, R., \& Weiss, D. (1975). Personality dynamics of heroin use. Journal of Abnormal Psychology, 84(1), 87-99. https://doi.org/10.1037/h0076258

211. Laghi, F., Lonigro, A., Pallini, S., \& Baiocco, R. (2018). Emotion regulation and empathy: Which relation with social conduct? The Journal of Genetic Psychology, 179(2), 62-70. https://doi.org/10.1080/00221325.2018.1424705

212. Langdon, P. E., Murphy, G. H., Clare, I. C. H., Steverson, T., \& Palmer, E. J. (2011). Relationships among moral reasoning, empathy, and distorted cognitions in men with intellectual disabilities and a history of criminal offending. American Journal on Intellectual and Developmental Disabilities, 116(6), 438-456. https://doi.org/10.1352/1944-7558-116.6.438

213. Larden, M., Melin, L., Holst, U., \& Langstrom, N. (2006). Moral judgement, cognitive distortions and empathy in incarcerated delinquent and community control adolescents. Psychology Crime \& Law, 12(5), 453-462. https://doi.org/10.1080/10683160500036855

214. Lee, M., \& Prentice, N. M. (1988). Interrelations of empathy, cognition, and moral reasoning with dimensions of juvenile delinquency. Journal of Abnormal Child Psychology, 16(2), 127-139. https://doi.org/10.1007/BF00913589

215. Lee, S. A., \& Gibbons, J. A. (2017). The Dark Triad and compassion: Psychopathy and narcissism's unique connections to observed suffering. Personality and Individual Differences, 116, 336-342. https://doi.org/10.1016/j.paid.2017.05.010

216. Lee, V., \& Egan, V. (2013). Predictors of aggression in Southeast Asian female prisoners. $\begin{array}{llll}\text { Personality and Individual } \quad \text { Differences, } & \text { 54(1), }\end{array}$ https://doi.org/10.1016/j.paid.2012.08.024 
217. Lengua, L. J., \& Stormshak, E. A. (2016). Gender, gender roles, and personality: Gender differences in the prediction of coping and psychological symptoms. Personality and Individual Differences, 43(11), 787-820. https://doi.org/10.1016/j.paid.2016.02.029

218. Lethbridge, E. M., Richardson, P., Reidy, L., \& Taroyan, N. A. (2017). Exploring the relationship between callous-unemotional traits, empathy processing and affective valence in a general population. Europe's Journal of Psychology, 13(1), 162-172. https://doi.org/10.5964/ejop.v13i1.1179

219. Levenson, M. (1990). Risk taking and personality. Journal of Personality and Social Psychology, 58(6), 1073-1080. https://doi.org/10.1037/0022-3514.58.6.1073

220. Levi-Shachar, O., Gvirts, H. Z., Goldwin, Y., Bloch, Y., Shamay-Tsoory, S., Boyle, D., \& Maoz, H. (2021). The association between symptom severity and theory of mind impairment in children with attention deficit/hyperactivity disorder. Psychiatry Research, 303, 114092. https://doi.org/10.1016/j.psychres.2021.114092

221. Levitan, J. A., \& Vachon, D. D. (2021). The nuanced association between deficient empathy and sexual aggression. Personality and Individual Differences, 177, 110812. https://doi.org/10.1016/j.paid.2021.110812

222. Li, S., Ding, D., Lai, J., Zhang, X., Wu, Z., \& Liu, C. (2020). The characteristics of moral judgment of psychopaths: The mediating effect of the deontological tendency. Psychology Research and Behavior Management, 13, 257-266. https://doi.org/10.2147/PRBM.S226722

223. Li, S., Xia, Y., Xiong, R., Li, J., \& Chen, Y. (2020). Coercive parenting and adolescent developmental outcomes: The moderating effects of empathic concern and perception of social rejection. International Journal of Environmental Research and Public Health, 17(10), 1-17. https://doi.org/10.3390/ijerph17103538 
224. Lima, C. (2021). RDoC approach to the study of psychopathy: Core features and implications for social decision making. Faculty of Psychology and Educational Sciences, University of Porto.

225. Lin, H.-C., Yang, Y., McFatter, R., Biggar, R., \& Perkins, R. (2017). Inmates' empathy in relation to perceived parenting and attachment working models. Journal of Criminal Psychology 7(4), 302-318. https://doi.org/10.1108/jcp-09-2016-0024

226. Lin, X., Chen, H., Tan, Y., Yang, X., \& Chi, P. (2021). The empathy questionnaire for children and adolescents (EmQue-CA) in Chinese: Psychometric properties and measurement invariance. Asian Journal of Psychiatry, 63, 102775. https://doi.org/10.1016/j.ajp.2021.102775

227. Lindsey, R. E., Carlozzi, A. F., \& Eells, G. T. (2001). Differences in the dispositional empathy of juvenile sex offenders, non-sex-offending delinquent juveniles, and nondelinquent juveniles. Journal of Interpersonal Violence, 16(6), 510-522. https://doi.org/10.1177/088626001016006002

228. Lishner, D. A., Hong, P. Y., Jiang, L., Vitacco, M. J., \& Neumann, C. S. (2015). Psychopathy, narcissism, and borderline personality: A critical test of the affective empathy-impairment hypothesis. Personality and Individual Differences, 86, 257-265. https://doi.org/10.1016/j.paid.2015.05.036

229. Lishner, D. A., Vitacco, M. J., Hong, P. Y., Mosley, J., Miska, K., \& Stocks, E. L. (2012). Evaluating the relation between psychopathy and affective empathy: Two preliminary studies. International Journal of Offender Therapy and Comparative Criminology, 56(8), 1161-1181. https://doi.org/10.1177/0306624X11421891

230. Litten, V., Roberts, L. D., Ladyshewsky, R., Castell, E., \& Kane, R. (2018). The influence of academic discipline on empathy and psychopathic personality traits in undergraduate 
students. Personality and Individual Differences, 123, 145-150. https://doi.org/10.1016/j.paid.2017.11.025

231. Litten, V., Roberts, L. D., Ladyshewsky, R., Castell, E., \& Kane, R. (2020). Empathy and psychopathic traits as predictors of selection into business or psychology disciplines. Australian Journal of Psychology, 72(1), 93-105. https://doi.org/10.1111/ajpy.12263

232. Liu, J., Qiao, X., Dong, F., \& Raine, A. (2018). The Chinese version of the cognitive, affective, and somatic empathy scale for children: Validation, gender invariance and associated factors. PLoS One, 13(5), Article e0195268. https://doi.org/10.1371/journal.pone.0195268

233. Llorca-Mestre, A., Malonda-Vidal, E., \& Samper-Garcia, P. (2017). Prosocial reasoning and emotions in young offenders and non-offenders. The European Journal of Psychology Applied to Legal Context, 9(2), 65-73. https://doi.org/10.1016/j.ejpal.2017.01.001

234. Lo, Q. (2007). The relationship of self-compassion and self-esteem to empathy, shame, and social functioning in adolescents who offend sexually [Unpublished doctoral dissertation]. University of Toronto.

235. Lockwood, P. L., Bird, G., Bridge, M., \& Viding, E. (2013). Dissecting empathy: High levels of psychopathic and autistic traits are characterized by difficulties in different social information processing domains. Frontiers in Human Neuroscience, 7, 760. https://doi.org/10.3389/fnhum.2013.00760

236. Lonigro, A., Laghi, F., Baiocco, R., \& Baumgartner, E. (2014). Mind reading skills and empathy: Evidence for nice and nasty ToM behaviours in school-aged children. Journal of Child and Family Studies, 23(3), 581-590. https://doi.org/10.1007/s10826-013-9722-5

237. López-Romero, L., Cutrín, O., Maneiro, L., Domínguez-Álvarez, B., \& Romero, E. (2021). Psychopathic Traits in Childhood: Insights from Parental Warmth and Fearless 
Temperament via Conscience Development. Brain Sciences, 11(7), 923. https://doi.org/10.3390/brainsci11070923

238. López-Romero, L., Gómez-Fraguela, J. A., \& Romero, E. (2015). Assessing callousunemotional traits in a Spanish sample of institutionalized youths: The Inventory of Callous-Unemotional traits. Journal of Psychopathology and Behavioral Assessment, 37(3), 392-406. https://doi.org/10.1007/s10862-014-9469-3

239. Lopez-Romero, L., Romero, E., \& Andershed, H. (2015). Conduct problems in childhood and adolescence: Developmental trajectories, predictors and outcomes in a six-year follow up. Child Psychiatry \& Human Development, 46(5), 762-773. https://doi.org/10.1007/s10578-014-0518-7

240. Loureiro, R. J., Kataoka, F. T., Viola, T. W., Vargas, G. I., Sanvicente-Vieira, B., GrassiOliveira, R., \& Kluwe-Schiavon, B. (2021). Decision-making under risk and theory of mind in adolescent offenders in provisional deprivation of liberty. Trends in Psychiatry and Psychotherapy. https://doi.org/10.47626/2237-6089-2020-0155

241. Lowicki, P., \& Zajenkowski, M. (2017). No empathy for people nor for god: The relationship between the Dark Triad, religiosity and empathy. Personality and Individual Differences, 115, 169-173. https://doi.org/10.1016/j.paid.2016.02.012

242. Luengo, M. A., Otero, J. M., Carrillodelapena, M. T., \& Miron, L. (1994). Dimensions of antisocial-behavior in juvenile-delinquency: A study of personality variables. Psychology, Crime \& Law, 1(1), 27-37. https://doi.org/10.1080/10683169408411934

243. Lui, J. H. L., Barry, C. T., \& Marcus, D. K. (2019). A short-term intervention for adolescents with callous-unemotional traits and emotion-processing deficits. Journal of Social \& Clinical Psychology, 38(6), 475-500. https://doi.org/10.1521/jscp.2019.38.6.475 
244. Lui, J. H. L., Barry, C. T., \& Sacco, D. F. (2016). Callous-unemotional traits and empathy deficits: Mediating effects of affective perspective-taking and facial emotion recognition. Cognition and $\quad$ Emotion, $\quad 30(6), \quad 1049-1062$. https://doi.org/10.1080/02699931.2015.1047327

245. Lunn, J., Lewis, C., \& Sherlock, C. (2015). Impaired performance on advanced theory of mind tasks in children with epilepsy is related to poor communication and increased attention problems. Epilepsy \& Behavior, 43, 109-116. $\underline{\text { https://doi.org/10.1016/j.yebeh.2014.11.010 }}$

246. Ma, C., Ma, Y., Wang, Y., \& Lan, X. (2019). Empathy and psychosocial adjustment in Tibetan and han adolescents: A person-centered approach. Frontiers in Psychology, 10, 113. https://doi.org/10.3389/fpsyg.2019.01896

247. Maheux-Caron, V., Gamache, D., Sellbom, M., Christian, E., Lussier, Y., \& Savard, C. (2020). French adaptation and validation of the expanded version of the three-factor Levenson Self-Report Psychopathy scale. Assessment, 27(7), 1448-1462. $\underline{\text { https://doi.org/10.1177/1073191118811607 }}$

248. Mahmut, M. K., \& Stevenson, R. J. (2012). Olfactory abilities and psychopathy: Higher psychopathy scores are associated with poorer odor discrimination and identification. Chemosensory Perception, 5(3), 300-307. https://doi.org/10.1007/s12078-012-9135-7

249. Mahmut, M. K., \& Stevenson, R. J. (2016). Investigating left- and right-nostril olfactory abilities with respect to psychopathy. Chemosensory Perception, 9(3), 131-140. https://doi.org/10.1007/s12078-016-9210-6

250. Mahmut, M. K., Homewood, J., \& Stevenson, R. J. (2008). The characteristics of noncriminals with high psychopathy traits: Are they similar to criminal psychopaths? Journal of Research in Personality, 42(3), 679-692. https://doi.org/10.1016/j.jrp.2007.09.002 
251. Mak, A. (1987). Psychosocial control characteristics and adolescent deliquent behaviour [Unpublished master's thesis]. Australia National University.

252. Mak, A. S. (1990). Testing a psychosocial control theory of delinquency. Criminal Justice and Behavior, 17(2), 215-230. https://doi.org/10.1177/0093854890017002005

253. Mak, A. S. (1991). Psychosocial control characteristics of delinquents and nondelinquents. Criminal Justice and Behavior, 18(3), 287-303. https://doi.org/10.1177/0093854891018003003

254. Malamuth, N. M., Lamade, R. V., Koss, M. P., Lopez, E., Seaman, C., \& Prentky, R. (2021). Factors predictive of sexual violence: Testing the four pillars of the Confluence Model in a large diverse sample of college men. Aggressive Behavior, 47(4), 405-420. https://doi.org/10.1002/ab.21960

255. Malcolm-Smith, S., Woolley, D., \& Ward, C. L. (2015). Examining empathy and its association with aggression in young Western Cape children. Journal of Child and Adolescent Ment Health, 27(2), 135-147. https://doi.org/10.2989/17280583.2015.1085386

256. March, E. (2019). Psychopathy, sadism, empathy, and the motivation to cause harm: New evidence confirms malevolent nature of the Internet Troll. Personality and Individual Differences, 141, 133-137. https://doi.org/10.1016/j.paid.2019.01.001

257. Marcoux, L. A., Michon, P. E., Voisin, J. I., Lemelin, S., Vachon-Presseau, E., \& Jackson, P. L. (2013). The modulation of somatosensory resonance by psychopathic traits and empathy. Frontiers in Human Neuroscience, 7, 274. https://doi.org/10.3389/fnhum.2013.00274

258. Mariano, M., Pino, M. C., Peretti, S., Valenti, M., \& Mazza, M. (2017). Understanding criminal behavior: Empathic impairment in criminal offenders. Social Neuroscience, 12(4), 379-385. https://doi.org/10.1080/17470919.2016.1179670 
259. Marín-Morales, A., Pérez-García, M., Catena-Martínez, A., \& Verdejo-Román, J. (2021a). Emotional Regulation in Male Batterers When Faced With Pictures of Intimate Partner Violence. Do They Have a Problem With Suppressing or Experiencing Emotions? Journal of Interpersonal Violence, 088626052098548. https://doi.org/10.1177/0886260520985484

260. Marín-Morales, A., Pérez-García, M., Catena-Martínez, A., \& Verdejo-Román, J. (2021b). Lower brain volume and poorer emotional regulation in partner coercive men and other offenders. Psychology of Violence. https://doi.org/10.1037/vio0000393

261. Marinho, E. (2021). The Antisocial Heart: Empathy, Interoception and Psychopathic Traits in Children and Adolescents [Master's Dissertation, School of Health, Polytechnic Institute of Porto].

262. Marion, B. E., \& Sellbom, M. (2011). An examination of gender-moderated test Bias on the Levenson Self-Report Psychopathy scale. Journal of Personality Assessment, 93(3), 235-243. https://doi.org/10.1080/00223891.2011.558873

263. Marsh, A. A., Stoycos, S. A., Brethel-Haurwitz, K. M., Robinson, P., VanMeter, J. W., \& Cardinale, E. M. (2014). Neural and cognitive characteristics of extraordinary altruists. Proceedings of the National Academy of Sciences, 111(42), 15036-15041. https://doi.org/10.1073/pnas.1408440111

264. Marshall, W. L., \& Maric, A. (1996). Cognitive and emotional components of generalized empathy deficits in child molesters. Journal of Child Sexual Abuse, 5(2), 101-110. https://doi.org/10.1300/j070v05n02_06

265. Marshall, W. L., Jones, R., Hudson, S. M., \& McDonald, E. (1994). Generalized empathy in child molesters. Journal of Child Sexual Abuse, 2(4), 61-68. https://doi.org/10.1300/j070v02n04_04 
266. Martin, S. M., Smith, F., \& Quirk, S. W. (2016). Discriminating coercive from sadomasochistic sexuality. Archives of Sexual Behavior, 45(5), 1173-1183. https://doi.org/10.1007/s10508-015-0595-0

267. Martin-Key, N. A., Allison, G., \& Fairchild, G. (2020). Empathic accuracy in female adolescents with conduct disorder and sex differences in the relationship between conduct disorder and empathy. Journal of Abnormal Child Psychology, 48(9), 1155-1167. https://doi.org/10.1007/s10802-020-00659-y

268. Martin-Key, N., Brown, T., \& Fairchild, G. (2017). Empathic accuracy in male adolescents with conduct disorder and higher versus lower levels of callous-unemotional traits. Journal of Abnormal Child Psychology, 45(7), 1385-1397. https://doi.org/10.1007/s10802-016$\underline{0243-8}$

269. Marton, I., Wiener, J., Rogers, M., Moore, C., \& Tannock, R. (2009). Empathy and social perspective taking in children with Attention-Deficit/Hyperactivity Disorder. Journal of Abnormal Child Psychology, 37(1), 107-118. https://doi.org/10.1007/s10802-008-9262-4

270. Marzilli, E., Cerniglia, L., \& Cimino, S. (2021). Antisocial Personality Problems in Emerging Adulthood: The Role of Family Functioning, Impulsivity, and Empathy. Brain Sciences, 11(6), 687. https://doi.org/10.3390/brainsci11060687

271. Mayer, S. V., Jusyte, A., Klimecki-Lenz, O. M., \& Schonenberg, M. (2018). Empathy and altruistic behavior in antisocial violent offenders with psychopathic traits. Psychiatry Research, 269, 625-632. https://doi.org/10.1016/j.psychres.2018.08.035

272. Megreya, A. M. (2015). Emotional intelligence and criminal behavior. Journal of Forensic Sciences, 60(1), 84-88. https://doi.org/10.1111/1556-4029.12625 
273. Mercadillo, R. E., Alcauter, S., Fernandez-Ruiz, J., \& Barrios, F. A. (2015). Police culture influences the brain function underlying compassion: A gender study. Social Neuroscience, 10(2), 135-152. https://doi.org/10.1080/17470919.2014.977402

274. Metcalf, S., Dickerson, K. L., Milojevich, H. M., \& Quas, J. A. (2021). Primary and Secondary Variants of Psychopathic Traits in at-Risk Youth: Links with Maltreatment, Aggression, and Empathy. Child Psychiatry \& Human Development, 52(6), 1060-1070. https://doi.org/10.1007/s10578-020-01083-5

275. Michalska, K. J., Zeffiro, T. A., \& Decety, J. (2016). Brain response to viewing others being harmed in children with conduct disorder symptoms. Journal of Child Psychology and Psychiatry, 57(4), 510-519. https://doi.org/10.1111/jcpp.12474

276. Mier, D., Haddad, L., Diers, K., Dressing, H., Meyer-Lindenberg, A., \& Kirsch, P. (2014). Reduced embodied simulation in psychopathy. The World Journal of Biological Psychiatry, 15(6), 479-487. https://doi.org/10.3109/15622975.2014.902541

277. Miguel, F. K., Machado, G. M., Pianowski, G., \& Carvalho, L. F. (2021). Compliance with containment measures to the COVID-19 pandemic over time: Do antisocial traits matter? $\begin{array}{lllll}\text { Personality } \quad \text { and } \quad \text { Individual } & \text { Differences, } & 168, & 1-8 .\end{array}$ https://doi.org/10.1016/j.paid.2020.110346

278. Mikuskova, E. B., Belovicova, Z., Cavojova, V., Chova, L. G., Belenguer, D. M., \& Martinez, A. L. (2011, Jully 4-6). Social understanding and prosocial orientation: Analysis of classroom relationships [Conference session]. 3rd International Conference on Education and New Learning Technologies (EDULEARN), Barcelona, Spain.

279. Milojevic, S., \& Dimitrijevic, A. (2014). Empathic capacity of delinquent convicted minors. Psihologija, 47(1), 65-79. https://doi.org/10.2298/psi1401065m 
280. Milone, A., Cerniglia, L., Cristofani, C., Inguaggiato, E., Levantini, V., Masi, G., Paciello, M., Simone, F., \& Muratori, P. (2019). Empathy in youths with conduct disorder and callous-unemotional traits. Neural Plasticity, 1-8. https://doi.org/10.1155/2019/9638973

281. Mitchell, D. G. V., Avny, S. B., \& Blair, R. J. R. (2006). Divergent patterns of aggressive and neurocognitive characteristics in acquired versus developmental psychopathy. Neurocase, 12(3), 164-178. https://doi.org/10.1080/13554790600611288

282. Molenberghs, P., Bosworth, R., Nott, Z., Louis, W. R., Smith, J. R., Amiot, C. E., Vohs, K. D., \& Decety, J. (2014). The influence of group membership and individual differences in psychopathy and perspective taking on neural responses when punishing and rewarding others. Human Brain Mapping, 35(10), 4989-4999. https://doi.org/10.1002/hbm.22527

283. Monnot, M. J. (2016). Of sociopaths and empaths: The relationship between linguistic primes and trait activation with subsequent employee moral disengagement. International Journal of Psychology, 51, 768-768.

284. Monto, M., Zgourides, G., \& Harris, R. (1998). Empathy, self-Esteem, and the adolescent sexual offender. Sexual Abuse: A Journal of Research and Treatment, 10(2), 127-140. https://doi.org/10.1177/107906329801000205

285. Monto, M., Zgourides, G., Wilson, J., \& Harris, R. (1994). Empathy and adolescent male $\begin{array}{llllll}\text { sex-offenders. Perceptual and Motor } & \text { Skills, }\end{array}$ https://doi.org/10.2466/pms.1994.79.3f.1598

286. Moriarty, N., Stough, C., Tidmarsh, P., Eger, D., \& Dennison, S. (2001). Deficits in emotional intelligence underlying adolescent sex offending. Journal of Adolescence, 24(6), 743-751. https://doi.org/10.1006/jado.2001.0441

287. Morosan, L., Badoud, D., Zaharia, A., Brosch, T., Eliez, S., Bateman, A., Heller, P., \& Debbane, M. (2017). Emotion recognition and perspective taking: A comparison between 
typical and incarcerated male adolescents. PLoS One, 12(1), Article e0170646. https://doi.org/10.1371/journal.pone.0170646

288. Morosan, L., Ghisletta, P., Badoud, D., Toffel, E., Eliez, S., \& Debbane, M. (2020). Longitudinal relationships between reflective functioning, empathy, and externalizing behaviors during adolescence and young adulthood. Child Psychiatry \& Human Development, 51(1), 59-70. https://doi.org/10.1007/s10578-019-00910-8

289. Morosan, L., Heller, P., Badoud, D., Zaharia, A., Eliez, S., \& Debbane, M. (2015). Emotion recognition and perspective taking in incarcerated male adolescent offenders. European Child \& Adolescent Psychiatry, 24, S195-S196.

290. Moshagen, M., Zettler, I., \& Hilbig, B. E. (2020). Measuring the dark core of personality. Psychological Assessment, 32(2), 182-196. https://doi.org/10.1037/pas0000778

291. Moulden, H. (2008). Social competence and sexual aggression: Social intelligence, cognitive distortions, and victim empathy in men who sexually offend against children [Unpublished doctoral dissertation]. University of Ottawa.

292. Mullins-Nelson, J. L., Salekin, R. T., \& Leistico, A.-M. R. (2006). Psychopathy, empathy, and perspective-taking ability in a community sample: Implications for the successful psychopathy concept. International Journal of Forensic Mental Health, 5(2), 133-149. https://doi.org/10.1080/14999013.2006.10471238

293. Muñoz Centifanti, L. C., Stickle, T. R., Thomas, J., Falcón, A., Thomson, N. D., \& Gamer, M. (2021). Reflexive Gaze Shifts and Fear Recognition Deficits in Children with CallousUnemotional Traits and Impulsivity/Conduct Problems. Brain Sciences, 11(10), 1342. https://doi.org/10.3390/brainsci11101342 
294. Muñoz, L. C., Qualter, P., \& Padgett, G. (2010). Empathy and bullying: Exploring the influence of callous-unemotional traits. Child Psychiatry \& Human Development, 42(2), 183-196. https://doi.org/10.1007/s10578-010-0206-1

295. Muntaner, C., Walter, D., Nagoshi, C., Fishbein, D., Haertzen, C. A., \& Jaffe, J. H. (1990). Self-report vs. laboratory measures of aggression as predictors of substance abuse. Drug and Alcohol Dependence, 25(1), 1-11. https://doi.org/10.1016/0376-8716(90)90133-y

296. Murphy, B. A., Costello, T. H., Watts, A. L., Cheong, Y. F., Berg, J. M., \& Lilienfeld, S. O. (2020). Strengths and weaknesses of two empathy measures: A comparison of the measurement precision, construct validity, and incremental validity of two multidimensional indices. $\quad$ Assessment, 246-260. https://doi.org/10.1177/1073191118777636

297. Nadler, A., Camerer, C., Zava, D., Ortiz, T., Watson, N., Carré, J., \& Nave, G. (2019). Does testosterone impair men's cognitive empathy? Evidence from two large-scale randomized controlled trials. Proceedings of the Royal Society B: Biological Sciences, 286(1910), 1-9. https://doi.org/10.1098/rspb.2019.1062

298. Nagoshi, C. T., Walter, D., Muntaner, C., \& Haertzen, C. A. (1992). Validation of the tridimensional personality questionnaire in a sample of male drug-users Personality and Individual Differences, 13(4), 401-409. https://doi.org/10.1016/0191-8869(92)90067-y

299. Negy, C., Ferguson, C. J., Galvanovskis, A., \& Smither, R. (2013). Predicting violence: A cross-national study of United States and Mexican young adults Journal of Social and Clinical Psychology, 32(1), 54-70. https://doi.org/10.1521/jscp.2013.32.1.54

300. Newbury-Helps, J., Feigenbaum, J., \& Fonagy, P. (2017). Offenders with antisocial personality disorder display more impairments in mentalizing. Journal of Personality Disorders, 31(2), 232-255. https://doi.org/10.1521/pedi_2016_30_246 
301. Newton, N. C., \& Bussey, K. (2012). The age of reason: An examination of psychosocial factors involved in delinquent behaviour. Legal and Criminological Psychology, 17(1), 7588. https://doi.org/10.1111/j.2044-8333.2010.02004.x

302. Nigel, S. M., Dudeck, M., Otte, S., Knauer, K., Klein, V., Böttcher, T., Maaß, C., Vasic, N., \& Streb, J. (2018). Psychopathy, the Big Five and empathy as predictors of violence in a forensic sample of substance abusers. The Journal of Forensic Psychiatry \& Psychology, 29(6), 882-900. https://doi.org/10.1080/14789949.2018.1439993

303. Nijhof, K., te Brinke, L. W., Njardvik, U., \& Liber, J. M. (2021). The Role of Perspective Taking and Self-Control in a Preventive Intervention Targeting Childhood Disruptive Behavior. Research on Child and Adolescent Psychopathology, 49(5), 657-670. https://doi.org/10.1007/s10802-020-00761-1

304. Nilsen, E. S., \& Bacso, S. A. (2017). Cognitive and behavioural predictors of adolescents' communicative perspective-taking and social relationships. Journal of Adolescence, 56, 52-63. https://doi.org/10.1016/j.adolescence.2017.01.004

305. Nilsonne, G., Tamm, S., Golkar, A., Olsson, A., Sörman, K., Howner, K., Kristiansson, M., Ingvar, M., \& Petrovic, P. (2021). Oxazepam and cognitive reappraisal: A randomised experiment. PLOS ONE, 16(4), e0249065. https://doi.org/10.1371/journal.pone.0249065

306. Nilsonne, G., Tamm, S., Golkar, A., Sorman, K., Howner, K., Kristiansson, M., Olsson, A., Ingvar, M., \& Petrovic, P. (2017). Effects of $25 \mathrm{mg}$ oxazepam on emotional mimicry and empathy for pain: A randomized controlled experiment. Royal Society Open Science, 4(3), 1-18. https://doi.org/10.1098/rsos.160607

307. Nitschke, J., Istrefi, S., Osterheider, M., \& Mokros, A. (2012). Empathy in sexually sadistic offenders: An experimental comparison with non-sadistic sexual offenders. International Journal of Law and Psychiatry, 35(3), 165-167. https://doi.org/10.1016/j.ijlp.2012.02.003 
308. O’Kearney, R., Chng, R. Y., \& Salmon, K. (2020). Callous-unemotional features are associated with emotion recognition impairments in young ODD children with low but not high affective arousal. Child Psychiatry \& Human Development. https://doi.org/10.1007/s10578-020-01070-w

309. O’Kearney, R., Salmon, K., Liwag, M., Fortune, C.-A., \& Dawel, A. (2016). Emotional abilities in children with Oppositional Defiant Disorder (ODD): Impairments in perspective-taking and understanding mixed emotions are associated with high callousunemotional traits. Child Psychiatry \& Human Development, 48(2), 346-357. https://doi.org/10.1007/s10578-016-0645-4

310. O’Nions, E., Sebastian, C. L., McCrory, E., Chantiluke, K., Happé, F., \& Viding, E. (2014). Neural bases of theory of mind in children with autism spectrum disorders and children with conduct problems and callous-unemotional traits. Developmental Science, 17(5), 786796. https://doi.org/10.1111/desc.12167

311. Oberle, E., Schonert-Reichl, K. A., \& Thomson, K. C. (2009). Understanding the link between social and emotional well-being and peer relations in early adolescence: Genderspecific predictors of peer acceptance. Journal of Youth and Adolescence, 39(11), 13301342. https://doi.org/10.1007/s10964-009-9486-9

312. Offermans, J. E., Duindam, H. M., Asscher, J. J., Stams, G. J. J., \& Creemers, H. E. (2020). Brief report: The effectiveness of Dutch Cell Dogs: A multiple case experimental study. Clinical Child Psychology and Psychiatry, 25(4), 1015-1021. https://doi.org/10.1177/1359104520940744

313. O'Halloran, M., Carr, A., O'Reilly, G., Sheerin, D., Cherry, J., Turner, R., Beckett, R., \& Brown, S. (2002). Psychological profiles of sexually abusive adolescents in Ireland. Child Abuse Neglect, 26(4), 349-370. https://doi.org/10.1016/s0145-2134(02)00313-7 
314. Olate, R., Salas-Wright, C. P., Vaughn, M. G., \& Yu, M. (2015). Preventing violence among gang-involved and high-risk youth in El Salvador: The role of school motivation $\begin{array}{llll}\text { and } & \text { self-control. } & \text { Deviant }\end{array}$ https://doi.org/10.1080/01639625.2014.924364

315. Oliver, L. D., Neufeld, R. W. J., Dziobek, I., \& Mitchell, D. G. V. (2016). Distinguishing the relationship between different aspects of empathic responding as a function of psychopathic, autistic, and anxious traits. Personality and Individual Differences, 99, 8188. https://doi.org/10.1016/j.paid.2016.04.058

316. Olson, S. L., Choe, D. E., \& Sameroff, A. J. (2017). Trajectories of child externalizing problems between ages 3 and 10 years: Contributions of children's early effortful control, theory of mind, and parenting experiences. Development and Psychopathology, 29(4), 1333-1351. https://doi.org/10.1017/s095457941700030x

317. Ortiz Baron, M. J., Etxebarria Bilbao, I., Apodaca Urquijo, P., Conejero Lopez, S., \& Pascual Jimeno, A. (2018). Moral emotions associated with prosocial and antisocial behavior in school-aged children. Psicothema, 30(1), 82-88. https://doi.org/10.7334/psicothema2016.143

318. Owens, E. S., McPharlin, F. W. H., Brooks, N., \& Fritzon, K. (2017). The effects of empathy, emotional intelligence and psychopathy on interpersonal interactions. Psychiatry, Psychology and Law, 25(1), 1-18. https://doi.org/10.1080/13218719.2017.1347936

319. Padilla-Walker, L. M., Christensen, K. J., \& Day, R. D. (2011). Proactive parenting practices during early adolescence: A cluster approach. Journal of Adolescence, 34(2), 203-214. https://doi.org/10.1016/j.adolescence.2010.05.008

320. Paiva, T. O., Almeida, P. R., Coelho, R. C., Pasion, R., Barbosa, F., Ferreira-Santos, F., Bastos-Leite, A., \& Marques-Teixeira, J. (2020). The neurophysiological correlates of the 
triarchic model of psychopathy: An approach to the basic mechanisms of threat

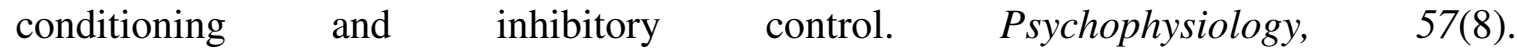
https://doi.org/10.1111/psyp.13567

321. Paiva, T. O., Pasion, R., Patrick, C. J., Moreira, D., Almeida, P. R., \& Barbosa, F. (2020). Further evaluation of the Triarchic Psychopathy Measure: Evidence from community adult and prisoner samples from Portugal. Psychological Assessment, 32(3), e1-e14. https://doi.org/10.1037/pas0000797

322. Pajevic, M., Vukosavljevic-Gvozden, T., Stevanovic, N., \& Neumann, C. S. (2018). The relationship between the Dark Tetrad and a two-dimensional view of empathy. Personality and Individual Differences, 123, 125-130. https://doi.org/10.1016/j.paid.2017.11.009

323. Pal, P., Mahour, P., Arya, A., \& Agrawal, V. (2021). A study on Theory of Mind among adolescents with Oppositional Defiant Disorder. Journal of Indian Association for Child and Adolescent Mental Health - ISSN 0973-1342, 17(4), 115-132.

324. Palucka, A. (1997). Relationships of moral judgement, emotional empathy and impulsivity to criminal behaviour in young and adult offenders [Unpublished doctoral dissertation]. University of Toronto.

325. Palucka, A., \& Nussbaum, D. (1995). The relationship between moral development, empathy, impulsivity and criminal behavior in young and adult offenders. Canadian Psychology-Psychologie Canadienne, 36(2), 20-20.

326. Pardini, D. A., \& Byrd, A. L. (2012). Perceptions of aggressive conflicts and others' distress in children with callous-unemotional traits: 'I'll show you who's boss, even if you suffer and I get in trouble'. Journal of Child Psychology and Psychiatry, 53(3), 283-291. https://doi.org/10.1111/j.1469-7610.2011.02487.x 
327. Pasalich, D. S., Dadds, M. R., \& Hawes, D. J. (2014). Cognitive and affective empathy in children with conduct problems: Additive and interactive effects of callous-unemotional traits and autism spectrum disorders symptoms. Psychiatry Research, 219(3), 625-630. https://doi.org/10.1016/j.psychres.2014.06.025

328. Paz, Y., Orlitsky, T., Roth-Hanania, R., Zahn-Waxler, C., \& Davidov, M. (2020). Predicting externalizing behavior in toddlerhood from early individual differences in empathy. Journal of Child Psychology and Psychiatry. https://doi.org/10.1111/jcpp.13247

329. Pechorro, P., Ayala-Nunes, L., Kahn, R., \& Nunes, C. (2018). The Reactive-Proactive Aggression Questionnaire: Measurement invariance and reliability among a school sample of Portuguese youths. Child Psychiatry \& Human Development, 49(4), 523-533. https://doi.org/10.1007/s10578-017-0772-6

330. Pechorro, P., Ayala-Nunes, L., Nunes, C., Marôco, J., Gonçalves, R., Marôco, J., \& Gonçalves, R. A. (2016). The Social Anxiety Scale for adolescents: Measurement invariance and psychometric properties among a school sample of portuguese youths. Child Psychiatry \& Human Development, 47(6), 975-984. https://doi.org/10.1007/s10578-0160627-6

331. Pechorro, P., Ayala-Nunes, L., Oliveira, J. P., Nunes, C., \& Goncalves, R. A. (2016). Psychometric properties of the socially desirable response set-5 among incarcerated male and female juvenile offenders. International Journal of Law and Psychiatry, 49, 17-21. https://doi.org/10.1016/j.ijlp.2016.05.003

332. Pechorro, P., da Silva, D. R., Rijo, D., Goncalves, R. A., \& Andershed, H. (2017). Psychometric properties and measurement invariance of the youth Psychopathic Traits Inventory - short version among Portuguese youth. Journal of Psychopathology and Behavioral Assessment, 39(3), 486-497. https://doi.org/10.1007/s10862-017-9597-7 
333. Pechorro, P., DeLisi, M., Andrade, J., Gonçalves, R. A., \& Quintas, J. (2021). Primary and Secondary Variants of Psychopathy in Incarcerated Youth: An Investigation with a Focus on Social Anxiety. Deviant Behavior, 1-13. https://doi.org/10.1080/01639625.2021.1925603

334. Pechorro, P., Goncalves, R. A., Andershed, H., \& DeLisi, M. (2017). Female psychopathic traits in forensic and school context: Comparing the Antisocial Process Screening Device self-report and the Youth Psychopathic traits Inventory-Short. Journal of Psychopathology and Behavioral Assessment, 39(4), 642-656. https://doi.org/10.1007/s10862-017-9605-y

335. Pechorro, P., Hawes, S. W., Goncalves, R. A., \& Ray, J. V. (2017). Psychometric properties of the Inventory of Callous-Unemotional traits short version (ICU-12) among detained female juvenile offenders and community youths. Psychology, Crime \& Law, 23(3), 221239. https://doi.org/10.1080/1068316x.2016.1239724

336. Pechorro, P., Hidalgo, V., Nunes, C., \& Jimenez, L. (2016). Confirmatory factor analysis of the Antisocial Process Screening device. International Journal of Offender Therapy and Comparative Criminology, 60(16), 1856-1872. https://doi.org/10.1177/0306624X15588903

337. Pechorro, P., Kahn, R. E., Abrunhosa Goncalves, R., \& Ray, J. V. (2017). Psychometric properties of Basic Empathy Scale among female juvenile delinquents and school youths. International Journal of Law and Psychiatry, 55, 29-36. https://doi.org/10.1016/j.ijlp.2017.10.008

338. Pechorro, P., Kahn, R. E., Ray, J. V., Raine, A., \& Goncalves, R. A. (2017). Psychometric properties of the Reactive-Proactive Aggression Questionnaire among a sample of detained and community girls. Criminal Justice and Behavior, 44(4), 531-550. https://doi.org/10.1177/0093854816686395 
339. Pechorro, P., Ray, J. V., Goncalves, R. A., \& Jesus, S. N. (2017). The Inventory of CallousUnemotional traits: Psychometric properties among referred and non-referred Portuguese female juveniles. International Journal of Law and Psychiatry, 54, 67-75. https://doi.org/10.1016/j.ijlp.2017.05.002

340. Pechorro, P., Ray, J. V., Raine, A., Maroco, J., \& Goncalves, R. A. (2017). The ReactiveProactive Aggression Questionnaire: Validation among a Portuguese sample of incarcerated juvenile delinquents. Journal of Interpersonal Violence, 32(13), 1995-2017. https://doi.org/10.1177/0886260515590784

341. Pechorro, P., Ray, J. V., Salas-Wright, C. P., Maroco, J., \& Goncalves, R. A. (2015). Adaptation of the Basic Empathy Scale among a Portuguese sample of incarcerated juvenile offenders. Psychology, Crime \& Law, 21(7), 699-714. https://doi.org/10.1080/1068316x.2015.1028546

342. Pechorro, P., Ribeiro da Silva, D., Andershed, H., Rijo, D., \& Abrunhosa Goncalves, R. (2016). The Youth Psychopathic traits Inventory: Measurement invariance and psychometric properties among Portuguese youths. International Journal of Environmental Research and Public Health, 13(9), 852. https://doi.org/10.3390/ijerph13090852

343. Pechorro, P., Seto, M. C., Alberto, I., Ray, J. V., \& Simões, M. R. (2019). The childhood and adolescent taxon scale - self-report: Validity among male and female youths from forensic and school contexts. International Journal of Forensic Mental Health, 19(1), 3343. https://doi.org/10.1080/14999013.2019.1623349

344. Pechorro, P., Simoes, M. R., Alberto, I., \& Ray, J. V. (2018). Triarchic model of psychopathy: A brief measure among detained female youths. Deviant Behavior, 39(11), 1497-1506. https://doi.org/10.1080/01639625.2018.1487171 
345. Peltola, M. J., Yrttiaho, S., \& Leppanen, J. M. (2018). Infants' attention bias to faces as an early marker of social development. Developmental Science, 21(6), Article e12687. https://doi.org/10.1111/desc.12687

346. Petrides, K. V., Vernon, P. A., Schermer, J. A., \& Veselka, L. (2011). Trait emotional intelligence and the Dark Triad traits of personality. Twin Research and Human Genetics, 14(1), 35-41. https://doi.org/10.1375/twin.14.1.35

347. Pfabigan, D. M., Seidel, E. M., Wucherer, A. M., Keckeis, K., Derntl, B., \& Lamm, C. (2015). Affective empathy differs in male violent offenders with high- and low-trait psychopathy. Journal of Personality Disorders 29(1), 42-61. https://doi.org/10.1521/pedi_2014_28_145

348. Pickett, L. (2006). Trait versus state empathy: Evaluating the stability of empathy and the relationship between negative affect and empathy in an incarcerated sex offender (Publication No. 3255336) [Doctoral dissertation, Central Michigan University]. ProQuest Information and Learning Company.

349. Pijper, J., de Wied, M., van Rijn, S., van Goozen, S., Swaab, H., \& Meeus, W. (2016). Callous unemotional traits, autism spectrum disorder symptoms and empathy in boys with Oppositional Defiant Disorder or conduct disorder. Psychiatry Research, 245, 340-345. https://doi.org/10.1016/j.psychres.2016.08.053

350. Pijper, J., de Wied, M., van Rijn, S., van Goozen, S., Swaab, H., \& Meeus, W. (2018). Executive attention and empathy-related responses in boys with Oppositional Defiant Disorder or conduct disorder, with and without comorbid anxiety disorder. Child Psychiatry \& Human Development, 49(6), 956-965. https://doi.org/10.1007/s10578-018$\underline{0810-\mathrm{z}}$ 
351. Posick, C., Rocque, M., \& Rafter, N. (2014). More than a feeling: Integrating empathy into the study of lawmaking, lawbreaking, and reactions to lawbreaking. International Journal of Offender Therapy and Comparative Criminology, 58(1), 5-26. https://doi.org/10.1177/0306624x12465411

352. Prata, C., Pasion, R., Fernandes, M., Almeida, R., Pereira, M. R., Mazer, P., \& Barbosa, F. (2019). Callousness and meanness traits are associated with increased N2 amplitude in a community sample of adolescents and adults. Neuroscience Letters, 706, 1-6. https://doi.org/10.1016/j.neulet.2019.04.056

353. Preller, K. H., Hulka, L. M., Vonmoos, M., Jenni, D., Baumgartner, M. R., Seifritz, E., Dziobek, I., \& Quednow, B. B. (2014). Impaired emotional empathy and related social network deficits in cocaine users. Addiction Biology, 19(3), 452-466. https://doi.org/10.1111/adb.12070

354. Preston, O. C., \& Anestis, J. C. (2018). Psychopathic traits and politics: Examining affiliation, support of political issues, and the role of empathy. Personality and Individual Differences, 131, 142-148. https://doi.org/10.1016/j.paid.2018.04.034

355. Puthillam, A., Karandikar, S., \& Kapoor, H. (2021). I see how you feel: How the dark triad recognizes emotions. Current Psychology, 40(8), 3966-3973. https://doi.org/10.1007/s12144-019-00359-x

356. Quednow, B. B., Hulka, L. M., Preller, K. H., Baumgartner, M. R., Eisenegger, C., \& Vonmoos, M. (2017). Stable self-serving personality traits in recreational and dependent cocaine users. PLoS One, 12(3), Article e0172853. https://doi.org/10.1371/journal.pone.0172853 
357. Ragbeer, S. (2015). A Developmental psychopathology perspective on psychopathic traits in girls: The role of maltreatment, maternal responsiveness and emotional functioning [Unpublished doctoral dissertation]. University of Rochester.

358. Raine, A., Chen, F. R., \& Waller, R. (2022). The cognitive, affective and somatic empathy scales for adults. Personality and Individual Differences, 185, 111238. https://doi.org/10.1016/j.paid.2021.111238

359. Randall, P., Carr, A., Dooley, B., \& Rooney, B. (2011). Psychological characteristics of Irish clerical sexual offenders. The Irish Journal of Psychology, 32(1-2), 4-13. https://doi.org/10.1080/03033910.2011.610191

360. Reniers, R. L., Corcoran, R., Drake, R., Shryane, N. M., \& Vollm, B. A. (2011). The QCAE: A Questionnaire of Cognitive and Affective Empathy. Journal of Personality Assessment, 93(1), 84-95. https://doi.org/10.1080/00223891.2010.528484

361. Reniers, R. L., Corcoran, R., Vollm, B. A., Mashru, A., Howard, R., \& Liddle, P. F. (2012). Moral decision-making, ToM, empathy and the default mode network. Biological Psychology, 90(3), 202-210. https://doi.org/10.1016/j.biopsycho.2012.03.009

362. Reynolds, C. J., \& Conway, P. (2018). Not just bad actions: Affective concern for bad outcomes contributes to moral condemnation of harm in moral dilemmas. Emotion, 18(7), 1009-1023. https://doi.org/10.1037/emo0000413

363. Rhee, S. H., Friedman, N. P., Boeldt, D. L., Corley, R. P., Hewitt, J. K., Knafo, A., Lahey, B. B., Robinson, J., Van Hulle, C. A., Waldman, I. D., Young, S. E., \& Zahn-Waxler, C. (2013). Early concern and disregard for others as predictors of antisocial behavior. Journal of Child Psychology and Psychiatry, 54(2), 157-166. https://doi.org/10.1111/j.1469$\underline{7610.2012 .02574 . x}$ 
364. Rhee, S. H., Friedman, N. P., Corley, R. P., Hewitt, J. K., Hink, L. K., Johnson, D. P., Smith Watts, A. K., Young, S. E., Robinson, J. Waldman, I. D., \& Zahn-Waxler, C. (2016). An examination of the developmental propensity model of conduct problems. Journal of Abnormal Psychology, 125(4), 550-564. https://doi.org/10.1037/abn0000128

365. Rhee. S, H., Woodward, K., Corley, R.P., du Pont, A., Friedman, N.P., Hewitt, J.K., Hink, L.K., Robinson, J., \& Zahn-Waxler C. (2020). The association between toddlerhood empathy deficits and antisocial personality disorder symptoms and psychopathy in adulthood. Development and Psychopathology, 1-11. https://doi.org/10.1017/s0954579419001676

366. Richell, R. A., Mitchell, D. G. V., Newman, C., Leonard, A., Baron-Cohen, S., \& Blair, R. J. R. (2003). Theory of mind and psychopathy: Can psychopathic individuals read the 'language of the eyes'? Neuropsychologia, 41(5), 523-526. https://doi.org/10.1016/s0028$\underline{3932(02) 00175-6}$

367. Roberts, R., McCrory, E., Bird, G., Sharp, M., Roberts, L., \& Viding, E. (2020). Thinking about others' minds: Mental state inference in boys with conduct problems and callousunemotional traits. Journal of Abnormal Child Psychology, 48(10), 1279-1290. https://doi.org/10.1007/s10802-020-00664-1

368. Robinson, E. V., \& Rogers, R. (2015). Empathy faking in psychopathic offenders: The vulnerability of empathy measures. Journal of Psychopathology and Behavioral Assessment, 37(4), 545-552. https://doi.org/10.1007/s10862-015-9479-9

369. Romero-Martinez, A., Lila, M., \& Moya-Albiol, L. (2016). Empathy impairments in intimate partner violence perpetrators with antisocial and borderline traits: A key factor in the risk of recidivism. Violence and Victims 31(2), 347-360. https://doi.org/10.1891/08866708.VV-D-14-00149 
370. Romero-Martinez, A., Lila, M., Sarinana-Gonzalez, P., Gonzalez-Bono, E., \& MoyaAlbiol, L. (2013). High testosterone levels and sensitivity to acute stress in perpetrators of domestic violence with low cognitive flexibility and impairments in their emotional decoding process: A preliminary study. Aggressive Behavior, 39(5), 355-369. $\underline{\text { https://doi.org/10.1002/ab.21490 }}$

371. Roose, A. a. B., P. and Decoene, S. and Claes, L. and Frick, P. J. (2009). Assessing the affective features of psychopathy in adolescence: A further validation of the Inventory of Callous and Unemotional traits. Assessment, 17(1), 44-57. https://doi.org/10.1177/1073191109344153

372. Rosas, A., Viciana, H., Caviedes, E., \& Arciniegas, A. (2019). Hot utilitarianism and cold deontology: Insights from a response patterns approach to sacrificial and real world dilemmas. $\quad$ Social $\quad$ Neuroscience, $\quad 14(2), \quad 125-135$. https://doi.org/10.1080/17470919.2018.1464945

373. Sakai, J. T., Dalwani, M. S., Mikulich-Gilbertson, S. K., Raymond, K., McWilliams, S., Tanabe, J., Rojas, D., Regner, M., Banich, M. T., \& Crowley, T. J. (2017). Imaging decision about whether to benefit self by harming others: Adolescents with conduct and substance problems, with or without callous-unemotionality, or developing typically. Psychiatry Research: Neuroimaging, 263, 103-112. https://doi.org/10.1016/j.pscychresns.2017.03.004

374. Salekin, R. T., Chen, D. R., Sellbom, M., Lester, W. S., \& MacDougall, E. (2014). Examining the factor structure and convergent and discriminant validity of the Levenson Self-Report Psychopathy scale: Is the two-factor model the best fitting model? Personality Disorders: Theory, Research, and Treatment, 5(3), 289-304. https://doi.org/10.1037/per0000073 
375. Samper, P., Llorca, A., Malonda, E., \& Mestre, M. V. (2021). Examining the predictors of prosocial behavior in young offenders and nonoffenders. International Journal of Behavioral Development, 45(4), 299-309. https://doi.org/10.1177/0165025421995930

376. Sandoval, A.-M. R., Hancock, D., Poythress, N., Edens, J. F., \& Lilienfeld, S. (2000). Construct validity of the Psychopathic Personality Inventory in a correctional sample. Journal of Personality Assessment, 74(2), 262-281. https://doi.org/10.1207/s15327752jpa7402_7

377. Sandvik, A. M., Hansen, A. L., Johnsen, B. H., \& Laberg, J. C. (2014). Psychopathy and the ability to read the "language of the eyes": Divergence in the psychopathy construct. Scandinavian Journal of Psychology, 55(6), 585-592. https://doi.org/10.1111/sjop.12138

378. Satlof-Bedrick, E., Waller, R., \& Olson, S. L. (2019). Emotion versus cognition: Differential pathways to theory of mind for children with high versus low callousunemotional traits. Journal of Child Psychology and Psychiatry, 60(12), 1300-1308. https://doi.org/10.1111/jepp.13078

379. Schade, E. C., Voracek, M., \& Tran, U. S. (2021). The Nexus of the Dark Triad Personality Traits With Cyberbullying, Empathy, and Emotional Intelligence: A Structural-Equation Modeling Approach. Frontiers in Psychology, 12, 659282. https://doi.org/10.3389/fpsyg.2021.659282

380. Schaffer, M., Clark, S., \& Jeglic, E. L. (2009). The role of empathy and parenting style in the development of antisocial behaviors. Crime \& Delinquency, 55(4), 586-599. https://doi.org/10.1177/0011128708321359

381. Schalkwijk, F., Stams, G. J., Dekker, J., Peen, J., \& Elison, J. (2016). Measuring shame regulation: Validation of the compass of shame scale Social Behavior and Personality: An International Journal 44(11), 1775-1791. https://doi.org/10.2224/sbp.2016.44.11.1775 
382. Schalkwijk, F., Stams, G. J., Stegge, H., Dekker, J., \& Peen, J. (2016). The conscience as a regulatory function: Empathy, shame, pride, guilt, and moral orientation in delinquent adolescents. International Journal of Offender Therapy and Comparative Criminology, 60(6), 675-693. https://doi.org/10.1177/0306624x14561830

383. Schiffer, B., Pawliczek, C., Muller, B. W., Wiltfang, J., Brune, M., Forsting, M., Gizewski, E. R., Leygraf, N., \& Hodgins, S. (2017). Neural mechanisms underlying affective theory of mind in violent antisocial personality disorder and/or schizophrenia. Schizophrenia Bulletin, 43(6), 1229-1239. https://doi.org/10.1093/schbul/sbx012

384. Schimmenti, A., Jonason, P. K., Passanisi, A., La Marca, L., Di Dio, N., \& Gervasi, A. M. (2019). Exploring the dark side of personality: Emotional awareness, empathy, and the Dark Triad traits in an Italian sample. Current Psychology, 38(1), 100-109. https://doi.org/10.1007/s12144-017-9588-6

385. Schmits, E., \& Glowacz, F. (2019). Delinquency and drug use among adolescents and emerging adults: The role of aggression, impulsivity, empathy, and cognitive distortions. Journal of Substance Use, 24(2), 162-169. https://doi.org/10.1080/14659891.2018.1531945

386. Schoeps, K., Monaco, E., Cotoli, A., \& Montoya-Castilla, I. (2020). The impact of peer attachment on prosocial behavior, emotional difficulties and conduct problems in adolescence: The mediating role of empathy. PLoS One, 15(1), Article e0227627. https://doi.org/10.1371/journal.pone.0227627

387. Schuberth, D. A., Zheng, Y., Pasalich, D. S., McMahon, R. J., Kamboukos, D., DawsonMcClure, S., \& Brotman, L. M. (2019). The role of emotion understanding in the development of aggression and callous-unemotional features across early childhood. 
Journal of Abnormal Child Psychology, 47(4), 619-631. https://doi.org/10.1007/s10802-

\section{$\underline{018-0468-9}$}

388. Schuler, M., Mohnke, S., Amelung, T., Dziobek, I., Lemme, B., Borchardt, V., Gerwinn, H., Kargel, C., Kneer, J., Massau, C., Pohl, A., Tenbergen, G., Weiss, S., Wittfoth, M., Waller, L., Beier, K. M., Walter, M., Ponseti, J., Schiffer, B., ... Walter, H. (2019). Empathy in pedophilia and sexual offending against children: A multifaceted approach. Journal of Abnormal Child Psychology, 128(5), 453-464. https://doi.org/10.1037/abn0000412

389. Schwenck, C., Ciaramidaro, A., Selivanova, M., Tournay, J., Freitag, C. M., \& Siniatchkin, M. (2017). Neural correlates of affective empathy and reinforcement learning in boys with conduct problems: fMRI evidence from a gambling task. Behavioural Brain Research, 320, 75-84. https://doi.org/10.1016/j.bbr.2016.11.037

390. Schwenck, C., Mergenthaler, J., Keller, K., Zech, J., Salehi, S., Taurines, R., Romanos, M., Schecklmann, M., Schneider, W., Warnke, A., \& Freitag, C. M. (2012). Empathy in children with autism and conduct disorder: Group-specific profiles and developmental aspects. Journal of Child Psychology and Psychiatry, 53(6), 651-659. https://doi.org/10.1111/j.1469-7610.2011.02499.x

391. Seara-Cardoso, A., Dolberg, H., Neumann, C., Roiser, J. P., \& Viding, E. (2013). Empathy, morality and psychopathic traits in women. Personality and Individual Differences, 55(3), 328-333. https://doi.org/10.1016/j.paid.2013.03.011

392. Seara-Cardoso, A., Neumann, C., Roiser, J., McCrory, E., \& Viding, E. (2012). Investigating associations between empathy, morality and psychopathic personality traits in the general population. Personality and Individual Differences, 52(1), 67-71. https://doi.org/10.1016/j.paid.2011.08.029 
393. Seara-Cardoso, A., Queiros, A., Fernandes, E., Coutinho, J., \& Neumann, C. (2020). Psychometric properties and construct validity of the short version of the Self-Report Psychopathy Scale in a Southern European sample. Journal of Personality Assessment, 102(4), 457-468. https://doi.org/10.1080/00223891.2019.1617297

394. Seara-Cardoso, A., Sebastian, C. L., Viding, E., \& Roiser, J. P. (2015). Affective resonance in response to others' emotional faces varies with affective ratings and psychopathic traits in amygdala and anterior insula. Social Neuroscience, 11(2), 140-152. https://doi.org/10.1080/17470919.2015.1044672

395. Sebastian, C. L., McCrory, E. J., Cecil, C. A., Lockwood, P. L., De Brito, S. A., Fontaine, N. M., \& Viding, E. (2012). Neural responses to affective and cognitive theory of mind in children with conduct problems and varying levels of callous-unemotional traits. Archives $\begin{array}{lll}\text { of General } & \text { Psychiatry, } & \text { 69(8), }\end{array}$ https://doi.org/10.1001/archgenpsychiatry.2011.2070

396. Seidel, E. M., Pfabigan, D. M., Keckeis, K., Wucherer, A. M., Jahn, T., Lamm, C., \& Derntl, B. (2013). Empathic competencies in violent offenders. Psychiatry Research, 210(3), 1168-1175. https://doi.org/10.1016/j.psychres.2013.08.027

397. Seinfeld, S., Arroyo-Palacios, J., Iruretagoyena, G., Hortensius, R., Zapata, L. E., Borland, D., de Gelder, B., Slater, M., \& Sanchez-Vives, M. V. (2018). Offenders become the victim in virtual reality: Impact of changing perspective in domestic violence. Scientific Reports, 8(1), 1-11. https://doi.org/10.1038/s41598-018-19987-7

398. Seivert, N. P., Cano, A., Casey, R. J., May, D. K., \& Johnson, A. (2018). Animal assisted therapy for incarcerated youth: A randomized controlled trial. Applied Developmental Science, 22(2), 139-153. https://doi.org/10.1080/10888691.2016.1234935 
399. Sellbom, M. (2011). Elaborating on the construct validity of the Levenson Self-Report Psychopathy scale in incarcerated and non-incarcerated samples. Law and Human Behavior, 35(6), 440-451. https://doi.org/10.1007/s10979-010-9249-X

400. Sellbom, M., \& Phillips, T. R. (2013). An examination of the triarchic conceptualization of psychopathy in incarcerated and nonincarcerated samples. Journal of Abnormal Child Psychology, 122(1), 208-214. https://doi.org/10.1037/a0029306

401. Sest, N., \& March, E. (2017). Constructing the cyber-troll: Psychopathy, sadism, and empathy. Personality and Individual Differences, 119, 69-72. https://doi.org/10.1016/j.paid.2017.06.038

402. Sethi, A., O'Nions, E., McCrory, E., Bird, G., \& Viding, E. (2018). An fMRI investigation of empathic processing in boys with conduct problems and varying levels of callousunemotional traits. $\quad$ Neuroimage $\quad$ Clinical, $\quad 18, \quad 298-304$. https://doi.org/10.1016/j.nicl.2018.01.027

403. Seto, M. C., \& Barbaree, H. E. (1988). Victim blame and sexual arousal to rape cues in rapists and nonoffenders. Annals of Sex Research, 6(3), 167-183. https://doi.org/10.1007/bf00849559

404. Shamay-Tsoory, S. G., Harari, H., Aharon-Peretz, J., \& Levkovitz, Y. (2010). The role of the orbitofrontal cortex in affective theory of mind deficits in criminal offenders with psychopathic tendencies. $\quad$ Cortex, $\quad$ 46(5), 668-677. $\underline{\text { https://doi.org/10.1016/j.cortex.2009.04.008 }}$

405. Sharan, T., \& Good, D. (2012). Empathic differences in individuals with sub-clinical psychopathy and mild head injury. Journal of Head Trauma Rehabilitation 27(5), E37E38. 
406. Sharp, C. (2008). Theory of mind and conduct problems in children: Deficits in reading the "emotions of the eyes". Cognition \& Emotion, 22(6), 1149-1158. https://doi.org/10.1080/02699930701667586

407. Sharp, C., \& Vanwoerden, S. (2014). Social cognition: Empirical contribution: The developmental building blocks of psychopathic traits: Revisiting the role of theory of mind Journal of Personality Disorders, 28(1), 78--95. https://doi.org/10.1521/pedi.2014.28.1.78

408. Siu, A. M. H., Shek, D. T. L., \& Lai, F. H. Y. (2012). Predictors of prosocial behavior among Chinese high school students in Hong Kong. The Scientific World Journal, 1-7. https://doi.org/10.1100/2012/489156

409. Sommer, M., Sodian, B., Dohnel, K., Schwerdtner, J., Meinhardt, J., \& Hajak, G. (2010). In psychopathic patients emotion attribution modulates activity in outcome-related brain areas. Psychiatry Research, $\quad$ 182(2), https://doi.org/10.1016/j.pscychresns.2010.01.007

410. Song, J. H., Waller, R., Hyde, L. W., \& Olson, S. L. (2016). Early callous-unemotional behavior, theory-of-mind, and a fearful/inhibited temperament predict externalizing problems in middle and late childhood. Journal of Abnormal Child Psychology, 44(6), 1205-1215. https://doi.org/10.1007/s10802-015-0099-3

411. Sorman, K., Nilsonne, G., Howner, K., Tamm, S., Caman, S., Wang, H. X., Ingvar, M., Edens, J., Gustavsson, P., Lilienfeld, S., Petrovic, P., Fischer, H., \& Kristiansson, M. (2016). Reliability and construct validity of the Psychopathic Personality InventoryRevised in a Swedish non-criminal sample - A multimethod approach including psychophysiological correlates of empathy for pain. PLoS One, 11(6), Article e0156570 https://doi.org/10.1371/journal.pone.0156570 
412. Spenser, K. A., Betts, L. R., \& Das Gupta, M. (2015). Deficits in theory of mind, empathic understanding and moral reasoning: A comparison between young offenders and nonoffenders. Psychology, Crime \& Law, 21(7), 632-647. https://doi.org/10.1080/1068316x.2015.1028542

413. Spenser, K. A., Bull, R., Betts, L., \& Winder, B. (2021). Gender Differences in Theory of Mind, Empathic Understanding, and Moral Reasoning in an Offending and a Matched NonOffending Population. International Journal of Offender Therapy and Comparative Criminology, 0306624X2110102. https://doi.org/10.1177/0306624X211010287

414. Stams, G. J. J. M., Deković, M., Brugman, D., Rutten, E. A., Van den Wittenboer, G. L. H., Tavecchio, L. W. C., Hendriks, J., \& Van Schijndel, M. (2008). The relationship of punishment- and victim-based moral orientation to prosocial, externalizing, and norm trespassing behaviour in delinquent and non-delinquent adolescents: A validation study of the Moral Orientation Measure. Journal of Experimental Criminology, 4(1), 41-60. https://doi.org/10.1007/s11292-007-9045-x

415. Stanley, J. H., Wygant, D. B., \& Sellbom, M. (2013). Elaborating on the construct validity of the Triarchic Psychopathy Measure in a criminal offender sample. Journal of Personality Assessment, 95(4), 343-350. https://doi.org/10.1080/00223891.2012.735302

416. Stathi, S., Humayun, S., Stoddart Isaac, R., \& McCarron, D. M. (2021). Psychopathy and prejudice: The mediating role of empathy, social dominance orientation and right-wing authoritarianism. Journal of Theoretical Social Psychology, jts5.116. https://doi.org/10.1002/jts5.116

417. Stellwagen, K. K., \& Kerig, P. K. (2013). Dark triad personality traits and theory of mind among school-age children. Personality and Individual Differences, 54(1), 123-127. https://doi.org/10.1016/j.paid.2012.08.019 
418. Sterzer, P., Stadler, C., Poustka, F., \& Kleinschmidt, A. (2007). A structural neural deficit in adolescents with conduct disorder and its association with lack of empathy. Neuroimage, 37(1), 335-342. https://doi.org/10.1016/j.neuroimage.2007.04.043

419. Sticca, F., Ruggieri, S., Alsaker, F., \& Perren, S. (2012). Longitudinal risk factors for cyberbullying in adolescence. Journal of Community \& Applied Social Psychology, 23(1), 52-67. https://doi.org/10.1002/casp.2136

420. Stickle, T. R., Marini, V. A., \& Thomas, J. N. (2012). Gender differences in psychopathic traits, types, and correlates of aggression among adjudicated youth. Journal of Abnormal Child Psychology, 40(4), 513-525. https://doi.org/10.1007/s10802-011-9588-1

421. Stockdale, L. A., \& Coyne, S. M. (2020). Bored and online: Reasons for using social media, problematic social networking site use, and behavioral outcomes across the transition from adolescence to emerging adulthood. Journal of Adolescence, 79, 173-183. https://doi.org/10.1016/j.adolescence.2020.01.010

422. Sutton, J., Reeves, M., \& Keogh, E. (2000). Disruptive behaviour, avoidance of responsibility and theory of mind. British Journal of Developmental Psychology, 18(1), 1-

\section{1. https://doi.org/10.1348/026151000165517}

423. Szabo, E., \& Bereczkei, T. (2017). Different paths to different strategies? Unique associations among facets of the Dark Triad, empathy, and trait emotional intelligence. Advances in Cognitive Psychology, 13(4), 306-313. https://doi.org/10.5709/acp-0230-7

424. Takamatsu, R. (2018). Turning off the empathy switch: Lower empathic concern for the victim leads to utilitarian choices of action. Plos One, 13(9), Article e0203826. https://doi.org/10.1371/journal.pone.0203826

425. Takamatsu, R. (2019). Personality correlates and utilitarian judgments in the everyday context: Psychopathic traits and differential effects of empathy, social dominance 
orientation, and dehumanization beliefs. Personality and Individual Differences, 146, 1-8. https://doi.org/10.1016/j.paid.2019.03.029

426. Takamatsu, R., \& Takai, J. (2019). With or without empathy: Primary psychopathy and difficulty in identifying feelings predict utilitarian judgment in sacrificial dilemmas. Ethics \& Behavior, 29(1), 71-85. https://doi.org/10.1080/10508422.2017.1367684

427. Tamnes, C. K., Overbye, K., Ferschmann, L., Fjell, A. M., Walhovd, K. B., Blakemore, S. J., \& Dumontheil, I. (2018). Social perspective taking is associated with self-reported prosocial behavior and regional cortical thickness across adolescence. Developmental Psychology, 54(9), 1745-1757. https://doi.org/10.1037/dev0000541

428. Tamura, A., Sugiura, Y., Sugiura, T., \& Moriya, J. (2016). Attention moderates the relationship between primary psychopathy and affective empathy in undergraduate $\begin{array}{llll}\text { students. } & \text { Psychological } & \text { 60ports, }\end{array}$ https://doi.org/10.1177/0033294116667699

429. Thomson, N. D., Kuay, H. S., Baron-Cohen, S., \& Towl, G. J. (2018). The impact of maternal incarceration on their daughter's empathy. International Journal of Law and Psychiatry 56, 10-16. https://doi.org/10.1016/j.ijlp.2017.10.010

430. Thomson, N. D., Towl, G. J., \& Centifanti, L. C. (2016). The habitual female offender inside: How psychopathic traits predict chronic prison violence. Law and Human Behavior, 40(3), 257-269. https://doi.org/10.1037/lhb0000178

431. Tierney, D. W., \& McCabe, M. P. (2001). An evaluation of self-report measures of cognitive distortions and empathy among Australian sex offenders. Archives of Sexual Behavior, 30(5), 495-519. https://doi.org/10.1023/A:1010239217517

432. Tisak, M. S., \& Goldstein, S. E. (2021). Criminality, cognitive distortions, empathy, and legitimacy of laws: Behaviors and perspectives of youth offenders. Current Psychology. 
https://doi.org/10.1007/s12144-021-02121-8

433. Tran, U. S., Laireiter, A. R., Schmitt, D. P., Neuner, C., Leibetseder, M., Szente-Voracek, S. L., \& Voracek, M. (2013). Factorial structure and convergent and discriminant validity of the E (Empathy) scale. Psychological Reports, 113(2), 441-463. https://doi.org/10.2466/03.02.PR0.113x20z9

434. Tremblay, M. B., Marcoux, A., Turcotte, V., Woods, J., Rouleau, C., Grondin, F., \& Jackson, P. L. (2020). I can but I shall not always be empathic. Psychological Reports, 139. https://doi.org/10.1177/0033294120945180

435. Tremoliere, B., \& Djeriouat, H. (2016). The sadistic trait predicts minimization of intention and causal responsibility in moral judgment. Cognition, 146, 158-171. https://doi.org/10.1016/j.cognition.2015.09.014

436. Trivedi-Bateman, N. (2019). The combined roles of moral emotion and moral rules in explaining acts of violence using a situational action theory perspective. Journal of Interpersonal Violence, 1-26. https://doi.org/10.1177/0886260519852634

437. Turner, I. N., Foster, J. D., \& Webster, G. D. (2019). The Dark Triad's inverse relations with cognitive and emotional empathy: High-powered tests with multiple measures. Personality and Individual Differences, $139, \quad 6$. https://doi.org/10.1016/j.paid.2018.10.030

438. Uzieblo, K., Verschuere, B., Van den Bussche, E., \& Crombez, G. (2010). The validity of the psychopathic Personality Inventory-Revised in a community sample. Assessment, 17(3), 334-346. https://doi.org/10.1177/1073191109356544

439. Vachon, D., \& Lynam, D. (2015). Fixing the problem with empathy: Development and validation of the affective and cognitive measure of empathy. Assessment, 23(2), 135-149. https://doi.org/10.1177/1073191114567941 
440. Van der Graaff, J., Branje, S., De Wied, M., \& Meeus, W. (2012). The moderating role of empathy in the association between parental support and adolescent aggressive and delinquent behavior. Aggressive Behavior, 38(5), 368-377. https://doi.org/10.1002/ab.21435

441. van Dijk, A., Hubbard, J. A., Deschamps, P. K. H., Hiemstra, W., \& Polman, H. (2021). Do Distinct Groups of Reactively and Proactively Aggressive Children Exist? A Confirmatory Latent Profile Approach. Research on Child and Adolescent Psychopathology, 49(10), 1303-1317. https://doi.org/10.1007/s10802-021-00813-0

442. van Dongen, J. D. M., Brazil, I. A., van der Veen, F. M., \& Franken, I. H. A. (2018). Electrophysiological correlates of empathic processing and its relation to psychopathic meanness. Neuropsychology, 32(8), 996-1006. https://doi.org/10.1037/neu0000477

443. Van Hulle, C., Zahn-Waxler, C., Robinson, J. L., Rhee, S. H., Hastings, P. D., \& Knafo, A. (2013). Autonomic correlates of children's concern and disregard for others. Social Neuroscience, 8(4), 275-290. https://doi.org/10.1080/17470919.2013.791342

444. Van Vugt, E. S., Asscher, J. J., Hendriks, J., Stams, G. J. J. M., Bijleveld, C. C. J. H., \& van der Laan, P. H. (2012). The relationship between psychopathy and moral development in young sex offenders. Psychology, Crime \& Law, 18(7), 655-667. https://doi.org/10.1080/1068316x.2010.533177

445. Varker, T., \& Devilly, G. J. (2007). Types of empathy and adolescent sexual offenders. Journal of Sexual Aggression, 139-149. https://doi.org/10.1080/13552600701661573

446. Velotti, P., Garofalo, C., Dimaggio, G., \& Fonagy, P. (2019). Mindfulness, alexithymia, and empathy moderate relations between trait aggression and antisocial personality 
disorder traits. Mindfulness, 10(6), 1082-1090. https://doi.org/10.1007/s12671-018-1048-

$\underline{3}$

447. Verkade, M., Karsten, J., \& Koenraadt, F. (2021). 'Conscience functioning and its developmental delays in Dutch female offenders'. The Journal of Forensic Psychiatry \& Psychology, 32(5), 715-735. https://doi.org/10.1080/14789949.2021.1900332

448. Verkade, M., Karsten, J., Koenraadt, F., \& Schalkwijk, F. (2019). Conscience as a regulatory function: An integrative theory put to the test. International Journal of Offender Therapy and Comparative Criminology, 64(4), 375-395. https://doi.org/10.1177/0306624x19881918

449. Verschuere, B., Candel, I., Van Reenen, L., \& Korebrits, A. (2012). Validity of the modified child psychopathy scale for juvenile justice center residents. Journal of Psychopathology and Behavioral Assessment, 34(2), 244-252. https://doi.org/10.1007/s10862-011-9272-3

450. Vitoria-Estruch, S., Romero-Martínez, A., Lila, M., \& Moya-Albiol, L. (2018). Differential cognitive profiles of intimate partner violence perpetrators based on alcohol consumption. Alcohol, 70, 61-71. https://doi.org/10.1016/j.alcohol.2018.01.006

451. von Borries, A. K. L., Volman, I., de Bruijn, E. R. A., Bulten, B. H., Verkes, R. J., \& Roelofs, K. (2012). Psychopaths lack the automatic avoidance of social threat: Relation to instrumental aggression. Psychiatry Research, 200(2), 761-766. https://doi.org/10.1016/j.psychres.2012.06.026

452. von Polier, G. G., Greimel, E., Konrad, K., Grossheinrich, N., Kohls, G., Vloet, T. D., Herpertz-Dahlmann, \& Schulte-Ruther, M. (2020). Neural correlates of empathy in boys with early onset conduct disorder. Frontiers in Psychiatry, 11, 178. https://doi.org/10.3389/fpsyt.2020.00178 
453. Vonk, J., Zeigler-Hill, V., Ewing, D., Mercer, S., \& Noser, A. E. (2015). Mindreading in the dark: Dark personality features and theory of mind. Personality and Individual Differences, 87, 50-54. https://doi.org/10.1016/j.paid.2015.07.025

454. Vyas, K., Jameel, L., Bellesi, G., Crawford, S., \& Channon, S. (2017). Derailing the trolley: Everyday utilitarian judgments in groups high versus low in psychopathic traits or autistic traits. Psychiatry Research, 250, 84-91. https://doi.org/10.1016/j.psychres.2017.01.054

455. Wai, M., \& Tiliopoulos, N. (2012). The affective and cognitive empathic nature of the dark triad of personality. Personality and Individual Differences, 52(7), 794-799. https://doi.org/10.1016/j.paid.2012.01.008

456. Waller, R., Hyde, L. W., Grabell, A. S., Alves, M. L., \& Olson, S. L. (2015). Differential associations of early callous-unemotional, oppositional, and ADHD behaviors: Multiple domains within early-starting conduct problems? Journal of Child Psychology and Psychiatry, 56(6), 657-666. https://doi.org/10.1111/jcpp.12326

457. Walsh, J. A., Krienert, J. L., Thresher, G., \& Potratz, K. (2018). Examining the link between bullying participation, psychopathy and empathy in a large retrospective sample of university students. Criminal Justice Studies, 31(3), 249-266. https://doi.org/10.1080/1478601x.2018.1461625

458. Walters, G. D. (2020). Positive peers-the neglected stepchildren of social influence theories of crime. Journal of Abnormal Child Psychology, 48(5), 719-732. https://doi.org/10.1007/s10802-020-00630-x

459. Walters, G. D. (2021). In search of a mechanism: Mediating the perceived parental support-delinquency relationship with child empathy. Journal of Moral Education, 1-17. https://doi.org/10.1080/03057240.2021.1872511

460. Wang, M.-C., Zhang, X., Gong, J., Deng, J., Luo, J., Gao, Y., \& Salekin, R. T. (2021). 
Variants of Psychopathy in Chinese Juvenile Offenders: A Latent Profile Analysis. Criminal Justice and Behavior, 1-20. https://doi.org/10.1177/00938548211043149

461. Wang, Y.-L., Guo, J.-N., Yin, X.-B., Zhang, Q., Dong, L.-Y., Wang, K., \& Wang, Y.-Y. (2021). The role of empathy in the relationship between childhood trauma and borderline personality tendencies in male offenders. The Journal of Forensic Psychiatry \& Psychology, 32(5), 679-696. https://doi.org/10.1080/14789949.2021.1886314

462. Waterman, J. M., Sobesky, W. E., Silvern, L., Aoki, B., \& McCaulay, M. (1981). Social perspective-taking and adjustment in emotionally disturbed, learning-disabled, and normal children. Journal of Abnormal Child Psychology, 9(1), 133-148. https://doi.org/10.1007/BF00917863

463. Watt, M. C., Frausin, S., Dixon, J., \& Nimmo, S. (2000). Moral intelligence in a sample of incarcerated females. Criminal Justice and Behavior, 27(3), 330-355. https://doi.org/10.1177/0093854800027003004

464. White, B. A. (2014). Who cares when nobody is watching? Psychopathic traits and empathy in prosocial behaviors. Personality and Individual Differences, 56, 116-121. https://doi.org/10.1016/j.paid.2013.08.033

465. White, B. A., Gordon, H., \& Guerra, R. C. (2015). Callous-unemotional traits and empathy in proactive and reactive relational aggression in young women. Personality and Individual Differences, 75, 185-189. https://doi.org/10.1016/j.paid.2014.11.031

466. Wied, M., Goudena, P. P., \& Matthys, W. (2005). Empathy in boys with disruptive behavior disorders. Journal of Child Psychology and Psychiatry, 46(8), 867-880. https://doi.org/10.1111/j.1469-7610.2004.00389.x 
467. Winter, K., Spengler, S., Bermpohl, F., Singer, T., \& Kanske, P. (2017). Social cognition in aggressive offenders: Impaired empathy, but intact theory of mind. Scientific Reports, 7(1), 670. https://doi.org/10.1038/s41598-017-00745-0

468. Wu, C. W., Guo, N. W., Hsieh, Y. S., \& Yeh, K. H. (2015). The facilitating effect of needsupportive parenting on the change rate and adaptation of dual autonomy among Taiwanese adolescents. Journal of Psychology, 74(4), 181-195. https://doi.org/10.1024/1421$\underline{0185 / \mathrm{a} 000161}$

469. Yang, W. D., Zhang, X. T., Wang, M. C., Zhong, C. X., Luo, J., \& Gao, Y. (2019). Factor structure and construct validity of the Youth Psychopathic traits Inventory and Its shorten version in Chinese detained boys. Frontiers in Psychology, 10, 1-27. https://doi.org/10.3389/fpsyg.2019.01831

470. Yavuz, K. F., Sahin, O., Ulusoy, S., Ipek, O. U., \& Kurt, E. (2016). Experiential avoidance, empathy, and anger-related attitudes in antisocial personality disorder. Turkish Journal of Medical Sciences, 46(6), 1792-1800. https://doi.org/10.3906/sag-1601-80

471. Yu, H., Lu, C., Gao, X., Shen, B., Liu, K., Li, W., Xiao, Y., Yang, B., Zhao, X., Crockett, Molly. J., \& Zhou, X. (2021). Explaining Individual Differences in Advantageous Inequity Aversion by Social-Affective Trait Dimensions and Family Environment. Social Psychological and Personality Science. https://doi.org/10.1177/19485506211027794

472. Zagon, I. K., \& Jackson, H. J. (1994). Construct validity of a psychopathy measure Personality and Individual Differences, 17(1), 125-135. https://doi.org/10.1016/0191$\underline{8869(94) 90269-0}$

473. Zeigler-Hill, V., \& Besser, A. (2019). Dark personality features and workplace outcomes: The mediating role of difficulties in personality functioning. Current Psychology. https://doi.org/10.1007/s12144-019-00527-z 
474. Zhang, X., Shou, Y., Wang, M. C., Zhong, C., Luo, J., Gao, Y., \& Yang, W. (2019). Assessing callous-unemotional traits in Chinese detained boys: Factor structure and construct validity of the Inventory of Callous-Unemotional traits. Frontiers in Psychology, 10, 1-9. https://doi.org/10.3389/fpsyg.2019.01841

475. Zirenko, M., \& Kornilova, T. (2021). Individual Differences in Decisions on Physical Distancing during the COVID-19 Pandemic. Психология. Журнал Высшей школь экономики, 18(2), 276-286. https://doi.org/10.17323/1813-8918-2021-2-276-286

476. Zirenko, M., Kornilova, T., Qiuqi, Z., \& Izmailova, A. (2021). Personality regulation of decisions on physical distancing: Cross-cultural comparison (Russia, Azerbaijan, China). Personality and Individual Differences, $170, \quad 1-7$. https://doi.org/10.1016/j.paid.2020.110418

477. Zumbach, J., Rademacher, A., \& Koglin, U. (2021). Conceptualizing callous-unemotional traits in preschoolers: Associations with social-emotional competencies and aggressive behavior. Child and Adolescent Psychiatry and Mental Health, 15(1), 24. https://doi.org/10.1186/s13034-021-00376-4 
99.94\% CIs

\begin{tabular}{|c|c|}
\hline Antisocial Behavior - Affective Empathy (Groups) & {$[-0.238,-0.021]$} \\
\hline Antisocial Behavior - Cognitive Empathy (Groups) & {$[-0.546,-0.309]$} \\
\hline Antisocial Behavior - Total Empathy (Groups) & {$[-0.508,-0.229]$} \\
\hline Psychopathy - Affective Empathy (Groups) & {$[-0.610,-0.187]$} \\
\hline Psychopathy - Cognitive Empathy (Groups) & {$[-0.365,-0.077]$} \\
\hline Psychopathy - Total Empathy (Groups) & {$[-0.976,-0.113]$} \\
\hline Antisocial Behavior - Affective Empathy (Correlational) & {$[-0.147,-0.088]$} \\
\hline Antisocial Behavior - Cognitive Empathy (Correlational) & {$[-0.154,-0.057]$} \\
\hline Antisocial Behavior - Total Empathy (Correlational) & {$[-0.192,-0.130]$} \\
\hline Psychopathy Total - Affective Empathy (Correlational) & {$[-0.333,-0.241]$} \\
\hline Psychopathy Total - Cognitive Empathy (Correlational) & {$[-0.230,-0.150]$} \\
\hline Psychopathy Total - Total Empathy (Correlational) & {$[-0.345,-0.237]$} \\
\hline Factor 1 - Affective Empathy (Correlational) & {$[-0.373,-0.286]$} \\
\hline Factor 1 - Cognitive Empathy (Correlational) & {$[-0.296,-0.217]$} \\
\hline Factor 1 - Total Empathy (Correlational) & {$[-0.438,-0.322]$} \\
\hline Factor 2 - Affective Empathy (Correlational) & {$[-0.152,-0.037]$} \\
\hline Factor 2 - Cognitive Empathy (Correlational) & {$[-0.197,-0.100]$} \\
\hline Factor 2 - Total Empathy (Correlational) & {$[-0.246,-0.097]$} \\
\hline Facet 1 - Affective Empathy (Correlational) & {$[-0.335,-0.161]$} \\
\hline Facet 1 - Cognitive Empathy (Correlational) & {$[-0.225,-0.083]$} \\
\hline Facet 1 - Total Empathy (Correlational) & {$[-0.324,-0.182]$} \\
\hline Facet 2 - Affective Empathy (Correlational) & {$[-0.391,-0.277]$} \\
\hline Facet 2 - Cognitive Empathy (Correlational) & {$[-0.324,-0.208]$} \\
\hline Facet 2 - Total Empathy (Correlational) & {$[-0.470,-0.326]$} \\
\hline Facet 3 - Affective Empathy (Correlational) & {$[-0.188,-0.053]$} \\
\hline Facet 3 - Cognitive Empathy (Correlational) & {$[-0.175,-0.025]$} \\
\hline Facet 3 - Total Empathy (Correlational) & {$[-0.190,-0.044]$} \\
\hline Facet 4 - Affective Empathy (Correlational) & {$[-0.186,-0.060]$} \\
\hline Facet 4 - Cognitive Empathy (Correlational) & {$[-0.199,-0.021]$} \\
\hline Facet 4 - Total Empathy (Correlational) & {$[-0.237,-0.042]$} \\
\hline Boldness - Affective Empathy (Correlational) & {$[-0.234,-0.105]$} \\
\hline Boldness - Cognitive Empathy (Correlational) & {$[-0.036,0.099]$} \\
\hline Boldness - Total Empathy (Correlational) & {$[-0.244,-0.028]$} \\
\hline Meanness - Affective Empathy (Correlational) & {$[-0.417,-0.288]$} \\
\hline Meanness - Cognitive Empathy (Correlational) & {$[-0.317,-0.208]$} \\
\hline Meanness - Total Empathy (Correlational) & {$[-0.478,-0.328]$} \\
\hline Disinhibition - Affective Empathy (Correlational) & {$[-0.165,-0.002]$} \\
\hline Disinhibition - Cognitive Empathy (Correlational) & {$[-0.164,-0.033]$} \\
\hline Disinhibition - Total Empathy (Correlational) & {$[-0.240,-0.032]$} \\
\hline
\end{tabular}

